\title{
Leadership and Organizational Change: Some Perspective from the Basics
}

\author{
Kiyoung Kim
}

Professor of Law and Governance

The Legal Research Institute, Chosun University 


\section{Chpater I. History and Types of Organizational Change}

\section{Introduction}

1-1. As we have been introduced by the reading materials, leadership is certainly a central concept that the contemporary society now requires to increase the chances of survival and prosperity. As the contemporary politics guides, the world now see a greater turn to the kind of strategic paradigm heavily departing from the previous adherence to the ideological tenet. The strategy is a vital way of approach to address the needs of followers, subordinates, stakeholders and shareholders although there are other strands of influence including the culture (For political discourse, it is also interesting to read the Huntington's viewpoint about the clash of civilization), ideology though (still heavily on the global politics), shared comradeship and intelligence, and others. The leadership, in the contemporary framework, is likely to be analyzed as several points of evolution. The leadership, as we set aside the assumed status of peaceful coexistence in the ancient communal society unlike the Marxism circle, can be seen as one of interactive products about some form of organization. For example, ancient Chinese leaders, through its imperial history, almost always have been concerned about the integration of his subject against the foreign threat of ingression. While we realistically see the phenomenon of world as a split nature, the organization, even most simple form for the state, has to find their leadership as one kind of interactive context. That is, without any submission, surely the case if we talk about a forprofit organization and also non-profit organization. We can see an idealistic organization that may be perceived as monopolistic, such as UN and NGOs. These organizations, however, are also facing the realistic challenge to interact with outside actors and other organizations. For the UN, a terrorist state or organization might be a good example which it needs to interact. In some cases, the states in the dispute and hostile confrontation may be concerned interactively. For the NGOs, the state and conservatists' group of WTO can be the actor or organization that they have to deal with. Then we can reach the deep structure or environmental element which the leaders of organization have to deliberate on his true nature of leadership.

1-2. While we like to divide the mode of leadership or evolution of leadership, the first point of important consideration has no way but to see the context of global transformation from the remarkable historical or humanistic time sequence. We can know the kind of deep structure revolutionarily spreads into three stages, what we can call the feudal, classical-capitalistic and contemporary-capitalistic. As we learn from the readings, the revolutionary change of organization for the case of British Airways during the neo-liberal initiative may be viewed as a fundamental restructuring to be directly influenced by the dimension of deep structure. That could be subclassed in terms of the transformation of capitalistic framework in the past century through the new millennium. The deep structure developed, for the case of UK and US during the 1980's. from the Keynesian welfarism to the greater liberalization of corporations. Of course, the example of small professional firm illustrated in the textbook as an evolutionary change, can well be understood from this viewpoint. The three points of leadership stage, in my submission, do not entirely explain the types of leadership within that specified period, but simply a dominant pattern of leadership to lead the organizations of that period. Therefore, it is simply the case even at these modern times that we can find a feudal style of leadership as typically characterized "charismatic" or "command control" concept. Vice versa, the Koreans have one of Kings in the Chosen 
dynasty around the $14^{\text {th }}$ century called Tae Jong. He represents an image of charismatic leadership in one aspect, who was very repressive against the potential political rivals. On the other hand, however, he invented a great tool of communicative purpose from his subordinates or ruled class of people. He placed a big drum in front of his palace in the effort that his people in grievances with any kind of injustice and personal dissatisfaction or frustration could utilize it to echo for initiating the state investigation. Without any scientific experience unlike the western civilization, it may be one of primitive form of participatory or shared leadership that the King and his people shared an information, compassion, empowerment and cooperation toward a desired goal of state justice. That would also be based on shared cognition to the sublime oriental virtue and ethics.

1-3. One other person to my note in terms of leadership analysis just comes into the mind, who is a former president, Chung-hee Park, during 1960's and 1970's in South Korea. His leadership has been critically evaluated by the political analysts and historians of South Korea. One camp eagerly supports his bright side of effective leadership to lead the developmental state around such burgeoning economy of the underdeveloped Korean republic. The opposing views heavily criticized the evil nature of his dictatorship, and deplored the excessive command and control largely arising from the military culture and that type of intelligence. His mottos, "do it, then nothing impossible" "for the vision of honorary Korea resurrected with my grand leadership", can be plainly attributed as the kind of charismatic content of the organization. The content of organization, itself, plainly proves the nature of his leadership. There could we hardly find any state symbolic during his times which was to subscribe to the democracy or equal opportunity, nor any mentioning of freedom essential to the democratic form of government. That was evident when we search many sources of social or governmental expression during his long tenure of 18 years. One of mottos just focused on "self-help of Korea" which meant an economic growth and more toils of the working class for a more advanced economy. The critics pointed, it seriously undermined the basic right of the poor working class who were charismatically misled and deprived of an adequate protection of the laws. The Kind of situation can be imagined by way of analogy with the initial period of industrialization in Britain, where factory workers worked under the poor working condition. The process of his leadership or organizational change is also remote from the participatory model where the election system was critically questioned to fail to represent the democratic will of Korean people. The 1972's constitutional reform even rearranged the check and balance scheme based on the separation of powers principle. The judiciary was restructured disabling to make an independent decision, and the judges could not practically enjoy any of insulation from the influence of executive branch. Of course, the head of executive branch, Chung-hee Park is a charismatic figure availing of the administrative staffs as the kind of feudal line of authority. It even went further for the president to select a third of congressmen, which is unprecedented in the history of political democracy. The process of his leadership, is absolutely charismatic the ground of which is entirely found from his personal greatness, monumental feature, or historic determinism.

1-4. The last person, in purpose of this research post, is related with the study group which I experienced at the times of the judicial apprenticeship in Korea. The prospective lawyers in that institution voluntarily advanced to organize the study group to learn the summary of rules. On Monday each week, 8-9 students convened to talk about the progress of study by designating the pages of court brief which was short about ten or fifteen minutes. They each studied the designated pages to understand the rules of law including various subject areas. The process was led by one voluntary leader, who was hardly viewed as charismatic or participatory one. The reason is obvious that he could not be charismatic 
because he was just a student of same status to the followers or participants. His leadership might not be seen participatory that the followers were led by simply reading the pages to prepare for the discussion held for as long hours in the Friday evening. He finally made a greater success by achieving higher grades, and also he was a great leader to plan and execute the progress and eventually purpose of the study group on a very means of scientific method, though easy one. He acted like the business owners or scientists of the modern period of industry such as Hawthorne factory experiment, sensitivity training, socio-technolgy framework, survey feedback and so forth. He set out a scientific plan to make a study progress chart. He routinely considered a more productive condition which each member of study group could yield a best turnout. He occasionally made a time to talk with and respond to the members about the nature as well as the pros and cons of his or her experience. He also thought about the most productive pattern of work with the available source of technology. It is, of course, needless to say he, though naïve in the nature of organization, used very effectively the method of feedback survey. Although he is a modern type of professional around the mid of 1980's, and one of my professional peers now, his method of voluntary leadership could be classed the kind of command and control type, but was grounded on the scientific discovery of industrial management. Many of less minded members actually were indebted to his initiative, and most of them finally achieved a good grade.

1-5. On this reflection, I now become aware that the participatory model of

leadership, as considered a most advanced and desired form, is fairly close to the modern line of authority on the scientific method given that the followers are awakened. The problem seems how to initiate or stimulate such awakening, and how to keep continuous on a proper operation of shared leadership. The regular feedback from the goal of organization also seems to be critical.

\section{History and Types of Organizational Change}

\section{2-1. Introduction}

Organization change must certainly be a supreme concern if we work as a leader of organizations of any type. That is true if the leader himself lacks a requisite mind or preparation. It is also even a concern of followers who held a common identification with the organization they devote their passion, labor, and career success. That is a part of reason which creates the point of discussion about the followership. The followership is one avenue to explore the true nature of participatory leadership. So we properly assume the thesis of organization change virtually comes within all context of working arrangement notwithstanding the time and space framework.

\section{2-2. Description of Three Historical Perspectives}

In understanding the organization more succinctly, we are required to consider a founding viewpoint which can be factored in historical terms. That three way division, as we are required to review, is not clear given the nature of less political or economic orthodoxy. As the textbook guides, we are able to find, at first, the Moses' loosely coupled system of organization change. The community or organization could hardly be well organized, but were composed of his followers on the personal commission or religious belief. So we can properly consider it as one of primitive form of ancient community which lacks the political control or other systemic institution to support his rule. This stage could be characterized as 
ad hoc dealings of problems, less system, intuitiveness and unplannedness, and less science and more personal wisdom or religious adherence, and so forth.

The second perspective of organization change would follow with an emergence of more heightened form of political integration and state system. There could we find a daunting examples throughout the world history which can interplay with the discourse of organization change. Still important, however, the leap toward the second stage can be normally found within the context of politics, and relatively little stark with the production mode or the kind of industrial context. For the feudal context of production, we are able to trace some notables in the systemic management of agricultural labor, which may be viewed a departure from the ancient mode of loosely coupled organization change.

The farmers of Chosen dynasty during the late feudal days were charted to organize the cooperatives to draw a workforce to develop large tract of lands, which corresponded to the condition in a specific community. Their point, typically on the initiative of one enlightened mind of the community, spanned so largely covering the age factors, shared cognition, motivating festive, and sharing a profit. That cannot be properly termed loosely coupled, rather one of planned nature and application of various factors systemically to achieve their desired goals. Despite the limited findings of economic or industrial leadership, we are able to illustrate a plenty of exemplary cases which would be of planned or systemic nature. As we know, Machiavelli is a prominent figure to infuse the modality of dictator's leadership, which enabled an effective change of organization. He actually was a great strategist to preserve or increase the power of dictators in the context of political regime. He offered a great lessons to manipulate potential rivals or competing powers by utilizing available resources and planned tactics. Leadership and organization change toward a more increased power, in his framework, are viewed one of planned nature where we can find differing factors other than the ancient form. His discourse and core points of assertion intrinsically political in nature. However, they can potentially, but in some cases actually and even at these modern times, be applied to make an effective change on various organizations. The characteristics of this stage on organization change can cover: more enhanced form of organization politically and institutionally, more line authority and hegemony of leadership, wider basis of the application of organization change in size and bureaucracy, more science or predictability, more ideals and social beliefs. The second stage of organization change could be brought into significance in the context of feudal centralization of power.

The last perspective of organization change can be traced to the modern development of industrial science. On the wake of evolution, the work studies as well as human and industrial psychology through the life science, significantly contributed to find a more plausible explication of the work efficiency as well as achievement of organizational goals. The theory and scientific findings at this stage is now generally considered to offer a paradigm of organization change for the leaders. For the nature of the last perspective, we can epitomize several points of importance to our note in rethinking the organization change. This period of time enabled a revolutionary change of deep structure that various of types of organization had to be submitted. First, In the political dimension, the feudal system of rules or regime of monarchy were largely dismantled that the public witnessed a rise of democratic form of government. The French revolution radically brought a restructuring of the society from the rule of King to the new rising power of bourgeois, what we call the class of "haves". The American revolution created an entirely new type of power structure based on the separation of powers principle. Further, the political or social status of ancient regime, on a hereditary basis, could no longer persist proclaiming that the people are equal under the law. They also turned to be graced with an inalienable right of liberty and could pursue a happiness under the blessing of god. The political leader should be chosen from the election 
and other justifiable means of democratic representation.

Second, the emerging feature of industrial revolution may well be seen a factor combined to bring this fundamental transformation of society. This would, in some aspect, be more significant to our discourse of modern scientific perspective of organization change. The structure of industry saw a shift from the first to the second generation. The agricultural, fishing, hunting, mining and others turned to be less important while the manufacturing sector profiled strikingly. The earlier stage of factory production had been gradually improved with a scientific advancement that the automatic mode could become popularized over the period. The mass production and mass consumption effected a new heart and perception through various classes of society. The leadership and organization perspective concurrently accorded with the kind of sea change and accompanied the shift of framework.

Third, we need to focus on the human enlightenment about the reason and self identification. The fundamental shift of deep structure was the turnout that could well be ascribed to a new paradigm of human being himself. The contrary is also true that the human perception, intelligence, reason, and consequent struggle to be the fittest can be as one of efforts to comport with the sea change. Thus both dimension is constantly interacting to drive the change of many things including the organization change. In any case, the enhancement of human, industrial and life sciences is truly a most important propeller in the evolution toward the modern scientific management.

\section{2-3. Similarities and Differences}

Now we can summarize the differences and similarities of above three perspectives on organization change.

First, all three perspectives are, in major part, the product of a given deep structure. Moses leadership were created in fairly instantaneous context while the deep structure of more heightened form of political system was not available unlike then Egyptian Kingdom. Machiavelli's perspective also corresponds to the settings at his given times. In the same way, the socio-technology analysis of work could not even be embraced without the equipment or tools enabled by the modern science.

Second, we find common attributes across three perspectives that they concern men or workers in the effort to induce, motivate, guide, and manipulate them toward the desired goals of organization. They are perceived or analyzed in the context of interaction with the leader and followers. Therefore, it is true that organization change comes into play fundamentally from the concept of human nature at the given deep structure. The humans in the Moses community are not the same as those of feudal subjects. They may be naïve, more friendly, more shared cognition from the persecution history, but can be more innovative and creative with the harsh challenge. The feudal subjects could be more tamed to adapt to the retrenched system of feudal exploitation in some aspect. Therefore, the perception of humans seemed to be critical when we approach the leadership and organization change. It is needless to specify that the humans between the feudal and modern period of time can be more critically differentiated.

Third, absent the utmost assumption that all the participants are equal in the organization, we can safely state that three perspectives are preconditioned on the concept of leader and followers. The leader may be just symbolic in the case we hypothesize on the most advanced form of participatory leadership paradigm. Still, however, the leader is a concept we need to adhere. I suppose that that context may be identified in terms of communist leadership. In theory, the communist leader is just a peer worker with the working class. That 
is not the case in actuality over the political process of communist states.

We also find the points of differences among three perspectives.

First, the modern science has not effected, as a matter of course, the concept of organization change for the earlier two cases unlike the third one. In the second stage, the political discourse only, and in some cases, economic point of strategy, could be resorted in a limited context. However, it is not incorrect to state that Machiavelli and other feudal consultants had foregone the aids of modern sociology.

Second, the leadership and organization change are generally different in terms of the nature of leadership. The span of leadership role in the first stage is fairly limited, person-toperson, and simplified in line hierarchy. The content of organization change would be largely basic to cover the subsistence, protection of tribes, religious integrity and so forth. The leadership, in the second stage, would differ to think about more base of people, and thus the consequence of organization change would come more complicated to require a systemic approach. The leadership at this modern times saw a fundamental shift about the role of leadership. The leader is now constantly demanded to increase their knowledge as prerequisite for effective leadership. The leaders need to be a science student in some cases and should understand the problems of followers in various contexts.

Third, the first two perspectives, on their basics, underlay the assumption of command and control framework, which is fundamental. We can see a famous illustration of Ten commandments of Moses. That is also true with the second one. In differential, the modern theory of organization change seeks a participatory paradigm. The focus actually shifted on the basic assumption to dominate the current scholarship of organization theory.

Fourth, the content of organization change is more diversified in the third perspective when we take the nature of this modern society. The goals and visions of organization change span with larger extent, which are in accordance with the types of organization.

Fifth, the process of organization, in this contemporary period, is one of important elements in the case the leaders initiate, enforce and keep continuous on their goal of organization change. In the first two cases, this aspect, the process of organization, fairly shrank that led to more adhere to the desired goal of organization change.

\section{2-4. Revolutionary and Evolutionary Change}

Beyond the thought of historical perspectives, the discourse of organization change requires to understand the two fold conceptualization: "evolutionary vs. revolutionary". In a notation, that is the same as "transformational vs. transactional."

\section{2-4-1. The Case of Evolutionary Change : Chosun University}

I would like to draw upon my experience here in Chosen university as an illustration of evolutionary change. The university is one of premier institutions in the region and the foundation can be assessed relatively sound to support the university. Over the decade since the new millennium, the university, however, expected a short cut of financial assistance from the foundation and government. The principal source of university income had to be found from the tuition fee of students. Of course, it has long been a major contributor to the university income, but the situation turned to be worse to increase the tuition. As a matter of course, it had to raise a persuasive defense against the students' voice for lower tuition fees.

This type of confrontation between the university administration and student protest is not merely the case of this university only in South Korea. That point has been a prime 
recipe for the politicians, which would mobilize the voters to their favor in the election of national assembly and president. The national association of college students also monitored the activity of local universities and backed up systemically their efforts to effect their request to lower the tuition fee. Other fears arose from a little differing context. The prospective pool of college applicants in the next decade would see a high diminution for the lower birth rate in 1990's in South Korea. Given this factor, the university may, for some time in the future, failed to receive a quota number of student. It would face the risk to be enlisted as a poor class of local universities. This enlistment would seriously undermine the prospect of financial assistance from the government. In that case, the university can no longer survive. In order to combat this predicament, the university administration planned on a gradual change, which could ensure a financial capacity to meet the budget in the long term perspective.

The university president during his terms identified a financial problem and worked to effect an organizational change. That is evolutionary in nature. The content and process of organization change were as follows: He shaped two strategic points including the sustainibility and progressive upgrading. In order to address the first point, he focused to make sure an optimum level of reserves. The level was constantly monitored and worked as a standard thorough a scope of financial decisions of university. He also introduced the concept of efficient administration to guide the staffs. The budget was required to plan more flexibly and the basic expense was urged to be less costly. The sustainability paradigm also included an incentive system for the innovation and superior administrative achievement. The givings and financial contribution system were reformed seriously to promote a potential donor group. For example, he ensured the process to comply with the donator's aspiration and wishes. It yielded a positive reaction from the local class of wealth. In the context of progressive upgrading, he implemented a business strategy on for-profit facilities within the campus. For example, The language institute and community learning centre were redirected to create more income. He also introduced an independence scheme in the purpose of budget and accounting. On the strategic prospect, he launched a vision to boost start-up companies, which was in connection with the local economic conditions as well as patent and technological innovation. That plan gradually pushed forward and yielded a considerable outcome on the evolutionary change framework. The university brand and images were planned and utilized to increase the financial capacity of universities. The evolutionary change, in this case, was most efficient way to counteract with the university financial crisis. That is because the university falls within non-profit educational sector, and the participants are generally highly educated, and mostly tend to favor the progressive and reformatist stance. The university is commissioned to serve the local public by providing an educational service. This factor generally works to restrain a radical change of organization except for the extreme cases. One alternative was raised in the effort of university reform. It was to sell the university to the city government and to manage the university under the name of city university of Kwangju. That would require to invoke the content and process of revolutionary change, but most of us saw it impracticable in many ways. It would be fortunate to keep continuous on the evolutionary change given the depraved financial condition of city government.

\section{2-4-2. The Case of Revolutionary Change :Republic of Korea during 1970's}

For the illustration of revolutionary change, my experience recalls the constitutional reform of South Korea in early 1970's. In 1972, the president Chung-hee Park seriously failed in the ambition to prolong his tenure for a virtually permanent dictatorship. According to the 
standing constitution, his term expired at the end of second tenure since the constitution provided the statutory limitation at two terms of presidency. He seized a power by military plan, and served ten years for two consecutive terms. At this juncture of critical period, he was ambitioned to perpetuate his rulings. It brought to initiate the constitutional reform which were actually realized in the late 1972, and offered a basis for additional seven years of tenure until he was shot to death by his most intimate staff. Under the assumption that the Republic of Korea is the kind of organization, this instance well exposes the elements of revolutionary change.

The content of organization change is revolutionary which entirely reshuffled the previous mode of state framework. A third of congressmen was chosen by the president himself contradicting the basic principle of representation. The independence of judiciary was never safeguarded in the institutional context and also as a matter of practice. The president was elected by a special assembly which were maneuvered to the interest of president. The election was actually meaningless and perfunctory that was just a venue to crown the president for his life time tenure. The republic of South Korea was revolutionarily remodeled on the misled content. The true nature of organization change was disguised from various propaganda, such as "upgrading Korea," "inherited political leader," "square challenge from the domestic and international factors," and most avidly "the threat of North Korea."

Then, could we find any kind of compromising process to effect the vision of revolutionary change? The process of organization change was also revolutionary indeed. He attempted one more incident of military coup, which could be identified with the photos of newspaper and other various sources. The tank stood at the front of presidential office to symbolize his might, and worked to force his plan of organization change. He created a study group of constitutional scholars to deal with his secret ambition. There is entirely absence of any public forum or administrative hearings and no congressional debate. The whole process was pushed forward in the way of strategy, confidential, far shortened, and under a menacing condition. His revolutionary change, for some circle of intelligence, is assessed commendable to effectively react to the hard times of 1970's. Their point is that Korea successfully leaped toward the group of developed countries for his great leadership. His constitutional reform can, in their perspective, enable a more strategic form of Korea in many ways. From that standpoint of view, the revolutionary change, in this case, is more easily accepted to adapt to the goal of developed economy. However, opposing views highlight the serious consequence of his undemocratic initiative and failed operation of the constitutional rule. We could find a plethora of stories victimized by the repressive power.

From the experience, I can note that the organization change needs to comport with the character of organization. The process of democratic principle is essentially required, which is fairly evolutionary in nature, when we think about Korea. The content of change also should not contravene the virtue long held by democratic states. 


\section{References}

Duderstadt, James J. (2000). University for the 21st Century. University of Michigan Press.

Earley, Peter Weindling, Dick (2004). Understanding School Leadership. Paul Chapman Publishing .

Eddy, P. L. (2004). The impact of presidential cognition on institutional change. Community College Enterprise, 10(1), 63-77.

Emerald Insight Staff (2005). Introduction to Modern Leadership. Emerald Group Publishing Ltd.

Fairholm, Gilbert W. (1998). Perspectives on Leadership : From the Science of Management to Its Spiritual Heart. Greenwood Press.

Fiol, C., Harris, D., \& House, R. (1999). Charismatic leadership: Strategies for effecting social change. Leadership Quarterly, 10(3), 449.

Marturano, Antonio Gosling, Jonathan (2007). Leadership : The Key Concepts. Routledge.

Seyranian, V., \& Bligh, M. (2008). Presidential charismatic leadership: Exploring the rhetoric of social change. Leadership Quarterly, 19(1), $54-76$.

http://en.wikipedia.org/wiki/Park_Chung-hee (last visited Dec. 6, 2012)

http://en.wikipedia.org/wiki/Chosun_University( last visited Dec. 6, 2012) 


\section{Chapter II. Leadership and Managership}

\section{Leadership and Managership}

The leadership and management would perhaps be one of most confusing concepts, and can go their way on inflection over most of cases.

If we take time for short reflection, we soon know a kind of delicacies between the terms. The firsthand impression from the words are that the leadership often assumes a more extended form of organization while the management would be implied on a belittled context or smaller size one. On the bottom line of daily communications, we generally use the word, "manager or supervisor," to denote our institutional life, while the word "leader" is far less frequented. We use the word "boss" if we like to designate the highest rank of the organization. The leader or leadership would perhaps be most patronized in the arena of politics. Less frequently, we encounter with the illustrations of public health institution, educational sector, and a small scope of biggest firms. The use of the words "leader and leadership," therefore, if with our routine experience, tend to match in the politics, public administration, and a notable corporations, such as, Louis Vuitton, Samsung, Apple, and so forth. Besides, we generally have a scope of myths about the words if we perceive the managership a negative implications. An Imagery of hard line supervisors may work in many minds, for example. It is essential however, that both words are truly dominating the organizational behavior, which should not be traded off on the kind of predisposed holdings. Given the managership being involved, she generally inserts a bland word while the leader inserts a hyperbole. It would be, in vast of cases, two sides of one coin that the leader also plays the role of manager. It is nice to be a leader and manager at the same time, but it is true we need to deliberate on its separate role, in the least, in their nature, need in time and situation, way of application, utility and effect, and philosophical foundation (Palchy, 2009).

\section{1-1. Differences and Similarities}

It is, in any case, actually amazing to enter the context of conceptual dynamics if we apply both terms to our daily settings of organization. From more intrisical reflection of the terms, both concepts share differences and similarities in terms of organizational study. Generally we can connote those in the following definition as Palchy introduced (Palchy, 2009);

\section{"Leadership is the ability to articulate a vision and gain support for it. Leadership ends, so to speak, where managership takes action to accomplish the vision.}

Being a leader means having an emotional bond with followers.

Managership is the ability to define and accomplish an organization's purpose

by studying needs; evaluating resources; setting goals and objectives consistent with the purpose and resources; and planning, directing, and evaluating actions designed to reach the goals and objectives."

A founding element, as meaningful on my assessment, is the creative and interhuman nature of leadership. It offers a differing aspect with the managership in that a manger 
generally starts their role on the kind of tangible and settled context. The manager would exercise their responsibility, in its definition, by defining and accomplishing an organization's purpose. It requires a talent to study needs, evaluate resources, and so forth. It is, therefore, more affiliated with the power analysis other than the life science aided paradigm of leadership, though a matter of extent. The scientific management study more typically addresses a management aspect, which is distinguishable from the shared leadership or followership studies (Burns \& Kelly, 2010). The managers normally adhere to the tangible element of organization process, and would explore a need or regret to switch to leadership role if affected with the organization's risk, unsettled status and contingencies. Therefore, the managership is less friendly with the organization change other than the leadership concept, in a general viewpoint. It is particularly spelled away when the organization wishes to intend on the revolutionary change. In comparison, the leadership requires a mind and mode of approach to be creative, and in some aspect, tend to be totalitarian and fundamentalist, on bottom line context, and on the context of structure and human elements themselves(Drucker P.F., 2001) . Therefore, I observe that the leadership concept can be more associated with philosophical (other than math science), interactive (other than line hierarchy), dynamism (other than static), more change-oriented (other than continuum), challenging and transcending (other than conservative or progressive), more humanized and political (other than objective or administrative). Of course, that is a way of approach for general purpose, which could overlap to define a specific instance of leaders and managers.

A founding element enabling to share the similarities between the leadership and managership could be found in the point that both look into the pattern of a specific person who is standing positively and distinctively to concern an organization. The pattern includes elements of the person including the attitudes, intelligence, mind, skills and technology, morals and ethics, career and background, and so forth (Drucker, P.F, 2001).

In this perspective, both concepts generally converge, with less distinction, on those, which include a power wielding, influence, command and control (particularly on the charismatic one), and other neighboring concepts. It generally operates within the context of leader and manager against the led or followers (Hollander, E.P., 2009) . They are standing positively to yield a certain outcome of the organization. It is true If it were to be the change or motivation of followers for the leadership case, and management goals of specific nature for the managership case. Both are subject to evaluation at some point of time, which involves a time and evaluation element, varying with the length of time and mode of evaluation though. As the organization plainly connotes, the voice of human reaction is certain and the time element would generally be shortened if the organization is more civilized or up-to-date form. It could be at the end of five year terms of presidency if the president is a dictator suppressing the free press. The most awesome leader of corporations can also fall within this class. For the most strategic and participatory leadership firms, the time lapse may be a weekly or monthly term for each meetings of prime figures. As of nature, the leader would normally conceive the managerial aspect when to manage and how to manage. The manager also can retrospect if required to recourse to the leadership role. They share similarities to conceive the other as interchangeably to adapt to the situation. Finally, the evaluation would generally be destined to a specific unit, what we call organization, except for the social context being involved. If we evaluate the leadership or managership of President Bush, it would generally be proper to see him in the context of his responsibility, the organization of United States. It would obviate the focus if we posit him a kind of UN leader to criticize or acclaim.

\section{1-2. My Classroom Performance on Analysis}


We perhaps may agree that the most distinctive way between the leadership and management can be found in the university classrooms. I propose the class would be assumed as one of organization being available of leader or manager, who is actually a lecturer or professor. Of course, the audit students are followers who are constituents of that organization. As a career lecturer, I have worked over the decade to interact with students, and were naturally concerned with the response of students at the final evaluation of class performance. I experienced a poor result in the first year at Chosun university, and it made me disappointing to retrospect on the methodology. I have assessed the system I developed to conduct the class, which includes an adequacy of class obejective, weekly class progress, the mode of exam, and other variables of class size, the year of students, and so forth. They were, with very few exceptions, fine indeed to well rival other peer items, on which I obtained a brief consultation from my high grade peers. They agreed on its superior nature. I just later found that the manner of instruction is fairly managerial other than creative or motivational. I realized that creating a vision and gaining a support from the audit students in many cases are essential to guarantee higher achievements. Many of class audience were later disclosed to pass the national exams, and I have received many comments of gratitude actually. They specifically remarked a useful indoctrination from the march-like class on the tight schedule, which brought their success. They had been, however, reluctant to give a high grade probably because I was less interactive or neglected on the class participation. I and my peer professor also had feedback on this point, and formed a basis to correct the mode of class leadership (Roggio, R.E., 2006). For next years on, I have been successful on my class to share congratulations with the peers. The style of conducting a class performance would show a differing aspect between the leadership and managership.

Let us see a brief over the typical pattern of class progress which I now subscribe to. For the first ten minutes, I present set of questions to be a point of focus and discussion with which I actually interact with the students. I expect that ten minutes are important to create a vision and gain a support from the audit students. The attitude and use of language is important to draw the students" attention. It would be rather managerial to simply, "what is that" or "on this question, what I will do.." (Palchy, 2009). It would be more helpful to frame an interaction intending to draw expectations of the students and to share a reaction or suggestion given by the lecturer. That manner would be the kind of leadership which would enable to perform a managership delivery of class contents. That divide, however, is of general nature where I frequently revisit above ten minutes creative time on the class progress. Finally, I may be available of the class success to finish up with the sharing of five minutes. A form of class evaluation would differ in a bit across the institutions. Chosun university has a computerized system, and offers two grounds of the qualitative and quantitative nature. Both are working to evaluate my dual aspect of class performance, but the qualitative section is particularly useful to assess the leadership aspect of class performance. In the section, the students can freely write their opinion without the scaled grade. Students' comment was useful to look into the manner of class performance and revealed the real nature of interhuman time sharing in the organization(Buytendijk et al., 2009). I sometimes think what else we are left on that organization, a class, and I suppose that a most critical touchstone on the leadership and organization change could be the maximum of happiness of leaders and followers in the end.

\section{1-3. Conclusion}

A. The class is finally evaluated in the way of human operation on a time basis, normally semester and terms. We usually see other cases particularly in the election or process of forming a new government. A past leadership of the particular party would be a 
factor for the next candidates, and could affect a public response. An evaluation in this case would occur on the constitutional term. In the class case, both aspects of leadership and managership are combined to be subject to evaluation.

B. A lecturer or professor would be on the status of positive and distinctive nature no matter if their way of teaching is managerial or on leader-like. He generally holds a steering position to define the nature of organization.

C. The elements of personhood are critical to shape a consequence in view of organizational leading or managing. The attitudes, mind, skills, technologies and others resting within the leaders or managers are important in the context of organization even if the elements would vary with the nature of organization.

D. Both concepts are actually not separable, and are generally observed on the continuum on to the whole viewpoint of organizational activity, and in the above case, could be found in the class activities through the end of terms. That is also true in various organizations.

E. Some lecturer would more rely on a creative way to gain the support of audit students while others may conduct in more managership way of delivery. Both ways are distinct each other that the leadership attitude would be on more human interaction while the management attitude seems generally indoctrinating and proctorship pattern of class delivery. However, they are not exactly said in one way as I have stated. One of most important goals in the law department is to yield more passers on various of national exams, and the knowledge-oriented education would be more effective, in some context, other than the creative way of class delivery. This complementary nature would also be found across various organizations.

F. I acknowledged that we can find more attributes of qualitative evaluation bearing a philosophical or leadership aspect, and the managership delivery of class would bear common understanding more keenly on the math-based evaluation (scaled one). This methodological tools would be correct over various organizations setting aside a small scope of exceptions.

G. We find the leadership aspect of class more interactive, dynamic, more challenging and transcending, more political while we find it more line hierarchy, more static, more objective and administrative in the managership aspect of class. This classification seems properly applied to most of other type organizations.

\section{On the Three Leadership Styles}

Generally, we are able to identify major three paradigm of transformational, transactional, and situational leadership, which include several important elements to define them.

First, we can find an enlightening contrast between the transformational and transactional leadership proposed by Zalenznik (Hickman, 2010). The theoretical and practical distinction between leaders and managers, elaborated by Zalenznik, properly address the basic dispositions of organizational leaders. The elements of leader and manager are generally distinguished on the points, attitudes toward goals, conceptions of work, relations with others and senses of self. For example, the leaders are more personal that managers, who are impersonal and tend on more adherence to the rules and standards, or quantitative work outcomes. This version would help to identify the leadership style, yet 
being not definitive to find a one way characterization of real context leader. The organizational leaders, in most cases, share both traits to some extent. This framework was developed in a virtually similar context by Burns, whose juxtaposition turned to the title of "transformational and transactional," and being expansive. His viewpoint for the contrast covers more widely the points on emotional involvement, personal life, the way of achievement and to hold the followers accountable, to appreciate from the followers and engender in them, value emphasis, problem and plan.

In his proposition, the leader's emphasis on value stressed more on the end state other than means. The way of emotional involvement differs in that the leaders are on more institution and ideal or vision-intense while the managers would focus on task and the people involved in the task. Particularly for the transformational case, Bass delineated four aspects of transformational leadership which work to effect an organization change. They include (i) idealized influence, (ii) inspirational motivation, (iii) intellectual stimulation, and (iv) individual consideration. The elements powerfully apply, as a way of characterization, to most of organizational leaders(Hickman, 2010). We most often see an idealized influence as an initiative to process the transformation of organization. For example, it is usual to see if this presidential candidate is very progressive to realize the welfare goals of nation with his constellation of behaviors and past achievements. Afterwards the leader may provide meaning and challenge, and cultivate a team spirit over the campaign, and later would hold national talks on TV for more communication with the followers on the points of public policy. He or she may appear on the street to show an improvement of poverty class or like to know the hardship of individuals.

We can note one of other important accounts of leadership style, what we call a situational leadership (Hersey \& Blanchard), which rests on two fundamental concepts: leadership style and the individual or group's maturity level. They characterized the leadership style on two distinct elements, say, task behavior and relationship behavior. If we say the classic theory of leadership as trait-oriented (Carlyle \& Galton), the former two would be quasi-trait nature to give a unilateral focus on the leaders of organization. While phenomenological and analytic, however, they did not directly mention about the genes or hereditary elements unlike the classic theorists. Within the situational model, the elements of followers were introduced (Burke, 2011). For the leader's side, they conceptualized four sorts of leader's disposition which would be variable depending upon the level of followers: telling, selling, participating, and delegating. These four accounts generally comport in terms of hierarchy and development of leadership. To say, the telling stage is basic and it may develop into selling or participating. For the most satisfactory or heightened level of leadership, the leaders may delegate a part of its power. Hersey and Blanchard also framed four basic perceptions to identify the maturity levels of followers : (i) incapable/unwilling (ii) incapable/willing (iii) capable/unwilling (iv) capable/willing. Although the subjects of modern organization, at considerable extent, have a mind and sense for their boss as the kind of classic monarchy, the situational theory seems representing fair balance between the leaders and followers. The factor of organizational competitiveness or efficiency still remains unclear about which theories better serve to identify more effective change of organization. As in seven factors of Gardener's, the transformation of organization might better to discontinue as in kinds of events, such as terrorist attacks, hurricane, and so on, which are so powerful to affect the leaders' attempt of organization change to be withdrawn.

In order to brief on my leadership style, I begin with some of reflection concerning 
the contemporary context of human nature. We note a scope of typical elements which are theoretical, but practically persuasive on many of our neighboring process and human achievements. If we are an ego to produce and of high tendency to subscribe to the meanings or contribution, the context of human and organization should be an immesuarably central concern in this modern world. A great number of people are now actually living in some of organizational context. They may work for the profit or non-profit organization, and the interaction as well as achievement seems essential in developing egos and emotional element of satisfaction (Piaget \& Ericson). It implies this corollary so strongly if we has continued to chart the employment problem as a top priority in the public election notwithstanding the countries involved.

An organizational life defines the whole of person at a greater extent more than other aspect of each individual. This point of focus would relate with history in the way of structural viewpoint. Across the classic and feudal monarchy, the organizational issues tend to be limited on a religious dominance or feudal status. While the liberal capitalism arose, the people are emancipated from sorts of hamshacklings, who can freely own the property and freely enter into the contract with other equal and esteemed subjects, a peer of their society. They are free, but in some cases, have to be more responsible for their self, and a dimensional diversity requires creating the true nature of modern people. For them, I could state several points of attribute which are pertinent to understanding the leadership styles and their elements: (i) human nature became very complicated under the modern social and technological environments (conceptual complexity),(ii) human nature turned to be wiser and more strategic other than tamed or passive which is due to informatization and universal trend of higher education(strategic egos), (iii) the leadership and organizational issues turned to be more intense, and the framework on competitiveness has a most strong profile in the organizational studies while this factor was, in feedback, to finally resort to the human elements, and return again to the competition point, in circular, as being likened to the input, throughput, and output analysis (humanity and organizational competitiveness).

Given the higher aspect of human nature, I prefer to exercise a transformational leadership, which, I think, can be more finely matched with the true sharing of values and organization change, a readiness to participate, and sincere compromise or concession with the followers(Burke, 2011). Of course, I see that a scope of elements reside within the potential of myself. I like to be personal to inspire the followers for idealized influence and lead them to share the vision and challenge. I sometimes prefer to implore on strict compliance with the working standard or organizational rules. The scope and extent of application would certainly differ, which has to be flexible to the nature of organization and the situation I may face up with. As I assume the human nature of contemporary citizens as above, it is required to subscribe to the strengths of situational leadership. The first two theories actually place more emphasis on the leader's side of elements. The leadership dynamics, however, is interactively perceived in the account of situational leadership. While the human standard grows to be enhanced, we generally are true if with the hierarchy of needs framework (Maslow).

Gardener's seven factors or levers enlightened me to find the latent elements of personality, which would complement with my leadership attitude by providing a way of thinking and useful action steps to persuade the followers(Hickman, 2010). Reason would be powerful to attain the followership, which could be supported in complements by research. The followers can form a scientific conviction in the course of leading and managing. It is 
necessary to assess the resonance of organizational members whether the argument for change is accepted or merits the favorable response from the followers. Redescriptions as well as resources and rewards should be the critical instrumentality, which increases a persuasive force and entices the followers. Two factors would work to evaluate the change leadership of mine, which are environmental and internal ones. Real-world events are indispensible on the constant monitor finding the true path of concerned organizations. That is particularly important if we consider the context of executive leadership. It is needless to stress that the factor of resistances is essential in the pursuit of effective leadership.

One other point needs to be remarked on the argument about the gender and cultural elements raised by Ming-Yi. His research found that public relation practitioners in Taiwan generally expect a transformational leader more favorably. These findings comport with the general tendency of western female subordinates. The difference lay in a similar share of female subordinates, who also have high expectations of transactional leadership. The research outcome, then, means that the Taiwanese female workers highly expect more concerns from their leaders, about the satisfaction of physiological, safety, and belonging needs (Ming-Yi, 2010). They also critically perceive the self-esteem and self-actualization as important, which could be substantiated with their profession and transformational leadership. The gender and cultural version of leadership theory, as proposed, could well be accommodated to apply to the Korean context. We have elected a new female president these days, and a fair portion of professionals and workers are women. Their voice would increase that is hardly on neglect if I were in the leadership position.

\section{Informal Leadership and Followership}

The first aspect we are related with the concepts would come from a bit ambiguous nature of informal leadership. It is plainly connoted outside the definition of formal leadership. The leadership is defined on the assumption of organization, and concerns a constructive dynamics toward a desired goal. In this point, we can properly distinguish just power wielders against the leader or led. The power wielding generally views the led as things under the structure and power generating elements of hard nature including high resources, skills, system and so forth. The organizational goal is usually brought unilaterally from top-down, and the power base is a central concept other than the critical human element. This distinct point is critical to exclude the followers' aspect of organization, participatory leadership or humanized concept of organization, as well as the process and goals of organization. In this case, we can generally find a less extent of organizational perspective, if it would be available. The power studies tend to give its true focus on the power itself, the system which they subscribe to, the pattern of power wielding, most effective way to preserve and increase it or so. Therefore, a focus on organization efficiency and change would be either curtailed or outside the scope of its research, and on a limited context only if not absolutely irrelevant. Other peer concept, influence, would also need to be distinguished in that influence would normally be seen as less extent of power-wielding, which is not directed to the certain goals, but a factor viewed to generally lead the people toward a desired direction. The leadership, on the other hand, would lead, communicate with, and motivate the led to the desired goal, which, in many cases, operate within a specific unit. It is not finished at one point of time, and usually kept continuous at the point of entropy. It is recycling generally while we can see the extreme cases of emergency leadership, and the feedback is essential to evaluate the effect of leadership or pros and cons which could improve on the subsequent term. 
Informal leadership is also understood in terms of constructive dynamics of organization, but operates outside the formal line of authority. It generally shares the attributes of leadership except that it operates informally other than formally. Given the distinction between the leadership and management, the informal leadership is the type which can be found in the leader rather than the manager. If the manager is linked to the concept, we need to recant the given scope of organization as to shrink to the limited unit where the manager played a leadership role. For the work unit or team within a larger firm, we may find an informal leadership of the manager while he or she being responsible to the higher authority or leaders.

As of the nature of organization, the informal leadership is a universal phenomenon regardless of the type or size of the organization. The organization certainly underlies the human elements, which generally means the gross sum of happiness of organizational constituents. That is plainly truthful when we illustrate the kind of contradiction about "genius v. common." If a genius produces gross sum of efficiency more than a routine proposal, but less than the gross sum of happiness for the organization, the leader and constituents would usually choose a routine proposal to reject the genius' proposal. The proposal, as less efficient, would still yield more happiness of all. That case may be found in the academic association of specific field. Suppose it publishes a science journal, and a genius article was submitted for contribution. The decision for contribution would be made by the all convened meetings. The convened constituents are led by the chief editor who is a leader of the association. In the course of profession, they all recognized the superior and genius content of the presented article. Imagine eventually that the article was rejected for whatsoever true reason but with a disguised comment to avoid its contribution. The rejection is truly grounded on the gross happiness of constituents, but sacrificed the genius article. The leader and followers agree and act on their due course of organizational dynamics. That is the case at the extreme, but generally delimits the organizational discourse other than power studies or influence. One real context of illustration may be found in the Iraqi war. The former president Bush waged the war to carry their international commission and other various reasons long debated until now. It is generally seen as to increase the satisfaction of United States, which of course, cannot be calculated simply on the economic math. It may meet the sense of justice for the American people, or may give a feel of satisfaction to see US working on the mission of international police power. In the course of various factors, the US government, which legitimately represents the organization of one leader and other 0.4 billion followers, finally decided to initiate war and successfully operated though the result. The opposing group may talk about more efficient way to address the Iraqi problem. Assume that it was considered, but was rejected. The decision would be made on the basis of gross sum of happiness of American people rather than other efficient or genius proposal. The leader generally focuses on the organization itself other than countering or indirect elements.

The context also may be viewed one type of informal leadership on the constitutional ground. The official way to engage in the war requires a congressional approval where the constitution vests the war making power in the US congress. For the international context, the war campaign is legitimate on the series of resolution of UN Security Council, and its several non-compliance on the Iraqi government. Of course, the war advancement has been questioned of its legitimacy by some group of international scholars. The action of US Supreme Court would be dubious if it was brought to the domestic justice. The general tendency would be the kind of judicial abstention about such class of political questions. That is one of grey areas which the presidential system of government is inefficient from the separation of powers principle. The parliamentary system would be effective to dissolve the congress and to reelect the government head. In any case, the war decision is typical in the 
constitutional rule where an informal leadership may work. The followers also generally consider it in a more flexible way, and assess the situation from various aspects, which would, in some sphere, be implied and illicit. In some cases, the leadership role can be escalated to the point of emergency one. From the various groups of followership, many would be "yes man or conformists" who would defer to the decision elites. There would probably far less about the life way paths under the classification of Kelly. The members of US army might be, but the military firms might not be fatally prejudiced on the negative decision. It is dubious if we can illustrate any group of society as dreamer's path. It would be morally enhancing or comport with the concept of just war if we avail of the disciple's path or comrades paths. On the effort toward that change, more public relations as well as adequate orientation or education on followers' side, however, would be necessary. Besides the group of war subscribers, we would not normally conceive the dreamer's path, but some social group may see it indispensable and urgent to proselytize the Middle East barbarians, which would be furthered on their evangelical activities there. They may be perceived as the dreamer's group. Of course, the situation is fairly distinctive and one of extreme illustrations on the normal leadership discourse.

I suppose that the informal leadership, in cases, have two attitudes: (i) it would be formed on a rather confidential ground; (ii) it could function more efficiently to reach a decision. For the Bush administration, the neo-conservative group is considered to work as an informal or strategic assistance force. The informal leadership may be found in a scope of instances about our neighbors. It is not incorrect to state about small firms or societies in Korea, that we can see a differing attitudes of followers if we offer a festive or amusement for the followers. Such service would not fall within the formal leadership, but is so powerful to affect the attitudes of followers in Korea. The government of South Korea also joined the united force to sanction the Iraqi government. Korean people generally opposed the war participation principally because it can bring a cost of young lives. Social and spiritual leaders in Korea, however, exercised their social prestige to persuade the public, which could make a success for the congressional assent in the event. They are not formal leaders in this case, but can be properly classed as an efficient leadership of informal nature.

Generally, we are able to identify major three paradigm of transformational, transactional, and situational leadership, which include several important elements to define them.

First, we can find an enlightening contrast between the transformational and transactional leadership proposed by Zalenznik (Hickman, 2010). The theoretical and practical distinction between leaders and managers, elaborated by Zalenznik, properly address the basic dispositions of organizational leaders. The elements of leader and manager are generally distinguished on the points, attitudes toward goals, conceptions of work, relations with others and senses of self. For example, the leaders are more personal that managers, who are impersonal and tend on more adherence to the rules and standards, or quantitative work outcomes. This version would help to identify the leadership style, yet being not definitive to find a one way characterization of real context leader. The organizational leaders, in most cases, share both traits to some extent. This framework was developed in a virtually similar context by Burns, whose juxtaposition turned to the title of "transformational and transactional," and being expansive. His viewpoint for the contrast covers more widely the points on emotional involvement, personal life, the way of achievement and to hold the followers accountable, to appreciate from the followers and 
engender in them, value emphasis, problem and plan.

In his proposition, the leader's emphasis on value stressed more on the end state other than means. The way of emotional involvement differs in that the leaders are on more institution and ideal or vision-intense while the managers would focus on task and the people involved in the task. Particularly for the transformational case, Bass delineated four aspects of transformational leadership which work to effect an organization change. They include (i) idealized influence, (ii) inspirational motivation, (iii) intellectual stimulation, and (iv) individual consideration. The elements powerfully apply, as a way of characterization, to most of organizational leaders(Hickman, 2010). We most often see an idealized influence as an initiative to process the transformation of organization. For example, it is usual to see if this presidential candidate is very progressive to realize the welfare goals of nation with his constellation of behaviors and past achievements. Afterwards the leader may provide meaning and challenge, and cultivate a team spirit over the campaign, and later would hold national talks on TV for more communication with the followers on the points of public policy. He or she may appear on the street to show an improvement of poverty class or like to know the hardship of individuals.

We can note one of other important accounts of leadership style, what we call a situational leadership (Hersey \& Blanchard), which rests on two fundamental concepts: leadership style and the individual or group's maturity level. They characterized the leadership style on two distinct elements, say, task behavior and relationship behavior. If we say the classic theory of leadership as trait-oriented (Carlyle \& Galton), the former two would be quasi-trait nature to give a unilateral focus on the leaders of organization. While phenomenological and analytic, however, they did not directly mention about the genes or hereditary elements unlike the classic theorists. Within the situational model, the elements of followers were introduced (Burke, 2011). For the leader's side, they conceptualized four sorts of leader's disposition which would be variable depending upon the level of followers: telling, selling, participating, and delegating. These four accounts generally comport in terms of hierarchy and development of leadership. To say, the telling stage is basic and it may develop into selling or participating. For the most satisfactory or heightened level of leadership, the leaders may delegate a part of its power. Hersey and Blanchard also framed four basic perceptions to identify the maturity levels of followers : (i) incapable/unwilling (ii) incapable/willing (iii) capable/unwilling (iv) capable/willing. Although the subjects of modern organization, at considerable extent, have a mind and sense for their boss as the kind of classic monarchy, the situational theory seems representing fair balance between the leaders and followers. The factor of organizational competitiveness or efficiency still remains unclear about which theories better serve to identify more effective change of organization. As in seven factors of Gardener's, the transformation of organization might better to discontinue as in kinds of events, such as terrorist attacks, hurricane, and so on, which are so powerful to affect the leaders' attempt of organization change to be withdrawn.

In order to brief on my leadership style, I begin with some of reflection concerning the contemporary context of human nature. We note a scope of typical elements which are theoretical, but practically persuasive on many of our neighboring process and human achievements. If we are an ego to produce and of high tendency to subscribe to the meanings or contribution, the context of human and organization should be an immesuarably central concern in this modern world. A great number of people are now actually living in some of organizational context. They may work for the profit or non-profit organization, and the 
interaction as well as achievement seems essential in developing egos and emotional element of satisfaction (Piaget \& Ericson). It implies this corollary so strongly if we has continued to chart the employment problem as a top priority in the public election notwithstanding the countries involved.

An organizational life defines the whole of person at a greater extent more than other aspect of each individual. This point of focus would relate with history in the way of structural viewpoint. Across the classic and feudal monarchy, the organizational issues tend to be limited on a religious dominance or feudal status. While the liberal capitalism arose, the people are emancipated from sorts of hamshacklings, who can freely own the property and freely enter into the contract with other equal and esteemed subjects, a peer of their society. They are free, but in some cases, have to be more responsible for their self, and a dimensional diversity requires creating the true nature of modern people. For them, I could state several points of attribute which are pertinent to understanding the leadership styles and their elements: (i) human nature became very complicated under the modern social and technological environments (conceptual complexity),(ii) human nature turned to be wiser and more strategic other than tamed or passive which is due to informatization and universal trend of higher education(strategic egos), (iii) the leadership and organizational issues turned to be more intense, and the framework on competitiveness has a most strong profile in the organizational studies while this factor was, in feedback, to finally resort to the human elements, and return again to the competition point, in circular, as being likened to the input, throughput, and output analysis (humanity and organizational competitiveness).

Given the higher aspect of human nature, I prefer to exercise a transformational leadership, which, I think, can be more finely matched with the true sharing of values and organization change, a readiness to participate, and sincere compromise or concession with the followers(Burke, 2011). Of course, I see that a scope of elements reside within the potential of myself. I like to be personal to inspire the followers for idealized influence and lead them to share the vision and challenge. I sometimes prefer to implore on strict compliance with the working standard or organizational rules. The scope and extent of application would certainly differ, which has to be flexible to the nature of organization and the situation I may face up with. As I assume the human nature of contemporary citizens as above, it is required to subscribe to the strengths of situational leadership. The first two theories actually place more emphasis on the leader's side of elements. The leadership dynamics, however, is interactively perceived in the account of situational leadership. While the human standard grows to be enhanced, we generally are true if with the hierarchy of needs framework (Maslow).

Gardener's seven factors or levers enlightened me to find the latent elements of personality, which would complement with my leadership attitude by providing a way of thinking and useful action steps to persuade the followers(Hickman, 2010). Reason would be powerful to attain the followership, which could be supported in complements by research. The followers can form a scientific conviction in the course of leading and managing. It is necessary to assess the resonance of organizational members whether the argument for change is accepted or merits the favorable response from the followers. Redescriptions as well as resources and rewards should be the critical instrumentality, which increases a persuasive force and entices the followers. Two factors would work to evaluate the change leadership of mine, which are environmental and internal ones. Real-world events are indispensible on the constant monitor finding the true path of concerned organizations. That 
is particularly important if we consider the context of executive leadership. It is needless to stress that the factor of resistances is essential in the pursuit of effective leadership.

One other point needs to be remarked on the argument about the gender and cultural elements raised by Ming-Yi. His research found that public relation practitioners in Taiwan generally expect a transformational leader more favorably. These findings comport with the general tendency of western female subordinates. The difference lay in a similar share of female subordinates, who also have high expectations of transactional leadership. The research outcome, then, means that the Taiwanese female workers highly expect more concerns from their leaders, about the satisfaction of physiological, safety, and belonging needs (Ming-Yi, 2010). They also critically perceive the self-esteem and self-actualization as important, which could be substantiated with their profession and transformational leadership. The gender and cultural version of leadership theory, as proposed, could well be accommodated to apply to the Korean context. We have elected a new female president these days, and a fair portion of professionals and workers are women. Their voice would increase that is hardly on neglect if I were in the leadership position. 


\section{References}

Burke, W. Warner. (2011). Organizational Change: Theory and Change. $3^{\text {rd }}$ Ed. Thousand Oaks, California: Sage Publications. Print.

Buytendijk et al. (2009), Performance Leadership : The Next Practices to Motivate Your People, Align Stakeholders, and Lead Your Industry

Drucker, P.F. (2001), Essential Drucker : Selections from the Management Works of Peter F. Drucker Drucker,

Hickman, G. Robinson (2010). Leading and Organizations: Perspective for a New Era. SAGE Publications. Thousand Oaks, California: Sage Publications.

Hollander, E.P. (2009), Inclusive Leadership : The Essential Leader-follower Relationship, Routledge.

Ming-Yi, W. (2010). Gender and cultural influences on expected leadership styles in the Taiwanese public relations field: Transformational and transactional leadership styles. China Media Research, 6(1), $37-46$.

Roggio, R.E. (2006), Transformational Leadership ( 2nd ed.) Erlbaum Associates. 


\title{
Chapter III. Organization Change: Some Case
} Reviews

\author{
1.Organization Change of Hanwha and Mr. Han's Leadership Style
}

\section{1-1. Introduction}

In the course of exploring Mr. Han's leadership style, we have to consider several important aspects that Hanwha has to assume and undertake to address over the decades since 1981, the beginning year of his CEO status.

\section{1-2. Variables of Organization Change}

A first aspect draws upon the particular economic conditions of national economy. Korea has long pursued a developmental state paradigm to boost our national economy ever since 1960's, during the times the economic growth and increase of GDP have always been placed a top priority for the heads of state (Fullan, 2011). This national passion enabled a shielded or fostered status of key sector businesses, which contributed so much to the current form of Korean chaebols. This means that other national or social virtue would be put to public neglect, such as social justice or fair distribution of national wealth, basic human rights, and so on. Hanwha is one of those chaebols, which is essential to understand his leadership style.

A second aspect is concerned about the cultural attributes of Korean nationals. Long indebted to the Confucian philosophy, aspects of a spiritual dimension within the Korean minds and social morale had been greatly influenced by Oriental virtue. As of the nature of business organization, a materialistic and western rationalistic traits have been mixed to provide the cultural and human elements within the group of Hanwha (Shein, 2010).

A third aspect factors in the context of internationalization or globalization during his hold of Hanwha for about 30 years. It critically posited that his leadership style can be properly understood in the wider context beyond a national dimension (Hackman, 2002). His followers actually spread over various foreign stations and a fair number of foreign workers are subordinates to his leadership. That is one of reasons that we can find a bit of servant leadership style despite the dominant part of his charismatic or transformational leadership. An implication of this factor should be more extended since his times witnessed a rapid progress for globalization of the nation (Ireland \& Hitt, 2005).

A fourth aspect could be found in his familial relations as a second generation leader, who has managed one of the largest groups in Korea (Salahuddin, 2010). It may go too far if we define him a kind of Victorian emperor as Carl Lyle and Galton propagated to support the hereditary or genetic elements within the leadership. At least, however, he may be considered a Bush or Kennedy family if we see him so long from his father's years, 1950's. There are several elements in the differing context between the feudal lines of King's status and 
business successors. King's status is simple to secure and easy to defend in normal cases which may persist longer than the business context. Therefore, the trait element of leadership would be more powerful in its discourse. With this reservation, the conglomerates, particularly chaebol in Korea, can well be said less dissimilar in its pattern of operation, leadership style, nature of capitals and succession practices. Given his charismatic style being a strong, his traits as a successor mean to comport as an increasing factor. If we begin with the analysis of leader's trait at the bottom line of leadership style, this aspect is essential point in need of consideration (Salahuddin, 2010).

\subsection{Organization change and Mr. Han's Transformational Leadership}

His leadership style can well expose the transformational elements through the crisis and challenges. That disposition is inevitable from the deep structure of Hanwha, and the leader's characteristic or traits on "transformational" comes rather in a smaller context. Upon a high dependency on foreign exports in the context of national economy, the challenge of globalization is serious to secure a negative entropy of the group. It is one way of understanding that the equilibrium would mean the dead end of organizations, and it is particularly true to the case of business organizations in Korea. A support from the government in Korea is vital to thrive and maintain its business, which had long been powerful to affect the businesses. The developmental policy of Korea required expanding to machinery and chemical during 1960's and 1970's. Later over the 1990's and new millennium (Ireland \& Hitt, 2005), the businesses could see more chances of governmental support, which would range over vast means, by pioneering into the new high tech sectors of industry. That path of organization change was successfully achieved while overcoming a set of specific challenges including the financial crisis(Hackman, 2002).

The challenge of globalization for the times of 1990's in Korea also required an international sense and strategy to restructure the group. As we see, globalization drove a deregulation initiative and liberalization of capitals in the global context. His transformational leadership correctly pointed to this essence (Fullan, 2011), and the organization was successfully led to new sectors of oversea corporations, branches and offices, which could compete with western counterparts in the context of fair competition and on the new concept of level-playing field.

In carrying his leadership, we can identify several elements which Zalenznik adduced for the leaders other than managers (Zalenznik, 1989). His attitude toward goals are personal and active. According to the source, He regularly held new year message ceremony with a crowd of cadres and workers, which was tailed to personal parties at the end. His message contains the clear goals and objectives of moral nature, which arouse a vigor and activism in the mood of cultural escalation. Participants said generally that they feel the kind of familial unity and common sharing of values. This forge them through their work of year- long term where his or her boss was projecting the idea into images exciting people and guided various options for innovative and creative minds. His concept of strategic meeting was not limited to it, and many instantaneous occasions occurred through the years, who preferred solitary civilities and naturally relate with the followers intuitively and empathically.

Bass' framework of transformational leadership also virtually reflects most of Mr. Han's leadership behaviors. He possesses a charisma and heavily relies on the method of idealized influence (Burke, 2011). For our neighbors, I confirm that his followers, who are 
esteemed as an elite in Korea and admired to become a business owner, largely regard him as a role model. They are disposed to identify with and share to emulate him in a good sense since they harbor in mind surprisingly the constellation of leading behaviors and successes. They are learnt from him and like to mimic in the feel of same identity, and manner or ways of leading(Maslow, 1998). I could also verify, though not on the scientific ground, that his leadership style has a right fit within the transformational form. To say some, he was disclosed a steady worker around the nation and oversea branches for leadership chances (MBWA: management by walking around). His constant stay has been made on the team spirit on which he has strenuously place an emphasis for thriving and poured a focus on its cultivation.

In shaping his leadership style, I suppose his familial and educational background seems to factor in some ways. He is A second generation owner, who could be bred being disposed as the context of absolutism around the group's environment. His way of thinking and acting are important and his request and desire have been wholly respected by the intimate and power followers of the group. His earlier prestige can be confirmed to enter Kyung-ki high school, which is most prestigious one in Korea and has a heavy profile of alumni working as a social elite. He had a chance to study in the United States, and obtained a master's degree in international politics. He has stayed long for the undergraduate and graduate studies, which is unusual even for the professors of Korea and often are found in the second generation leaders. Therefore, he is a fluent speaker of English and has a strong profile of international context. This personal background seems to increase his charismatic style of leadership and bred a competence to cope with the international challenge properly.

As we made a description, his leadership focused its concentration on the moral and spiritual aspect of followers. Motivation has been a fair amount of leadership requirement, and the way of approach has taken a part from the oriental value and culture. It appears to generate a readiness and sharing between the leaders and followers toward the desired change (Hickman, 2010).

In my findings and assessments, I like to mention that he is also a situational leader based on the maturity of followers as Hersey guides. At the highest point of leader's evaluation, he delegated his power and authority to the lines and each responsible post. According to the theory from Maslow, he applied the hierarchy of needs frame to choose more efficient way of leadership between the transformational and transactional style (Maslow, 1998).

\section{Leadership Style : A Case of Law Firm, "Choon-choo"}

\section{2-1. Background and the Institution}

For the years over 1998 through 2002, I was recruited as an attorney for the small law firm located at the heart of Seoul city. The law firm was titled "Choon-choo", which means an "age of noble person" in Chinese. Around the time, I taught at Ajou university located Suwon, a nearby city of Seoul, the capital of South Korea. I was a full-time professor, and thus required to serve a dual responsibility as an attorney and law professor. For some potential conflict of responsibility, I obtained a requisite approval from the administration and legalized my engagement. Thereafter, I enjoyed happy times to practice and teaching laws, although the income did not double, but to make a small increase than one single job position. The law firm is, therefore, familiar with me, and allows me to retrospect by enabling the 
leadership styles to be applied, though in a small context.

The law firm was created in the initiative of my college alumni, Jong-ryull Kim and Hee-ryong Won (Fullan, 2011). Both are Korea-licensed attorneys, and worked several years independently as a practicing lawyer and public prosecutor. They both made a highest and second highest score in the national bar exam, and Mr. Won was also summa cum laude in the national college entrance exam. Both exams are usually considered as most difficult and redeemable, which brought them in the context of social respect and aspirations. Not against the expectations, they have performed well as an attorney and public prosecutor, and agreed to jointly create a law firm for provision of legal service (Network Weekly, 2009). They were actually an engineer to manage the law firms although the legal formality is on a partnership basis. Therefore, the member attorneys had an equal share and it took a decentralized form of decision making authority with an equal vote for member attorneys. The other four attorneys were me, one of Chinese origin, and two younger fresh bar members of South Korea. My engagement was a bit limited to my expertise (Constitutional law), and other two juniors were a kind of working horse, who were most heavily charged of caseloads within the firm. One last from the Chinese bar association was responsible to provide a counsel for the Chinese clients and litigation arising from the multiple context. The firm was staffed with one male chief administrator and four female secretaries.

The organization described above performed well and yielded a slightly more annual profit as compared to other similar size of law firms. Both two key figures later became congressmen, and one of them, Mr. Won, was once considered as one of presidential hopefuls for the Republic of Korea. The times I served were actually under the situation of foreign currency crisis in Korea, and which would be bitter to many businesses, but not exactly for the case of legal service sectors (Hackman, 2002).

\section{2-2. The Most and Least Effective Leadership Styles}

Over the experiences, I found that that small law firm is most fitting within the transformational and servant leadership, if where it pertained to a professional aspect concerning lawyers, who being also the status of owner and management. The situational leadership would say more to manage the staffs. The charismatic leadership would leastly function, and in some cases, appeared to bring a contrary reaction to make the firm falter with a significant stalemate (Mullen \& Schunk, 2010).

As we see, the transformational leadership includes sharing value and vision, orienteering and breeding the change, and placing a greater emphasis on motivation, spirit and morals of followers where the communication and participation play as a prime means to address the leadership mission (Fullan, 2011). The servant leadership approximates a fair of

elements to share with the transformational one, but it requires to focus on the service of leaders themselves and even advancing to coach, educate and train the followers as a prospective leader. A more deep and individual concern, touch, and humanistic interplay can be seen to reinforce its attributes distinguishable from the transformational leadership. The situational leadership has a least potential to be applied to the owner or manager attorneys given their normal standard of professionalism and mind of positivism. Hersey's maturity level are fairly less of claim to find an adequate form although each attorney has a different level of career experience, or junior and senior status. The trade-off relations seem to operate if the younger ones have a fresh mind and updated knowledge. That is a factor tradable for a rich experience of senior attorneys where the simple classification of Hersey's model would less come within the right fit. 
The transformational leadership is essential for this case if the firm needs to be constantly adaptive to the changing market condition, which makes it less effective to continue on the management style leadership. They were required to discuss regularly the trend of clientele, and the hardship needs to be overcome with the vision and values of professional as a public service agent. They were leaders and also followers who motivated and encouraged themselves through the meetings, regular feast of night time sake, and exchange of familial events (Schein, 2010). Their leadership, therefore, is collective to emphasize a mutual engagement where the turn would be set in the interval of familial events (for example, a half annual visit to one member's garden party) for each attorney. The leaders of regular business meetings did not usually ask "Have it done, now the due date," rather asked "This task is significant to raise the fame of firm, and to the best of us." (Mullen \& Schunk, 2010)

While the concern is less of a specific task, the leaders and followers had been more oriented to the team spirit, and relationship is critical to foreclose a split of members which could jeopardize the whole of firm. The clientele are divided to form the basis of law firm that a kind of antagonistic mood could vitiate the competitiveness of firm, and for other firms' case, even occasionally brought a disorganization of the firm. While the task is on the similar standard as of its nature, the relationship is fairly individualistic, particularly within that small context. The servant leadership was required to ensure a long term evolution of law firm. As junior attorneys would later take a major lead beyond the formal equal voting power, their adaptation and settlement in the environment of law firms were needed to pull out their potential as the followers' aspect and educating or training them as a more prospective caliber of leaders. The firm, in this aspect, had a budget to allow one year foreign apprenticeship in US and Europe, and other nations, which normally was coupled with the LL.M course (Hackman, 2002)

The necessities of servant leadership was found in other context, which was about an attorney of foreign origin (Schein, 2010). A Hersey's model was hardly applied in one aspect, and very delicate in other aspect. They were normally very willing to perform their duties, which brought a less meaning between "unwilling/willing." The aspect of competence was delicate if they were a skillful professional in their countries, while being less about the orthodox Korean nature of work. In this situation, the servant leadership was the last bulwark with coaching or mentorship, and required a provision of service to build a same identity with the leaders. That was despite a different class of values in terms of legal business, which would normally involve a special clientele on the foreign basis or so. In this context, the charismatic leadership seemed to leastly effective while the foreign culture and different base of passion or intelligence would make it come belatedly over the long period of career endeavor. Given such context of special clientele, he was also independent in some aspect from the major stream of compassion which vitiated the charismatic nature of leadership.

The transformational leadership was also required to increase if the situation I experienced was undergoing the economically hard times. The leaders and followers had to be sensitive about the dynamics of market change, in which the firm saw a type of organization change in terms of its work frame. It was the times when a scope of Korean businesses practiced a merger and acquisition, and realized mass layoffs on the business reason. Therefore, they frequently convened to share an information and exercised a motivation or stimulation to find the large pool of clients. Their participatory leadership worked effectively to transform the organization with motivated followers.

For the staffs' level, I found that the transactional or situational leadership had a good nature to keep them continuing. An ungrounded touch or deep involvement would occasionally see a negative consequence, which was never the case of Choon-choo though. 
There have been many stories in Korea about the misunderstanding and unethical events, which could disappoint the morale of staffs or expose the organization in bad aspect (Schein, 2010). A chief administrator and the hiring attorney of one local law firm were convicted of the violation of attorney laws because of the attorney's high and illegal motivation for him to subsidize the clients. In some cases, female staffs were mischieved by their hiring attorneys. Therefore, it seemed to be indispensable to keep the work section strictly with less involvement, and as limited on the management supervision. Particularly within the culture of Orient and Korea, the task-oriented or management nature of leadership would work to keep them stable on their work.

\section{2-3. Conclusion}

Across the reflection of my past experience in terms of leadership style, I found a couple of points on insight.

First, I found that the leadership issue lies as not unfamiliar with our small context of professional life. That issue is omnipresent across the various nature of organizations within the community. It actually offers the point of engineering, dynamics and evaluation of each organization.

Second, the leadership style can be diverse theoretically,, but requires a focus on its strength and weakness if we advance to apply it in the special context of each organization. Therefore, finding an effective leadership style requires an analysis about the nature of organization and its environment or deep structure.

Third, the small law firm, titled Choon-choo is special to find a various context of effective leadership as described above in terms of its most and least effective paradigm. 


\section{Reference}

Fullan, M (2011). Change Leader: Learning to Do What Matters Most, Jossey-Bass.

Hackman, J.R. (2002). Leading Teams: Setting the Stage for Great Performances, Harvard Business Review Press; 1 ed.

Ireland, R. D. \& Hitt, M. A. (2005). Achieving and maintaining strategic competitiveness in the 21st century: The role of strategic leadership. Academy of Management Executive Journal, 19(4), 63.

Maslow, A.H. (1998). Maslow on Management, Wiley; 1 ed.

Mullen, C.A. \& Schunk, D.H. (2010). Un Regard Sur Les Communautes D'apprentissages Professionnelles À Travers Trois Cadres Contextuels : Le Leadership, 'Orgainsation Et La Culture, McGill Journal of Education (Online) 45.2. pp. 185-203.

Salahuddin, M. M. (2010). Generational Differences Impact on Leadership Style And Organizational Success. Journal of Diversity Management, 5(2), 1-6.

Service Performance Insight; Confidence in Professional Service Organization Leadership is a Leading Predictor of Fiscal Health According to SPI Research's Newly Published Report, 2009 Professional Services Maturity Model Benchmark, Network Weekly News (Mar 2, 2009): 38.

Shein E.H.(2010). Organizational Culture and Leadership (The Jossey-Bass Business \& Management Series), Jossey-Bass.

Zalenznik, A. (1989). The Managerial Mystique: Restoring Leadership in Business, Beard Books. 


\section{Chapter IV. The Leadership Qualities}

\section{On the Leadership Elements :Servant Leadership}

The term "servant leadership" was firstly coined by Greenleaf, who has offered a countering version to then dominant power-centering and authority or hierarchy version of leadership. It was originated in the context of United States, but now generally perceived as more fitting within a rather diverse or cultural environment. Therefore, it is more welcomed in the international context, and may vary with the countries involved. For example, Hannay's research revealed that the leaders and followers of the United States have a general perception on two major variables, individualism and masculinity, on contrary force against the servant leadership style (Hannay, 2009). This findings are comparatively pictured with Germany, France and Japan where there are a bit difference among another, yet exceeded US in terms of more favorable conditions fostering the effect of servant leadership. We can find notable elements from the work of Hannay and lessons from Spears. Hannay pointed to the service of leader as most distinguishable from other paradigm of leadership. As the dominant narrative of leadership is found in the transformational type, we need to make a comparison shortly.

The servant leadership shares much common traits with the transformational one, in which the leaders effort on the influence and vision for followers (Smith et. at, 2004). The leaders also focus on value and risk sharing, respect, credibility, and others. They are transformational on psychological or spiritual dimension of followers, the leader intending to motivate them. The leaders place an emphasis on the integrity of organization and organizational member, and generally tend be relationship-oriented to enable the leaders and followers to align in the same mind, vision, value, skills and technology, direction or goals. They also practice interacting to motivate the followers', which could be shared in both styles (Hannay, 2009).

It can depend, but the common elements of servant leadership would generally cover vision, honesty, integrity, trust, service, pioneering, appreciation of others and empowerment (functional attributes from Hannay); communication, credibility, competence, stewardship, visibility, listening, encouragement, teaching and delegation (accompanying attributes); listening, empathy, healing, awareness, persuasion, conceptualization, foresight, stewardship, commitment, building community (from Spears). In understanding the servant leadership, we are able to identify its advantages and disadvantages. In the summary from Harold, it has a merit about the human aspect, in which, to say some, the leaders approach their followers in value and ends other than means and engage with them to develop and flourish. There are drawbacks that the applying leaders need to bear in mind, which, for example, relate with its facial taste of religious concept and thus is alien to modern sensibilities. It may also go easy, in some cases, to disturb a traditional hierarchy.

Given the servant leadership style being orthodox on its own, there are factors or environments where it works most effectively to lead the followers and to bring an organization change (Hickman, 2010). Hannay's account proposes four succinct and brightline elements to weigh in, which include power distance, individualism, masculinity, and uncertainty avoidance. In his version, if the power distance is strong, intense or structured, the servant leaders would see a less chance to succeed. For the feministic mood or attributes 
being stronger, the servant leadership would yield a more return in comparison with the high masculinity in the leaders and followers or organization (Hanny, 2009).

The role and strength of servant leadership in the contemporary period are fairly powerful to penetrate most of organizations in theory and practice. If we see the contemporary paradigm of man and organization in three essences, i.e., (i) conceptual complexity, (ii) strategic egos, (iii) humanity and organizational competitiveness, the servant leadership style can offer a more aspect of pertinence than any other leadership models (Kim, Discussion Post Week 4). A fair of us may be sided on the relationship-oriented since the task aspect may be considered as subsidiary to human nature. Then we may share an essential importance within the human resource. If so, the servant leadership style can be most updated form of leadership, which yet requires us to be conscious about its potential strengths and adequacy of application. This flexible nature was briefed as above.

In my evaluation, the servant leadership is characterized in these four points: (i) its most involved and earnest way of leadership (ii) its commonness and equalism (iii) education and training (iv) diversity and culture-oriented.

The servant leaders would probably be viewed as most involved and earnest, which even brings the situation into a kind of religious experience (Hickman, 2010). Besides the Jesus or Hesse's east journey, I could support it in a plenty of my previous occasions. When I was a high school student, I and some students were assigned to clean up the restroom after the class is over. The duty was made in the context in which I then served as a vice chief of students and supervised the cleaning work. Many of assigned students had generally practiced a renege or been reluctant to participate due to the nature of dirty work. It was also same for that occasion, and I worried if I could complete my duty successfully. If the students were those in kind for other cases, I have to clean up as many as ten sections all by myself. I had a formal authority delegated from my class teacher, but it did not effect upon other students even if I tried to stress that point. Although my responsibility is just to supervise as a vice chief, I initiated cleaning the first section up. Upon this pioneering work, the reluctant students, who prepared home with their personal belongings, returned to entangle earnestly with their duties. This situation may illustrate one incident which the servant leadership had worked out.

I realized that many elements of servant leadership would perhaps be enshrined in my personal traits. If I lead or manage an organization, particularly in the context of modest size of organizations, I believe it work and fitting to deeply engage in the followers' aspect in earnest way. This leadership style is appealing if I prefer to be equal with the co-workers and followers, and rather like to subsidize a communication, and to utilize education and training to develop the followers. My perspective on humans see them strategic, and thus we could share a common growth of the leaders, followers, and organization, by serving each other. They are also a prospective leader upon succession. I see it important that the human creatures, within this concept, are of diverse nature and culture where he or she is spiritual, strategic, cultural, hard to define in a unitary conceptualization, with the potential to be cultivated and developed, equal and communicable, sharing and serving, and so forth. For the complexity and post-modern context of human existence, it could work more properly in a certain context of organizations.

\section{A Case Review of Two Leaders}


For the discussion purpose, I chose two leaders to evaluate their qualities of leadership, who are Korean nationals, Doo-jin Choi and No-hyun Kwak. A note on their leadership qualities would be as impressive rather than modest or continual to make a point of leadership qualities.

Doo-jin Choi is a former dean of Chosun college of law, and one of my senior attorneys. He entered a position with me to staff the law faculty in the course of law school reform. His expertise in the civil procedure was created over the decades of career as practicing attorney. His performance as a law professor was moderately brilliant, which means never less competent to the existing group of legal scholars. We elected him as a dean the couple of years ago gladly, which was made on less dissent than the last year election. He served two years from 2010, and we witnessed his ambition as a dean in his candidacy remark. His two years service as a dean would go the same way, which was strongly organized, more uniform, and authority or formal line-oriented and rigid framework of management.

The leadership qualities, in Choi's case, may depend on several variables (i) gender of leaders (ii) the character and intellectual aspect (iii) the context between the organizations and leaders where a leadership is exercised (Jacobson, 2007). His image and personality is very male nature to favor a hierarchy, planning, accurate reward and punishment, tightness on the schedule and feedback. His character reinforced this aspect while practicing the laws in Korea is generally more competitive and business-driven to require hardworking (Hickman, 2010). The context developed between Chosun law and Mr. Choi as a professor and later dean, is a bit exotic in the wake of law school reform. For the past, Korean jurisprudence had been dominated by German educated legal researchers, who are required, by way of laws and regulation, hold a research doctorate in law. When he was recruited, he had a master degree in law, and later obtained a Ph.d in law under the supervision of his senior fellow here in Chosun. He initially and generally had not paid a high value on that degree, and performed well even before the completion of his doctorate. He contributed several useful articles in the major law journal. Therefore, I suppose it played a less factor to look into the context of his leadership.

Upon a completion of his two years service, we generally see no serious fault on one hand, but also no significant leap on the other. If we like to refer to any quantified measure of organizational status, it is modest and acceptable. An interesting point related with his leadership is on the aspect less socialized with the passion and attitude of Korean academicians. He absolutely did not fall short of his duty, but the social aspect of organization would turn a little autonomous. One example may be drawn within the vacation settings. Professors normally dislike convening during the winter and summer vacations, which is partly because it is a local university to which many professors commute weekly from Seoul. A dean of law school, as we face in the case of current dean, normally has not plan a faculty meeting for those four months annually. This practice was overhauled under his leadership. His manner of leading likely saw the college as a kind of law firm to productivity -driven. That is fairly contravening the mainstream of culture and passion for Korean academicians (Ciulla, 1998).

This interchange within the context of professional organization may also be seen in law schools or medical schools in US, but more settled or socialized than those created from 
the recent reform in Korea. The training or education aspect would share, and like in Korea, make less important, in which we see both backgrounds yield a similar performance in its scholarly work. In US case, a taught-based JD degree would perform even better than the research degrees, such as LLM or SJD, in terms of research impact, which is as shown in the report prepared by Shapiro from Yale law school in June 2010. There would be several reasons for that result, but it primarily implies that the training or education factor would explain less even for the productivity or skills in job, but possibly more to look into social aspect of organization. They offer, however, a seed for the division of professional labor (law practice v. legal teaching: unlike Korea, however, most law professors in US have a JD degree). In a Choi's case, it may reinforce the social aspect of the qualities of professional and later affects that of leadership.

I found points (i) the outcome of interchange in the professional organization would depend on the years of career and character of jobs rather than education element (ii) artificial fuse with practicing attorneys and law professors may yield a common productivity but possibly less socialization or organizational congruence.

No-hyun Kwak showed a similar pattern of leadership, in which the qualities of leadership seemed professionally equivalent, but less appealing to passion or organizational culture. He is generally considered a left-wing elite, who was elected and served as an education chief of Seoul city. He is a career attorney and completed his LL.M degree in the University of Pennsylvania. On his adherence to the leftist policy, he performed a set of radical reforms like a free meal plan of public school and the charter of student's human rights. His expertise and career could have been well received by the tax payers of Seoul, which were to fit within his responsibility. On the rise of leftist politics in Korea during the early of new millennium, a scope of public local posts were filled with the reformer candidate, and Mr. Kwak was highly welcomed at the time of his election. The organization of public education, however, could be different, which had traditionally welcomed the leaders of education career. An interchange of leaders from a different background would possibly hinder his settlement and pursuit of political programs. Practice and general perception about the role and image of public education chief also seemed to play a part. In any case, Seoul citizens favored a leader in the last election, who has a more conservative image and has a teaching or education background such as professor or high school superintendent (Covey, 2009). Mr. Kwak, was impeached from his incumbency while being convicted of violation of election laws.

Their leadership qualities would be properly observed as (i) least bogus, but authentic or sincere in the aspect of leaders' quality, but unintentionally a bit bogus on empowerment dimension lacking or being less focused (ii) exterior and in a bit fundamentalist way to approach the leading of organization (iii) less corruptive, less eclectic nor narcissistic, but highly morality or spirit-driven (iv) trust or reputation of leaders built rather out- of- organization context (Hickman, 2010).

In both cases, we can find a common level of performance, but the social aspect of leadership qualities would possibly be weakened. If that aspect were to be improved, it's leadership can be great beyond effective. I would see this kind of transitory, some exotic for the members, more expectant, and humanly refreshing from the stalemate or commonplace persistence. It can also be effectively utilized if the organization explores a radical change . I also would like to call it a sprite-impact leadership, which would place us on analysis 
between the sprite and extent of impact on the organization.

\section{On the Empowerment}

In the step to discussion, I suppose to have some reflections on empowerment. Empowerment generally has a scope of definition across the disciplines where the theorists, such as Potterfield, saw the workplace empowerment one of most crucial concept in the modern organizational studies. A sociological empowerment often classes the group of members who are excluded from the decision-making process, which is based on race, sex, disabled, and other socially minority group. Thus, we usually use the term of consciousnessraising, empowerment of women, and so on, and the concept presupposes a marginalized group as addressed by empowerment. As the government represents a general public good, marginalization is not friendly with it, and empowerment may occur in this context politically as in the case of the human rights act in US. Empowerment may also occur in the context of social enterprises for the disabled, aged, or indigenous group, which needs to be distinguished from a passive scheme of welfare benefits.

From the nature of empowerment, we can draw several elements as its attribute (i) assumption of inequality and marginalization (ii) autonomous and responsibility (iii) openness, assimilation, or congruence (iv) replacement of myth or traditional hierarchy. To specify, empowerment comes within an unequal context, such as masculinity or manager's authority and hierarchy.

That is fairly entrenching if the equity across the assets, skills and education, share of political or managerial post are grossly unbalanced between the different sexes. An organizational purview is typical between the managers and followers when we consider a general of their status or role and decision-making process (Ciulla, 1998). It is fairly rare and normally unsupported by laws, which concerns an equal share of decision making as participated by the labor and manager in the cases of German company. Given this, empowerment offers the way of sharing to redress an alienation or marginalization by fostering "autonomous and responsibility." They work to effect openness and environmentfriendly against the traditional hierarchical concept, which triggers an assimilation and congruence, idealistically a follower of leader's identification (Jackson, 2011). Therefore, the empowerment concept is rather sociological or psychological, and even pseudo-religious other than political or economic. The believers in empowerment and its strategy would like to produce 100 managers or leaders if the followers of organization are 100. In due course, a spiritual aspect is important to motivate followers and trust is critical to base the truth and honesty. They may appear to pursue like preachers to conjure them up with the mighty power of Jesus for the organizational productivity and welfare. This would be in contrast with the organizations, which are econo-politically assumed as that of the same working class or partially for share or participatory concept in decision making process within the enterprises.

Then we are faced with the empowerment strategies, and I like to propose four selected items to effectively safeguard the goals of empowerment. For my selection work, it offers a standard how to make effectively yield 100 leaders for the organization of 100 followers.

The first one is sharing information with everyone. Without the information equipped with the leader, the followers could not be motivated never as if he or she is responsible and 
autonomous. This is also related with the trust aspect of empowerment. Once I experienced a leader's sincerity to inform a worse aspect of university finance, which necessitated a profit business of Kimchee production. An attitude or established mind-set of mine, which is generally on normal followers temporarily disappeared and felt unified with his authenticity and manner of openness as well as sharing (Jackson, 2011). I became congruent with him beyond just teaching and researching, and, later on, turned to be an activist to promote Kimchee business as if I were a university president.

The second tactics to enforce an empowerment is creating autonomy through boundaries. Empowerment, as briefed, focused on the decentralized but integral involvement of followers to safeguard a common vigor and enthusiasm. So that we understandably and properly imagine on the spread of knowledgeable or escalated minds with competence as well as on the idealistic workplace like Google. Google would be exemplary for the most occupations aspire to work. Their work hours are free to set on the member's choice, and trust is built on its efficiency as well as the leader's initiative or effort. The kind of enterprises in Korea also create autonomy of followers, which prove to be effective. They are more than being merely against the traditional work division and line hierarchy. It would be rewarding in the empowerment concept to replace the old hierarchy and utilize the self-managed teams. For the modern type of workers, I suppose that this initiative would see more chances of success, particularly within the context of high-educated caliber followers.

The third item for empowerment should be found in trust, which is essential to address the problem of a bogus empowerment. Empowerment should not be hypocratic, yet to be based on truth and honesty, as well as being authentic and sincere. For the workers fearing of layoffs or restructuring to dismiss, the leader's vision and promise would echo meaningless, his motivation being far less fruitful. In this case, the follower's attitude would not change merely calculating the chances of that misfortune and took defensive to self- interest (Floyd, 2008). Without the trust, the workers would be least motivated, and we are unable to expect the turns of empowerment. Empowerment strategies, therefore, require that the leaders should keep their promises. An adequate training of employers, mutual respect, as well as loyalty are important to make sure of trust. It is indispensable to share the point that the trust will sustain and better the company (Ciulla, 1998). In order to build a trust, they would more specifically serve, talking straight, creating transparency, delivering results, clarifying expectations. For the followers, it is hard to empower themselves from ambiguous or narcissist leaders. The way of creating transparency will allow an ample space for the follower's vision and orientation, which is essential of empowerment. Delivering results also enables the followers to assess and motivate themselves to prepare for better and empowered performance.

In short, these strategies would guarantee a successful work environment, and the achievement of empowerment is a kind of journey on trust build-up. It is one of crucial way for the modern managers, and also productive way to maximize all around work efficiency, which eventually is to exercise the right kind of authority. 


\section{References}

Ciulla, J.B. (1998), Ethics: the Heart of Leadership, Qourum Books 2.eds. pp. 59-82.

Covey, S. (2009). How the best leaders build trust. Retrieved from http://www.leadershipnow.com/CoveyOnTrust.html

Floyd, B. (2008). Empowerment Strategy of the Future, Retrieved from http://www.corporatevine.com/library/AttitudeinAlignment.pdf.

Hannay, M. (2009). The cross-cultural leader: The application of servant leadership theory in the international context. Journal of International Business \& Cultural Studies, 1, 1-12

Hickman, G. Robinson (2010). Leading and Organizations: Perspective for a New Era. SAGE Publications. Thousand Oaks, California: Sage Publications.

Jacobson, D. (2007). Growing leaders of character. Retrieved from http://govleaders.org/character.htm

Smith, B., Montagno, R., \& Kuzmenko, T. (2004). Transformational and servant leadership: Content and contextual comparisons. Journal of Leadership \& Organizational Studies (Baker College), 10(4), $80-91$. 


\section{Chapter V. The Theory and Practice of Organization Change : A Case Review of WTO}

\section{A Case Review of WTO}

\section{1-1. Introduction}

In order to address the organization change and its process, I like to choose the GATT and WTO, in which we can see a stark change to elucidate the aspect of this assignment. GATT and WTO are an international organization that the governments are members. So we call it a governmental organization, as abbreviated GO while the NGO is classed as contrary concept. For the purpose of organizational study, some distinction needs to be made to see the nature of discourse. The first view, of categorization, would see organizations within the for-profit and non-profit context, or for the private and public nature. Within this classification, we can have a plethora of organizations specific over the public education, private enterprises, public businesses, sorts of governmental branches, and so. If we see the government as the kind of orthodox organizations for study purpose, the second view may rise about the government itself, governmental organizations and agencies, and non-governmental organizations. The last two are an international organization while some radical viewers call GOs an "international government." I consider that the government itself would possibly fit within the framework of organization change. That seems not incorrect although we generally see it within the province of political science or public policy. For the international context, NGOs may be of more flexible nature to adapt to the organizational analysis since it can be flexible, more changing-friendly, and of civilian nature. GOs may be intermediary on this spectrum between the government itself and NGOs (Sjöstedt, G., 2012).

\section{1-2. Institution :The Case of WTO}

I would let me briefly describe the organization I adaptively investigate concerning its change and theories possibly applicable. WTO was given a birth in the year of 1995 after a series of ministerial conference and special work team for seven years (Kostecki, M.M., 2010). This occurred in what we usually call Uruguay Round where GATT reform agenda was negotiated. The Round was GATT's eighth round on mostly years of interval since its inception around 1947. We occasionally come across the Kennedy Round, Tokyo Round, or Doha Agenda, which are actually ministerial conference of GATT and WTO. One most exceptional name is found Doha agenda, which did not follow with the word "Round". That conference used 'agenda' rather than Round principally because Round is more nuanced for the developed states. Agenda would be friendly and more touching in favor of developing countries. Uruguay Round held in 1987 endured to plan, negotiate, and enforce the GATT reform agenda (Kostecki, M.M., 2010). GATT was created in 1947 after the world war, which actually constituted one of three pillars sustaining the world economic order. It is one of institutions that the Bretton Woods Conference created, the rest of two being IMF and IBRD. GATT was designed to be a responsible trade regime in the international context. Initially, ITO was envisaged which was a more powerful and comprehensive organization. The US senate refused to approve ITO subscription, which drove it to drop in reality. GATT was rather of restrictive nature which regulated principally the tariff and other trade issues of international principle. It had successfully performed to address the needs of international trade as we see such radical decrease of tariffs in the 1960's Kennedy Round. 


\section{1-3. The Demand System}

For the years over 1970's through 1980's, the international economy witnessed a serious recess since the major economies faltered upon the challenge of new economic powers. Japan and other Asian developing countries featured forward to dominate the US market. Their cheap labor and state capitalism increased their competitiveness that US suffers a chronic fiscal as well as trade deficit. This pattern of international trade make it inextricable that the developed nations protect their economy. This is what we call new protectionism, which arose in the context of 1970 and 1980's. GATT, as known, is an international organization, which is committed to increase and safeguard the free trade ideals. It is founded upon the fundamental values such as the most favored nation treatment and national treatment. The swift of trade dynamics gradually affected the GATT regime, and US played typically to blur the principle of multilateralism. The bilateral arrangements to redress trade deficit was made in the multi-fiber, and other sectors. US alleged that the sectors were unreasonable or discriminatory against her trade interest. It means a substantial and exterior pressure which GATT could not sustain (Kostecki, M.M., 2010). For the ideals, most trade issues had to be resolved within the GATT, being based on multilateralism.

Two other factors demanding the organization change for WTO may include the growing importance of service trade and rising concern of the increased protection for the intellectual property. The service trade is still less in portion other than the trade of goods. Its share in the total of international trade had grown significantly, which required a kind of regime similar to the trade of gods. The issue of intellectual property had been governed separately in the traditional context, in which WIPO is a central and governing organization with the treaties on each subject matter. A less protection of intellectual property is one of troubles which the developed nations always have had a complaint about. An enhanced protection across the global nations, on the standard of developed nations, would likely be pivotal to their interests. There had been many other forces to renegotiate the GATT regime around 1970's and 1980's, and eventually UR is devoted to create a most proper regime governing the international trade.

\section{1-4. Organization Change in The GATT and WTO}

WTO experienced a revolutionary change other than evolutionary. This means that the GATT reform toward WTO was undertaken in a fundamental and comprehensive context. GATT was created in 1947, hence it now is called 1947 GATT while new GATT earned a new name, 1994 GATT (Koul, A.K., 2010). 1994 GATT is not the same, yet to be virtually same containing the basic trade rules agreed and confirmed through the decades since 1947. It was incorporated into the WTO regime as one of principal multilateral agreements. We need to be aware that the goods are still a dominant sector for international trade. 1994 GATT are norms to regulate with the compiled practices and GATT precedents

WTO were enabled to have a scope of multilateral agreements, which would address many problems identified during the tremor of GATT years (Kostecki, M.M., 2010). Agricultural Agreement, what we call AA in abbreviation, is one of them. SPA, the Sanitary and Phytosanitary Agreement, is also new agreement to counteract the regulatory measure of member states. In this way, new and reformed multilateral agreements, fourteen in number, were incorporated into the new regime.

A most notable point on the organization change can be found in the sharp increase of member states. GATT started with as few as 24 members states in 1947, but WTO now 
includes as many as about 150 member states. This means that virtually all the countries in the world now are member states of WTO, which implies a critical interdependence of global economy. Recently, we see that China and Russia achieved a membership in WTO. They have been a communist economy which are not easily inculcated into the free trade regime despite the specific provision including state trade organization. That hard point was resolved to harmonize and to share.

One other point of the organization change need to be remarked about the efficiency of implementation as well as the increased judicial nature. GATT administered the international agreement on the trade of goods. It is, however, very political in nature while the panel performed partly a judicial function. The decision of panel about the trade dispute of member states could not be enforced without a unanimous consent of member states. Therefore, a political decision of even one member state could effectively overrule its judicial decision null and void. That context is fundamentally revisioned that the reversed consensus system was introduced (Busch, M. \& Reinhardt, E., 2003). Within this new system, all member states must disagree with the decision of panel or appellate body if it is made invalidated. Unless otherwise, it becomes an official opinion of WTO which implies that the decision, once made by the panel or appellate body, virtually automatically obtain its validity. We can hardly imagine if all member states, as many as 150 , disagree with it. This prevents a procrastination practiced formerly by GATT member states, which is also due to the new systemic dispute settlement mechanism. It also created the appellate body as a standing organization, exclusively dealing with the dispute involving an interpretation of agreements. The implementation of decisions was reinforced with the cross sector retaliation and other revisions pertaining. As needless to say, WTO now has multilateral agreements on the trade of service (GATS) and TRIPs on the protection of intellectual property. In short, it now benefits from the increased organizational efficiency and the reform was comprehensive indeed, which was fundamental and revolutionary in nature (Kostecki, M.M., 2010).

\section{1-5. What to Change : Content}

For the change of GATT, the content played an important role for the most endeavor to be flooded. This type of organization change is rarely charted, but can be most typically illustrated in the merger and acquisition. The BA (British Airway) example may fit within this pattern of change, in which the change may occur in the context of two distinctive points : (i) preordained and (ii) well planned with the clear purposes. The GATT reform was preordained given the chronic dilemma between the developed and rising economies, which necessitated a new vision of organizational change. It was well planned to expand the scope of organization and intensification of free trade ideals and multilateralism. To be specific on one example, there are set of time sequence to retrieve the multi-fiber regime as well as grey area of agreements (such as VERs or OMA) into the WTO regime. The differences lie in its expansive nature while the BA reform operated to restructure for the reduction of organizational scale.

\section{1-6. How to Change: Process}

For the process theory and practice framework, it is important to consider the readiness of followers and extent of their resistance which would play to factor the social and psychological costs. Beyond, we are also required to explore the change process in a more applied or practice-oriented way, which means the actual steps involved, its sequence and related interventions (Hickman, G.R, 2009). 
For the process of change, we briefly analyze the trajectory of GATT reform within the three steps proposed by Lewin and Schein (Burke, W.W., 2010). For the unfreezing phase, we are able to find many attributes to initiate the reform necessities. A usual worry and concern during the 1970's and 1980's served creating a basic consensus of global citizen or policy makers, who questioned a legitimacy as well as efficiency of GATT. The newspapers or other informative media played a role to unfreeze the trade regime and its people directly or indirectly affiliated with it. The trade elites of major member states in GATT typically recognized this problem, and frequently led a public opinion about the new agenda of organizational change. US lawyers within the Congress, USTR, and the international trade commission, who are experts of international trade, would be one of such groups, and the response from EU would perhaps support the reform. In comparison, concerned people from the developing nations generally had less aspired to reinforce the free trade concept (Lija, J., 2012). Even about the understanding of fairness, they revealed a different status and attitudes (Mitchell, A.D. \& Voon, T., 2009). Their status and attitudes, however, would less factor to sustain firmly the former governance of GATT. They were neither the power nor had interest to resist with the organization change. Under these circumstances, the change agents easily initiate their process particularly backed up by the staggering international economy chronicled over the decades.

Our focus now turns to see the phase of "movement or changing," which had occurred during as many of seven years through the process of multilateral negotiation (Burke, W.W., 2010). We need to have a particular look to understand the dynamics of GATT reform. There was, on point, no unitary leader nor any keenly shared leadership to work out the reform mission. The leadership was collective in nature and decentralized or bifurcated in the context of sharp confrontation between the developing and developed countries. What to change, the aspect of content, was critical given the high nature of mechanic organization as Bion perceived. The players are normally lawyers, policy makers, and diplomats, who are neutral and generally law subscribing, as well as the officials envisaging the end state in the form of international agreements (Lija, J., 2012).. Therefore, the role of negotiation and mindset about the trade interest as well as global economy were a point of emphasis to understand their process. Normally the end state or content overwhelmed the change process, so that reaching a multilateral agreement means to marginalize any kind of problems arising from the process or negotiation. Of course, at the floor level, some kind of operations might be assumed about the need theory or expectance theory (Burke, W.W, 2010). For example, one member state might not reach a dimension of belongs if the agenda seriously jeopardized their national economy. In that case, they would even retreat from the membership, a dimension of belongings, who had to ensure their subsistence. On other hand, they may expect some kind of returns in other fields if they submit within any specific field of negotiations. That could occur actually in the context of negotiation process.

For the freezing phase, it is straightforward to receive much accolade about the important role of WTO as an umpire of international trade. Its dispute settlement mechanism serves to guarantee the predictability and stability of international trade (Busch, M. \& Reinhardt, E., 2003). The panel and appellate body has produced the precious case laws, which are considered to reinforce the international trade regime by way of the rules of law. It may well be compared with the European Court of Justice, in the wake toward the integration of European community. Now WTO functions as one of quasi-constitutional regime to monitor the trade policy of each member state and settles their trade dispute by the increased power of judicial nature. Of course, adversary forces are not non-existent. The pro-activists stress on more democratization of WTO including the institutional reforms about the method 
of decision making and way of incorporating the opinions of global public. They strongly urge to officialize the participation of NGOs (Sjöstedt, G., 2012), which now partly are allowed to file an non-party opinion upon the request of panels or appellate body. That may enable an evolutionary change within the WTO organization, yet to be uncertain to see any kind of revolutionary change as happened since 1987 through 1995. Despite a small scope of criticisms, WTO has successfully achieved closure to freeze their reform, who can steadily perform as the active leader or manager of the international trade.

\section{1-7. Conclusion: WTO in The Theory of Van de Ven}

A noteworthy point in the process of change would involve the econo-political confrontation between the two groups. The developing nations generally disfavored any advanced extent of protection about the intellectual property, and tended restrictive to open their domestic market of service (Koul, A.K., 2010). They were actually leaders for the change given the equal and sovereign status, yet lacking or making short of the power and skills to defend their trade interest. This context militated to push them to be merely followers. In this aspect of process, we are able to apply the four theories suggested by Van de Ven (Burke, W.W., 2010). In his framework, we more easily find that the teleological or dialectical concept could take much account for the process of change. The negotiation process was intensely purposeful and adaptive to the trend of the world economic condition. This placed it in a fairly similar context as if the merger and acquisition were processed. It would be more intensified, however, if the players had been delegated a plenary power to negotiate. The complicated settings and interactions as combined with outer variables (i.e., economic conditions and history of GATT) would clog any kind of failing attempt as mentioned before. It was well predestined that the change should be agreed on and implemented. The dialectical concept would play that GATT and new WTO have existed and exist "in a pluralistic world of colliding events, forces, or contradictory values that compete with each other for domination and control." The trade dispute of member states and dispute settlement mechanism plainly prove this context. If we see a competition in the international trade as the kind of jungle, it is certainly a force to stand on the conflicts and retaliation. That may be one reason why we call the trade remedies as retaliatory measure. For the negotiation stage, this context was revealed far impressively around much agenda for the dichotomy of "developed v. developing." One of interesting points is that NGOs have gradually raised their voice and context of involvement, which made the organizations interact with the pluralistic parties (Sjöstedt, G., 2012). They are normally pro-activists for the environmental protection, and the contrast is usually drawn between "the developmentalist and environmentalist." Of course, the trade elites can well be seen as a developmentalist to emphasize the economic aspect. For the long-term retrospect since its inception, the life cycle or evolutionary paradigm of organization change may apply to the creation of WTO. The GATT reform was not embraced as an agenda at one point of time, yet to be streamed and exchanged over the period of trends and transformative context of global economy (Hickman, G.R., 2009). Although the governing principle in norms did not shift significantly, the underlying elements are not the same as before. As mentioned, the service trade increased sharply over the period, the developing nations being challenged, who allegedly practice the unfair way of competition, such as pillage of copy rights or violation of trademarks. Therefore, the life cycle of GATT organization may mandate the reshaping of it, and would also corroborate with the evolutionary nature of international trade.

\section{A Case Review of Seoul National University (SNU)}


Organizational change usually occurs in the multilevel context in its practice. As W. Bion viewed, the organization may exist in the nature of mechanic organization, which may be compared with an organic organization. An organic organization has a less focus on the traditional hierarchy or formal system, which would be immensely extrapolated from the interpersonal dynamics or so on. While the organization on more common and wider basis is less susceptible to that tight dichotomy, we usually encounter a moderate nature of organization. An organization is usually mixed with the mechanic nature on system, work flows, diagram on performance and feedback, which also factors partially an organic aspect. In understanding a multilevel change, we are required to consider both facets of organization to grasp its dynamics. The level of organization in terms of its change can be properly classed as those three, "individual, group and larger system" (Burke, 2011)

For this week, I chose the Seoul National University (SNU) as an organization, which saw a recent change of legal paradigm in its formal status. This means that a new statute redefined its status as an independent public organization, which is formerly one of institutions within the national government. It has been given an independent status as a legal person, which brought a change on several aspects. SNU was discussed seriously since 1995 by national policy makers, and it itself explored a long term development plan since 1987. One of strategic focus on that progress was made on the status change to an independent public organization, and it was implanted in March, 2011.

A policy drive for transformation was based: (i) the status change is prominent over major global universities (ii) it enables an incentive and performance-based management of university. An opposing group counter-argued that it is purely market-oriented concept lacking neither a pragmatic dynamics nor substantial evidence. They also opposed that the transformation would undermine a knowledgeable community and competitiveness of university. A most evil aspect on that initiative lay in that it would dismantle a public nature of higher education. A market myth and the logic of its superiority can be made a point to vitiate the public concept of university education. An issue of tuition reduction is the hyperbole of students and concerned parents, which would turn seriously disabled due to its privatization.

In the course of transformation, we witnessed a serious challenge and resistance from the tenured professors, part-time lecturers, administrative staffs, and students. Their status and expectancy from the change were not actually seriously affected within the group of tenured professors and staffs. They could largely maintain as before, and the pension context also can be as the same as before. Other group of interests is also virtually intact, except for some potential worries about the competition-driven remodeling of university. The students may feel adverse against their efforts of tuition reduction.

The change plan was properly staged as "unfreeze, movement or change, and refreeze" as proposed by Shoen (Burke, 2011). It was explored long before at the time of 1987, and maturated through the years with communication and exchange of ideas. An action plan was envisaged in late 1990's, and it moved forward as a legislative package to pass the Congress. For its rigidity from the forms of statute, it is needless to say that a "refreeze" has been easily achieved. Achieving closure is less problematic because of the formal and strong enforcement power entertained by the government.

One of note has to be made in the process for the final stage of change. The 
university headquarter had been passive and of limited reach to persuade the concerned members. A specific action plan was classed confidential until July 2009. That disabled any response, even if constructive or supportive, from the followers. Most professors basically agreed on the transformation, who expressed their views through the faculty board, but proposed a different plan for privatization. Their views and specific plan were published in the booklet, but the university headquarter rejected their proposal. This context fueled a creation of independent resistance circle (Hickman, 2010).

For an individual level, Bridges' view can explain the current context of SNU on this issue. A major of individuals are on three symptoms, "surrender, the no man's land, and a beginning," in which achieving closure can be well perceived (Burke, 2011). They may end the turmoil individually, and seem to let it go. In an extreme context, small groups of reaction still voice their opposition, though on lapse in time as of one and half years. For them, it may not fall within "change," rather within "transition" on the Bridges' point. Government role and intervention to implement the change can be said to reinforce this process in that only one incident was reported to demonstrate their power. A surrender and a new beginning have been charted as dominant.

At the group level, the kind of response, what we call "turf protection and competition," occurred. They strongly pointed out, at the university-wide and college level, the problem of privatization, who stressed endangering the central and core competence of organization. They exhibited the political and ideological resistance, which raised a heavy criticism on the basis of academic freedom. Professors within the college of letters held a lengthy debate about the draft of bylaws, and attacked a deprived process as well as insufficient or bogus communication between the concerned and administration. They also saw a flaws of cause, ambiguities in knotty issues as well as ill aspect of financial plan.

Professors across the departments and colleges, at the floor level, divulged their intention to impeach the chancellor, whose criticism was shared by staffs and students. During the course of changing process, they had acidly questioned a legitimacy of chancellor's leadership (Hickman, 2010). They argued on an insulate and discrete process in compromise between the campus leaders and national policy makers. In their eyes, a democratic process was lacking or heavily shorn. Generally, they agreed on the changing content, which was required by the demand system at society level. It could well be perceived to epitomize the wishes of Korean public, in which more flexibilities and competitiveness can engineer making SNU one of prominent global universities. They saw it improper and undemocratic the process of privatization, which justified a demand of new leadership.

A large scale response from the students and union members also incurred diversionary tactics, and in some cases, developed of diminished fellowship. The officers and staffs, during the course of demonstration usually featured in a head ribbon, showing "Do not push us to go impasse" or "It diverts us from fidelity and loyalty to the best University in Korea." A sabotage work culminated in the student occupancy of Chancellors' office all day and night through. This type of demonstration eventually led, at some extent, to distrust among the members pressing on change and those receiving it.

The aspect of "how to change," in this case, according to the four theories proposed by Van de Ven, espoused more closely the teleological or dialectical one rather than life cycle or evolutionary theory (Burke, 2011). Therefore, the process of change focused on the 
designed purpose of privatization. Toward this central goal, the planners and actors pushed forward their time schedule to the end state, legislation, and held a forum for public relations during the phase of movement. It tended on a dialectic model of change, which exposed the context of pluralistic world within the organization. The process of change and bitter reaction from the members penetrated colliding events, forces, or contradictory values that compete with each other for domination and control. For the case concerning SNU, this point contributes more starkly to breed easy soils for veracious followers.

\section{References}




\section{References}

Burke, W. W. (2011). Organizational Change: Theory and Change. $3^{\text {rd }}$ Ed. Thousand Oaks, California: Sage Publications. Print.

Busch, M. \& Reinhardt, E. (2003). WTO Dispute Settlement Design and Developing Countries. Conference Papers -- American Political Science Association. 2003 Annual Meeting, Philadelphia,1-29. DOI: apsa_proceeding_381.pdf.

Hickman, G. R. (2010). Leading and Organizations: Perspective for a New Era. SAGE Publications. Thousand Oaks, California: Sage Publications.

Kostecki, M.M., (2010). The Political Economy of the World Trading System: From GATT to WTO, New York: Oxford University Press.

Koul, A.K. (2010). Guide to the WTO and GATT: Economics, Law and Politics, Hague: Kluwer Law International.

Lija, J. (2012). Domestic-Level Factors and Negotiation (In)Flexibility in the WTO, International Negotiation, 17(1), 115-138. DOI: 10.1163/157180612X630956.

Mitchell, A.D. \& Voon, T. (2009). Operationalizing Special and Differential Treatment in the World Trade Organization: Game Over?, Global Governance, 15(3), 343-357.

Sjöstedt, G. (2012). NGOs in WTO Talks: Patterns of Performance and What They Mean, International Negotiation, 17(1), 91-114. DOI: 10.1163/157180612X630947. 


\section{Chapter VI. Organization Change: Chosun University and Mr. Chun's Leadership Role}

\section{Introduction: Description of the Institution}

For the description purpose, I intend to make several points of element to attribute the university in terms of organizational change, which Mr. Chun realized.

In the historical background, it needs to be understood that the Chosun University (CU) has been immensely nationalistic which would characterize its basic spiritual ground. Being nationalistic would perhaps be less sacred in modern terms since it generally brings a sense in some conflicting contexts. The context, however, should certainly be distinguished in that the creation of $\mathrm{CU}$ is highlighted as an endeavor to counteract the illegitimate Japanese imperial rule.

In the nature of organization, $\mathrm{CU}$ is certainly an educational institution, which is of non-profit nature and is commissioned to educate and to produce a scholarly work serving the public. CU is one of premier institutions in the southern part of Korea, and as a private institution, regionally competes with Chon-Nam University, which is a state university.

In the aspect of cultural factors, Chosun University is distinctive in that the school policy is widely liberal to institute an independent faculty board. It interacts with the university administration (Hickman, G.R., 2010). The group of members, who are students and faculty, would favor, as common over the scope, a sense of social virtue and justice, more than the orthodox mission of rigorous academics. One of important points in this aspect is a student activism during the 1970's and 1980's along with then political turmoil. The university is located at the city of democratic sanctity, Kwangju, South Korea. An initiative of students can also be highlighted, which is connected with the founding spirits of nationalism and sovereign independence.

On the point of management, $\mathrm{CU}$ has relatively a stable board of regent, but is not exactly sure about its prospect in the future (Hickman, G.R., 2010). That could be seen as worse in some aspect than the 1970's and 1980's, but the size and educational performance have gradually increased to front up at the national and regional context. A highest priority during Mr. Chun's is generally similar on its basics as of its organizational nature. The circumstances, culture, and social cognition of members are based on the same tradition, but have been changing over time. For example, the globalization impacted on the school administration bringing a wider network built-up with other international universities

\section{Campus Leader, Chancellor Chun, and Organization Change}

I made and will make five contacts on Mondays in the weekly interval from Dec. 21Jan 25, each for three hours in his office at Chosun campus and the second one half hours in the nearby restaurant in Kwangju city. Before conducting an interview, I gave a standard of interview. I also advised to respect the survey ethics and asked for the interviewee's cooperation in order to obtain true evidence to prove the thesis. The process was completed based on the guidance of qualitative research at the first meeting, where it was held four o'clock, Dec. 21 in his office. It was located in the college of medicine of CU.

Mr. Chun has been a revered campus leader of CU (2007-2012), who was elected for two consecutive terms since 2007. In the 2011 election, he earned a second highest vote, and was recommended one of nominees for the approval of the Board of Regent. The board, after one day interview about the qualification and competence of two nominees, determined to 
select Mr. Chun. A screening process was sincere and rigorous, but later fueled a cause for students and the faculty about its illegitimacy and undemocratic nature. He eventually filed a resignation being pushed from the group of students and activist faculty members. His interim leadership until his formal resignation during then six months had been faithful and loyal within a fiduciary engagement and trusteeship. Upon clarification of all pending issues, he announced a resignation, and in the summer, 2013, new chancellor, Mr. Seo, took the oath for his position. In short, he forged a great and generous impression during his tenure of four and half years, four years for the first term and six months for the second. He accomplished several major achievements. His background as a professor is charted impressively given his scope of engagement as well as rich career as a pathological researcher. He is a graduate from $\mathrm{CU}$, and obtained a medical degree and $\mathrm{PhD}$ on the pathological science. We, at this point, need to know that most of chancellors during the campus history have been actually an alumnus as is also the case about the current Chancellor, Mr. Seo. That may be one of attributes of $\mathrm{CU}$ and its leadership culture, in which an affiliation would bring the keen interests of person, being more fertile to breed their ambition as a campus leader (Bastedo, M.N., 2012). That also enabled them more communicative to fellow professors and to have much time on the campus issues. His career expands to oversea studies and research practice, who worked as holding a visiting professorship in the University of Okayama and University of Connecticut. He also served as an associate dean and director of the Center on Radiation Application and Promotion. He later was staffed as the Dean of Medical college. We can highlight his leadership in five goals, which were pursued in the slogan "Pride of CU". Those are MBPWH; "Management Innovation, Build-Up of the Financial Base, Production of the Global Elites, and World Renowned Chosun, and Happiness of the Campus Members (CU Brochure, 2010)" His scholarship is well recognized with many awards and research grants.

One of most notable changes during his office can be illustrated in that Chosun University reverted to the normal form of board governance. It had taken a governmentcontrolled mode decades long. On the pertinent statutes, it provides that the temporary board members shall be appointed in several cases; (i) the Board of Regents fails to staff the members to make a normal operation impracticable, (ii) the government renounced an approval of member's status, (iii) the government impeaches the members (The Act of Private Schools, Art. 28). Provided if one of these conditions arises, the interested party or the government ex officio shall appoint the temporary board members upon a review and recommendation of the coordinate commission. The temporary board members are responsible to redress the cause or deviation within a shortest possible time. Unless the cause or deviation is settled, he legitimately holds the office, but his term cannot exceed more than three years. The temporary board member is disqualified from any formal title in the board, and the government has the right to convene the board meeting once the temporary member was appointed.

The government-controlled board is traced back to the turbulence of campus during the 1970's and 1980's. The alleged founder of CU, C.W. Park was a charismatic figure who led the campus as a chancellor for over ten years. His history was controversial, where many conscionable professors or local people actually believed that CU was created from the patriot funds of local people and concerned intellectuals in late 1949's (CU Brochure, 2010). In this context, the story involves the context of legitimacy and nationalism against the Japanese emperor, which has long been placed at the core of organization culture. Worse on evolution, Mr. Park's leadership had endured the harsh period of militaristic government in Korea during 1970's and 1980's. A democratic tradition and conscience of local people rose to be in conflict with Mr. Park's enormous power and arbitrary manipulation of both the board and university. The student activism, and counter response were not effective at the 
initial stage of protest, but the strenuous pursuit for the justice and passion enabled the campus controversy to be brought to the government attention. The government endorsed the petition to mediate and invoked the APS to base its legal grounds. This is the brief course of development which CU is governed by the statutorily appointed board regime (CU Almanac, 1988). That emergency or temporary board regime had, thereafter, long persisted to intervene the campus administration, which were less suited to the needs of Chosun people. A reputation of CU had long been tarnished for this regime despite its extended achievements over the scope of campus agenda. It had been chronicled aspirations of the local and school people, which were to restore a school governance to the hands of Chosun's own foundation. That was realized in 2010 during Mr. Chun's leadership, which is a most notable point of change.

\section{Chancellor Chun, and His Overarching Role}

For understanding his overarching role on this change, his personhood needs to be briefly described. He is tall at height and look calm and handsome, but evoked a bit the feel of tranquility and meditation as if requesting a deep concern, which is about the matters the leaders and followers would share. His eyesight is profound, and likely attracts his counterpart to some of esoteric dimension. His tone of speech is low, but steady to be grounded and comprehensively convincing about the scope of serious issues within the university (Burke, W.W., 2011). It seems to prove his concern, research and meditation, development of tactics and strategies for the improvement as well as long years of faith and commitment as a campus leader.

In the course of discussion, it seems essential to take a look at two fold aspects, say, the environmental variables and leader's attitude. These two are not let alone to function, but rather interact each other to shape his leadership style and to effect an organization change.

He had no other viable choice but to follow the transformational and shared leadership and implement his reform plans of university (Burke, W.W., 2011). Of course, most of leaders, in the contemporary times, favor them, which is, however, more pressing in the context of university election and administration. That is principally because the organization of public university is particular:(i) in terms of its members, a cluster of liberal and intelligent ones both within the faculty and group of students (ii) the culture and dominant atmosphere are disposed to see "us" as peers more than other bureaucratic elements (iii) the input, through put, and output process is not simple in the university, but rather complex involving diverse features (iv) the university's commitment is normally pioneering with the expectations of community more beyond other type organizations (Allen, K.E. \& Cherrey, C., 2000). These particularities would get more deepened in the context of CU given the description at the beginning of this assignment

His leadership style is vision-oriented, which is also inclusive, transformative, and value sharing. It is not unusual in the university context that the prospective or current administrators generally employ both task and relationship oriented leadership (Hickman, G.R., 2010). This is the case of Chancellor Chun, but the relationship oriented leadership is more strongly profiled in the election process.

\section{A Prelaunch Phase, and Candidate Chun for the CU Chancellorship}

In order to facilitate his plan to recover the normal regime of board governance, his leadership performance can be properly analyzed in accordance with four stages of the change process. As was specified, he had been an active researcher and school administrator 
from his college background. That enabled him reflect on times of meditation about his capacity, environment, and his extent of commitment. His concrete nexus with the locality and campus could be finely matched with his personal ambition as a campus leader. For the point of self awareness, he knows far better than others on his person, major issues, and ways of approach and dealings. (Burke, W.W., pp. 270-271)

His assessment on the external environment is fairy realistic and accurate to make a ground for the cause as well as to maturate an action plan (Song, Y., 2009). Most important on this point is it that he mobilized the voice and engagement of interested groups to promote a campaign for the normal board regime. A group of students participated in due course, and it was so encouraging that the congressmen, alumni, office holders of the local government and major businesses engaged to petition the Department of Education (DOE) (Burke, W.W., p. 276). He looked at the essence of nature surrounding his plan, which was "disturbed, reactive or turbulent" other than "placid." That fostered a more favorable condition to pursue his plan of change on the board governance (Burke, W.W., pp. 276-277). He enchanted the cases of other three universities, which struggled to obtain a regime change about the board governance. Around that time, Kwang-Woon, Sang-Ji, and Se-Jong Universities urged to reform the government-controlled board governance through a series of protest and official proclamation. An environment on this aspect turned to be seriously disturbed or even turbulent (April, K. A. \& Hill, S., 2000). CU formed a coalition responding to the dispassionate and passive government. Their struggle, of course, under the leadership of Mr. Chun for the CU case, prolonged to hold a public forum rebuking the unlawful attempt of DOE. Their position had been strong about any statutory authority between DOE and the Special Commission of Private Schools. This approach, based on the legal point of arguments, served importantly to discourage the stern attitude of DOE. The forum later developed to demonstrate a picketing and street marching, in which over 600 concerned people participated.

His vision and interactive plan with the concerned group had a strong faith on establishing the need for change (Kaufman, H., 1973). It also exhibited a correct fit with the aspirations of local people and other coalesced universities. A board regime of emergency degraded the reputation of university, and generally weakened its image in advancing to the international cooperation or enhanced public recognition. His mindset and commitment to bring the change was networked, in a culture and motivation, with the group of concerned professors. His informal activities for the socialization of issue and to promote the public relations were serious and effective, which was solid on his personality and skills to communicate as was introduced. He was a note taker to record every bit of useful comment from his audience. His response is faithful, tactical and well grounded on the reality to implant the need and urgency for change. He provided a clarity of vision and direction. (Burke, W.W., p.280). This context was evidenced on the series of engagement from the members of Chosun. For example, CU faculty board, labor union, and student association announced for the press in 2009, "Chosun people implored on the reversion to the normal regime within the shortest possible time" They spoke in an intense manner, "we continued to concern the irregularity and bad nature of school administration arising from the temporary regime. For the change petition, we had already filed the plan and implantation schedule two years ago with the prior consent of local people and campus community (CU Daily, Dec. $10^{\text {th }}$, 2009)." Of course, one of causes for this all-dimension uprisings would also lay in the DOE's attempt to abolish the election system of university president.

\section{A Launch Phase and His Strategies for the Change}


For the launch phase, he exercised a greatly effective leadership role to facilitate the panned goals. He persuasively and powerfully communicated the need by delivering his messages about the need for change. That is generally the way employed by Mr. Chun, but he also utilized shrewdly any more effective medium of personnel for each specific context. The British Airway's precedent may be properly revived pertaining to his changing mission (Burke, W.W., 2011). A fundamental aspect was already shared by the intimate strategic team, and many major figures involved, but Mr. Chun was not convinced that their hearts and prospect really had gone with the success. Some of them seriously questioned the whole probability of success granted, though, if their passion and desire are on the same direction. Some of his colleague should be culturally dissident about the administrative vision, being principally due to split and rivalry of the election process. In this situation, they were not exactly sanguine about going through the whole process unless there was a compelling reason to do so (Burke, W.W., 2011). To overcome this type of communication challenge, he sought much help from the Dean of the colleges who could be more familiar and keenly associated to move the followers to participate. The Vice Chancellor also is significant player to convey the needs of restoration for the passive campus members. They delivered the message again and again with the feedback survey, who were persuaded to champion the ambitious initiative of Chancellor Chun.

The most typical point disclosed in the regime change is that it was performed on the consensus of concerned or interested people (Hickman, G.R, 2010). The units or sections, and academic departments could not bear any means of disagreement about the change since the agenda had the nature of general goodness and legally a more prototype in terms of university governance. Other reason may perhaps lie in the factor that such emergency regime had endured as long as decades. This tended to foreclose, as a matter of context, any kind of opposition or resistance from the members. Most members recognized as if they murmur "...justice and force of the nature in ways of working to bring the change." One of interesting points is about the response of family members, who are allegedly a former owner of the university foundation. Mr. Park's wife and his son claimed his founder status, and brought a civil action, which embroiled the leadership into over half years litigation within the courtroom. The procedure was hard, but the outcome just made them to buy a public remorse and criticism. CU prevailed the case in 2012, and the victory promoted a great advantage in the effort that Chancellor Chun managed on further implementation (Burke, W.W., 2011).

\section{A Postlaunch Phase, and the Chancellor Chun's Role to Facilitate}

As we are exposed, the nature of change, which Mr. Chun planned and implemented, involved a less feature about postlaunch elements. A governmental measure to restore the normal governance alone is generally sufficient to refreeze the change outcome. A resistance from the members usually charted over many cases was far weakly present, only one counteraction on the private interest driven basis notwithstanding. However, the consequence witnessed after the change was multiple and diverse (Burke, W.W., 2011). One way of evolution is related with the political morale of the Democratic Party in Korea. Other aspect would partially requires a multiple leverage about the changing attitude of the staffs and professors. They are generally vigilant to restore the autonomy of university administration, which should be emancipated from the government control. This means that they became more loyal and fiduciary to new regime of governance. A least of them might have a personal passion about his or her inter-linkage with Mr. Park's family, who are, therefore, vulnerable on their status. This group, however, is actually negligible in number who was staffed under 
the influence of Mr. Park's family. Most of them were recruited on the fair competition and public process.

\section{Sustaining the Change}

Mr. Chun, in his endeavor to sustain the change, had engaged ways to counteract any vitiating factor. Those were designed and schemed to penetrate the core vision of normal regime. A restoring mission triggered a sound, constructive and more fitting role of the Board, which lies at the core of change plan. The statutory form or governmental level of remedy was procured, yet that would not tell all the story well going. Some of the newly appointed board members profiled undemocratic and conservative rooted on his career and personality. Their one year testing period proved that this worry was not just the gut feelings of community members. They were often disinterested and distanced from the Chosun community. It yielded a result that their execution of duty and role performance were less high failing to reach the expectations of campus people. We now launch a new change plan in the purpose of sustaining the change initially conceived (Burke, W.W., 2011).

One other story allows us to see an expansion effort to sustain the change result. That involves the local compassion and cultural pride about democratic sanctity. A demise of the government-controlled regime strengthened the heritage, morale and sharing of the recognition for the enhanced democratic sentiment. This context is never confined within the spiritual dimension of local people, but is practically operationalized over the prevalence of opposing democratic party.

\section{Conclusion}

The story may be revealed more sensually in the news article, Jan $8^{\text {th }}, 2012$, describing the $22^{\text {nd }}$ memorial of 1.8 campaign and the commemoration ceremony for the erection of democratic statue. It enabled an overview of the previous discussion, which is as follows: "In May 1 st 1987 , the students and activists were aligned to protest and strike out Mr. Park's administration as well as President Chun's authoritarian government. A democratic movement in the university progressed in a heat of passion where the students, professors, union members and parents acted to engage and support. The demonstration was suppressed and ceased by the police power Jan. $8^{\text {th }}, 1988$, which had endured on 113 days campus occupancy and rioting in station. On Feb. $4^{\text {th }}, 1988$, the Board dismissed its members who were led and directed by Mr. Park, and the temporary member assumed all responsibilities to restore the identity, culture, tradition and public commitment of the university. The incident, through the sixty four years of campus history, is memorialized by the public as one of leading campus activism, which also triggered a democratization of the authoritarian form of government... This year's ceremony is particularly significant since it is the first year upon that precious reversion to the normal governance of board....The Democratic Statue was designed and crafted by the stone artist named Jeong-whan Kim, an alumnus. It sympbolizes the compression of campus people's will and devotion aspiring for democracy within and beyond the campus. The basis of statue was sized 12,000/6,000/500, and the main idol was stoned in size, 3,400/3,400/3,800. They are helped with six stones of indication for the public...The statue symbolizes the power and energy united through Chosun people, which would embosom the history, culture, spirit and heritage as a sacred force for democratization....(CU Daily, Jan. $\left.8^{\text {th }}, 2012\right)$." 


\section{References}

Allen, K.E. and Cherrey, C. (2000). Systemic Leadership, University Press of America. Lanham: MD.

April, K. A. and Hill, S. (2000). The Uncertainty and Ambiguity of Leadership in the 21st Century. South African Journal of Business Management, 32: 45-53.

Bastedo, M.N. (2012). The Organization of Higher Education: Managing Colleges for a New Era The Johns Hopkins University Press (April 2, 2012) Baltimore, MD

CU Almanac (1988).

CU Brochure (2010).

Jung, B.K. (Dec. $\left.9^{\text {th }}, 2009\right)$. A Voice for the Board Change. CU Daily.

Kang, S.K (Jan. $8^{\text {th }}$, 2012). An Inauguration of the Democratic Statue. CU Daily.

Kaufman, H. (1973). The Direction of Organizational Evolution. Public Administration Review, 33: 300-307. doi:10.2307/975108.

Song, Y. (2009). The Leadership Effectiveness in the Process of Planned Organizational Change._Public Organization Review. 9(3): 199-212. doi: 10.1007/s11115-0090075-x. 


\section{Chapter VII. Ethics and Leadership}

\section{Ethics and Leadership}

Ethics and moral aspect of leadership are delicate in nature because of reasons (MacKinnon, B., 2011). In my view, (i) it is difficult to quantify, which muddies the clear line of understanding (ii) the value or standard ethics may differ given some of confines or limitations (iii) ethics or moral aspect usually is unable to account for the whole of leadership. If a high efficiency company yields much operational or net income, its virtue of organization may be understood in any quantification terms easily without a countervailing argument. It would be generally true if the organization is for-profit, and it often would be correct if the assessment has gone with a profit-context focus. That does, however, less apply in the dimension of ethics. Simply put, as Kellerman experienced, there are even contrasting views about Hitler, in terms of the virtue of his leadership. We may properly say that the ethics matters with "right v. wrong," and that the value is a central concept. But how we come universal about it? Is it correct to say that he is great or morally revered if Hitler mobilized his war force so effectively to serve the fascism or German idealism? For some, it may not be absolutely unacceptable. It would, however, be far less appealing to the general public. We can hardly quantify any idealistic motivation or other spiritual factors for German people around the World War II. I am not sure if the Nazism still may echo for some of enclaves believing or subscribing to its goodness.

\section{Ethics and Organzation Change}

A Grounded theory, developed by Glaser and Strauss, would perhaps allow more ways to address the need to understand the ethics of leadership (Hickman, G.R., 2010). If any quantitive methodology is used in research design about the ethics issue, it would be easily contracted with the pre-oriented frames of researcher, and often tends to extrapolate a kind of bias. In any case, ethics is hard to quantify, but deals with the dimension of human perception or mind covering a belief, adherence, value, and conscience (MacKinnon, B., 2011). Further, the value or standard of ethics will go deeper and more complicated from any simple dichotomy like between "fascism v liberalism." You would certainly come in other way if you are asked to evaluate the ethics of Hyun Dai's CEO other than Hitler (Shaw, W.H. \& Barry, W, 2012). From where will you draw your parameter to see through him? For the organization students, ethics issue normally pressures around the maze of competing narratives which the author sheds his light of indulgence. Despite the long brilliance of leadership research, it is understandable that Lipman-Blumen approached more carefully with illustrating seven elements of toxic leaders (Hickman, G.R, 2010). It is also plausible to start at the bottom-line about "being bad (Hickman, G.R., 2010)." Can we make any meaning from the leaders and organization, who are perceived or attributed bad on the basis of followers or social evaluation? That is the point from which we begin to consider the ethics of leadership. It seems similar if a sociological meditation seems emanating from that inquisitive floundering into a suicide as in Durkheim. A failure of society finalizes with the suicide of an individual. Likewise, I suppose, the failure of ethical leadership recourses the evaluation of "being bad." An ethics dilemma would perhaps be derived from its characteristics triggering the whole of person.

\section{Ethics and Accountability}


The problems, here, seem to lie in its persistence or entrenchment of human adherence ( MacKinnon, B., 2011). Laws, regulations, or UN resolution may work at some extent, which is deemed as most powerful and effective at the contemporary framework. That would come, however, as more vitiated and complicated, if we are on the dimension of liberalist world. In other words, individuals and most organizations are basically on the context of self-supervision when we say about the ethics. This context gradually develops into a kind of moral mazes, as proposed by Jackall (Hickman, G.R., 2010). A bureaucracy is typical of the organizations. It would come generally weak on the individual context, but the individual also forms a kind of value structure while he develops in person. Unless he or an organization is forced by outer influence or power, his adherence to the value system remains persistent and entrenching.

\section{An attorney General, Mr. Han and His Resignation}

For the discussion purpose, I have made some trend about the ethics of modern leaders, its consequence and accountability. It arises from two points. A leader's ethics is organizational specifically, but usually takes a broader context of leadership. The followers work under the direct supervision of leader, but the leader is received rather socially. The followers are workers of organization, but less does it govern the whole of person. They cognize or are receptive of the evils or goodness with an open and broader influence. The leader, therefore, is let within the open and social context beyond the boundary of specific organization. Plainly, the leader, who is a culprit in the morning newspaper, should feel dying or troubled with his followers. The face issue can relatively matter when we take the ethics issue. One other is that the accountability of misbehaved leader may get socially constructed, particularly if the organization is (i) public, (ii) non-profit, and (iii) socially impressive nature.

I wish to illustrate a case of these days about the chief leader of prosecution office in Korea (KPO). In November, 2012, Sang-dae Han, who is an attorney general resigned from his position. The basis for his resignation was announced that one of senior persecutors had illegally financed from the neighbors as deviating from the normal rate of market transaction. The context implies that he may exercise an influence of his office to extort or coerce to his private interest (Svara, J.H., 2010). This story was popularized through the days of newspaper. He was alleged to be an economically worse household, which is inevitable, but also not illegal to subsidize his family. Other worse incident fueled the public opinion, in which a young and newly appointed prosecutor had an improper sexual relations with the suspect during an interrogatory in the office. The public were shocked at two news stories. It continued to raise a serious and rebuking concern of the public particularly because the prosecution office had been held as a bulwark for the public justice. It was an only revered institution to investigate and prosecute the powerful or wealthier men of society. The general beliefs and expectations aggravated the consequence of incidents. To be honest, Sang-dae Han can be said to neither commit any ethical violations. We may, in a way of difficult math, deduce some of his misconduct if he is loose or less minded about his supervisory role for his lower ranks. But practically, it is doubtful that a chief officer can intervene in every case of lives to defend the ethics or value of the organizations and so (Svara, J.H., 2010).

One other context seems to have operated, which stripped him off his official power. A chronicled issue about KPO had been to reform the central investigation bureau. The issue has risen in every case of presidential elections as one of judicial reform agendas. While I am not exactly sure of its merits and scope of proactive groups, the political circle and other 
interest groups generally perceived it is a factor to make the prosecution authority omnipotent and to entertain a prerogative power, which may be arbitrary or abusive in some occasions. The wake of development about two incidents and resignation of a former AG, Han, ironically overlaps an intense period of presidential election in Korea. Two most promising candidates, on days and weeks, pursued to appeal to the voters, and they attacked the incidents so as to announce their conviction about the reform. Their words were, "AG must be dismissed, and hierarchy should be reverted to the policy makers...Every time when we urge the reform, the institutional or judicial response curbed the initiative of reform." Their assertion seems to be likened, "this is a compelling and most favored occasion to tame and hamshackle the stern and rigid prosecutors." This atmosphere, over the days of news report, certainly affected a resignation of Han.

Provided if Han's ethical violation would go to his supervisory duty, that is fairly remote in sense. It seems socially constructed, and the atmosphere fairly influences the context of accountability. Han, as stated above, is certainly not the leader of organization only, but is received in a wider and broad ambit (Shaw, W.H. \& Barry, W., 2012). It seems a face issue in some sense. However, the atmosphere, particularly if political or on wider public, would turn more strong to influence. That is so even if Korean people had made a statutory safeguard of two year terms for the attorney general. His resignation was made during the terms, and it is even a fourth case to see an interrupted attorney general. This kind of example would perhaps be less probable if the organization is private or for-profit. We may also go in comport with the blurring nature of ethics issue. Ethic matters on the whole of person. However, if the organization is socially impressive, their ethics and accountability may, in some aspect, be harshly constructed in terms of social factors.

\section{Ethical Guidelines and Organization Change: Korean Governmental Employees}

\section{5-1. Introduction: Two Ethics Codes Consulted and Cited}

As introduced, I perused the internet site to locate the ethical guidelines most matched. As if any chance being given, I wish to serve as a ranked governmental officer or court judge in Korea. In this context, I chose the ethical guidelines of Korean judge which was promulgated in 1998 by the administration unit of Korean Supreme Court. I also found it helpful that being applied for all scope of public officers. In specifics, two ethics codes are part of Korean laws, which expect to be applied in a mandatory nature, and, therefore, should be enforced under the rule of law framework. This implies that the discretion or flexibility usually characteristic over many other organizations radically shrinks in these two cases (Dzur, A.W., 2008). They are laws under the hierarchy of legal framework. Therefore, the ethical guidelines are of multi-layer nature, in which they would be invalid if being contrary to the dictate of Korean constitution, the highest law in Korea. Between these two, the hierarchical concept applies that the ethical guideline for judges are subject to that of all scope of governmental officers. If the former contradicts the latter, the majority views see it invalid. Some minority view asserts the importance of judicial independence that the former still is a valid law despite a conflict.

\section{5-2. Four Ethical Guidelines Relevant to My Case}

In illustrating four most relevant ethical guidelines, we are required to weigh, in 
terms of organization change. It is now a general belief of Korean public that the judiciary and executive branches should change to restore a "public trust." As they are a governmental organization, it is generally a most esteemed virtue along with an "efficient administration (Dzur, A.W., 2008)." The public trust may incorporate a scope of subclass virtues to increase its leverage. I observe them in four: "transparency, sanctity, fidelity or loyalty, service spirit for the public."

Four ethical guidelines relevant with the organization change are drawn in line with the set of virtues. They were, as above mentioned, excerpted from the Code of Supreme Court (CSC) as well as the Act of Transparency (AT). The Code was enacted in 1963, but revised in 1998. It comprises seven articles, and is relatively shorter given the small number of judges (The Code, 1998). Guidelines were encoded dealing with a special aspect of judicial ethics. Judges were, as a matter of structure, regulated in a double scheme based on the Code and Act. The statute was enacted in 1996, and underwent several revisions for the final version of 2002. A statutory scheme is comprehensive with six chapters and thirty articles in detailed provisions (The Act of Transparency, 2008).

The ethical guidelines among the Code and Act, can also be made distinguishable in that the emphasis of Code was highlighted with more aspect of "personal and official integrity." In comparison, the statute immensely involved a prevention of "unjust enrichment" of the officers. It includes a general section, as well as disciplinary action and criminal penalty. The subject matter of statute are set forth across the second, third and fourth chapters. A registration duty for personal and familial property or assets would be one, and also the stock transaction should be reported with a registration. Gifts and endowment also are required to file about its content and economic value. One of notable apparatus to prevent a corruption is the statutory duty to avoid a "job of similar scope" related with his official authority and power. The duty endured until specified years elapsed upon resignation.

Assuming I were to be nominated or appointed as a ranked officer or senior judge, my responsibility may incur some kind of role as a change agent for the Court and other governmental branches. As a change agent addressing the ethics of organization, I would turn to shape an engineering paradigm with the ideals of public trust. It comes into play how to increase the public trust, and the paradigm would span over the subclasses; "transparency, sanctity, fidelity or loyalty, and service spirit of public officers (Dzur, A.W., 2008)." In this line, the relevant ethical guidelines are found in Art. 3 and 7 of the Code as well as Chapter 2 and 4 of the Statute respectively.

Article 3 of the Code requires the judge to faithfully execute their job duty maintaining the personal dignity or integrity (The Code, 1998). This ethics principally relates with "fidelity or loyalty," but also expands, at some extent, to the "service spirit" of judges (Noonan J.T. \& Winston, K.I., 1993). Article 7 of the statute is aligned with the "sanctity" of judicial position where the judges are forbidden to involve in political activities, neither to engage in other commercial or social activities. A registration clause provided in Chapter 2 was selected to describe how it serves preventing corruption and increasing the public trust. Finally, the duty to avoid the job of similar scope within the statutory period of time is generally considered as an ethical tool for the anti-corruption practices.

\section{5-3. Two Ethical Guidelines for the Organization Change.}

It would be one of my priorities to impose the ethics that judges in Korea should more effort to faithfully execute their job duty. As are specified in the Code, judges are also required to make a steady effort for the improvement of his performance (The Code, 1998). He should preside for the speedy and efficient proceedings, but are responsible to safeguard 
the fair administration of justice on faith and prudence (Noonan J.T. \& Winston, K.I., 1993). Judges should contact a litigant and his empowered attorney in the manner of "kindness and courtesy." His contact should be scrupulous and must avoid unnecessary ex partite arrangement. The article proscribes further that the judges should not make a public comment about case, except otherwise permitted in the academic context or fact report for public awareness (Noonan J.T. \& Winston, K.I., 1993).

The rationale for stressing this point is that recent practices on several occasions arouse a public resentment about the judiciary. One of them has gone with practices on a summary form of judgment. One judge in the Seoul District, wrote an court opinion, as briefly covers the order of court, articles of the relevant statutes, and a short paragraph for the reasoning. This practice was revealed in the newspaper as an unfaithful commitment for the interested parties. There are pros and cons about the length of court opinion. The way of dealings would perhaps differ as a matter of judicial system. For example, French judges favor a short court opinion, but it is rooted in tradition and survived a public debate. The situation in Korea was not the same that the practice could undermine the basis of justice, and also tended to frustrate the parties and attorneys in the case. That is because they generally aspire to look at the logic and reasoning in details. This form of disloyalty may be defended on a certain ground, i.e., clarity or uniformity of the court opinions. They are less persuasive given the current context of judicial service in Korea.

Other point of focus concerns the manner of "kindness and courtesy" which the judges should keep on the process of executing his job duty (Noonan J.T. \& Winston, K.I., 1993). As the judge's work is limited on reviewing of the record, researching of the laws, and writing the opinion, this point would generally be less problematic. The issue rises in the context of one day of court proceedings which is usually scheduled on a weekly basis. For that designated day in the week, the parties, attorneys in power, and public convene the courtroom to debate, interrogate, and announcement of the court order. One note is that the Korean Bar Association performs an annual survey about the judge's manner and competence in presiding the court procedure. It was reported that some judges had been indiscrete using a demeaning or provocative words. In extreme cases, they practiced a kind of verbal abuse for the parties in a divorce suit, "you had better not invoke a suit if you wish to divorce. Simply have a bed time with other woman around the time your wife returns home..."

These incidents probably work to degrade the public trust of judiciary. The context would come rather worse if it is vulnerable to improve due to the prevailing moral mazes (Dzur, A.W., 2008). To say, the situation aggravates because of easy attitude of the judges. They enjoy a high extent of job security, and any reactionary voice has been relatively weaker than within other institutional context. Their job role is lofty that the lay community generally see it sacred and inviolable. A bureaucracy is entrenching and firmly networked to protect an individual judge's autonomy (Hickman, G.R., 2010). They generally share a common nobility to form a stern ethics structure (Noonan J.T. \& Winston, K.I., 993). It is less applicable if we preach the importance on "right v. wrong (Hickman, G.R., 2010)." In above cases, they would be viewed as bad leader in ethical terms. However, it is never easy to "construct a meaning from being bad (Hickman, G.R., 2010)." They also could be the kind of toxic leaders on a tedious and continued mode of job engagement. These factors are serious in terms of the reliable or committed role of judiciary, and my endeavor for change would go emphasizing this aspect sincerely. I reinforce a reward and disciplinary institution to mobilize their cooperation. The evaluation of Korean Bar would be more effectively referred to in the promotion decision process. I would encourage an informal meeting about the service ethics of court judges. It would be useful to sponsor the training and education program breeding a competent and kind judge. 


\section{5-4. Two Challenging Ethical Guidelines}

In regard with the increase of public trust, I take two ethical guidelines as challenging, which is, however, to require a square review of its merits. They are viewed generally necessary to ensure an integrity or transparency, and the people's right to know as well as sanctity of the public office. Other compelling interest, however, brings a point of consideration, in which the change leader should take care around the multitude of consequences. It may offset the advantages of point. For our case, a potential of ill effect would possibly incur an unsatisfactory recruitment, degradation of organizational morale, poor job satisfaction, possible infringement of constitutional rights, and distrust among or narcissism of organization members.

One ethical guideline, as above mentioned, is concerned of two years prohibition during which resigned officers are forbidden to engage in the job of similar scope (The Act of Transparency, 2008). The influence and power of an officer is considerable that the for-profit organizations have long practiced hiring a resigned officer with the premiere work conditions. Their salary is too high to properly compensate his value of labor. This implies that the arrangement plots on some unethical ground, which may typically include an exercise of influence from his former position power or improper networking with the current officers. It had long been a high tone of public to eradicate this type of corruption.

Second, the judges and prosecutors are regulated with a statutory ban about their employment upon resignation. The statute triggered a geographical confines where they should avoid to open a law office or to be employed in the law firm, within the locale they served in recent two years. This frame developed in an expansive ambit for all the public offices, who are congressmen, ranked executive officers, and for other branches of government. Their remit in power entertained during the office can have a potential to create a corruptive ties with the for-profit organizations. This aspect, therefore, was incorporated into the scheme. The statute primarily proscribes an employment in the same or similar scope in power other than a geographical approach (United States Office of Government Ethics, 2010). For example, directors of the financial board of government could not obtain a job position within the bank until two years have lapsed upon his resignation.

For the nature of its arrangement, it is essential to restore the public trust. It increases a sanctity and loyalty of officers who should maintain his personhood as entirely committed to the public servant-ship. It should be an ethical guideline in Korea if a number of developed countries now enforce this type of state laws. There have been a plenty of news stories about an enormous compensation made by the law firms and chaebol, which went to the recently resigned and high ranked officials. A contrast generally sensitizes the poor public to frustrate, and eventually leads them to public criticism. An inquisition, "should we be ethical while the boss is not?" can well apply to this case. The public tend to suspect if any ethics functions to enshrine their basics of moral sense and interactiveness (Moehring, J., 1994). They can turn to be callous like their toxic leaders (Hickman, G.R., 2010), "My misconduct is minor to be negligible. See the mandarin compile an unjust wealth. Who can blame me?" Beyond the public distrust, the atmosphere and moral subscription of society is put to jeopardy. The moral hazard comes at front, as one of hyperbole issues, to restore the integrity of society.

The change leader for government should not bypass this ethics, and it would be enforced strictly with the penalties as well as the statutory process of reporting, auditing, and post-event remedial measure (United States Office of Government Ethics, 2010). On the other hand, it could bear on some weaknesses which makes it challenging. A fine caliber of young professionals may not wish to become a public officer. In some cases, an aggrieved 
attorney retired from the prosecution office may assert their constitutional rights for the free occupation and economic freedom. Current officers may easily come discouraged about their post-retirement blueprint. All of these countervailing factors should be minimized. For instance, a revised pension plan or adequate compensation system could be supplemented to boost the progress of change.

I was amused these days with the happenings of nomination for the second men in Korea. The president elect, who is a lady president, allegedly had spent much time speculating and reviewing the pool of candidates for prime minister. Her preference was heard to slant on a group of senior law people, who worked as chief justice or chief administrator of the constitution court. Newspapers heralded a mocking context that they abhor of being nominated (Jung-Ang Dairly, 2013). The reason was reported that they could not obtain a job if they retire from the position of prime minister. As the prime minister has a plenary scope of power and influence, the statute above effectively bars any type of postretirement employment. This is one other challenge, and the change leader has to redress it for a more reasonable system of anti-corruption.

\section{5-5. Conclusion}

In contemplation, the organizational studies are generally on the track of multiple and interdisciplinary investigation. A scope of science would play any meaning part to enrich the understanding and to find a better solution. It would perhaps one of major categories in academic terms, which is "most practical, comprehensive, and interdisciplinary" along with the law or medicine. It is distinguishable from a pure art or science in that it deals with the whole of person more than any other field of science. We learn economics, but it is partial on the aspect of economy even if we talk about "homo economicus." We cite the Aristotle's words "political animal," but is defined in the word of "animal" other than homo sapiens. An intelligent circle deplored a social injustice, which would be the subject issue of sociology. Most of us, however, see that an egoism or liberty concept had been pivotal to promote the economic prosperity.

This nature of organization studies generally leads the students to rethink the complicated whole of leaders and followers. They have to linger on the nature of members in humanity dimension, but drove them, on the other hand, to ponder on job description and any efficient cells, units or networks. They involve looking into a "job satisfaction" while planning a restructuring adjustment based on the quantitative science. They like to pose an inquiry concerning the psychology of members, while emphasizing the ethics or moral aspect of leaders. As in the theory of "moral mazes," the factor of bureaucracy intervenes to derive a more accountable version of ethics or moral dynamism within the organization (United States Office of Government Ethics, 2010).

It would be practical if our most parts of life are professional in nature within some organizations. Comprehensive is it that we are hard to arrive at its true description, provided if we are the whole concept of personality. This never means that the "whole person" assumption is desirable nor has more persuasive power about the organizational narrative. For any exceptionally prosperous stores or firms, they may manage as simple on the quantitative indicators. Leaders might also get easier on a routine check-up with the performance. They may rest on the mechanics of economic jars to enjoy simplicity, but just on the condition that he or she is not avarice to grow any bigger scale of stores or firms. Interdisciplinary indeed are we required to subscribe if we need to recycle or upgrade the discipline of organizational studies. It is, in due course, necessary given the rapid transformation of society as well as many of new theories from other disciplines. 
An ethics issue or moral challenge would perhaps be more intertwined with the above three attributes. It is delicate, but practical (Moehring, J., 1994). From one philosopher's view, we are situated every time between the ethics and calculation. Needless to mention the "mind and body" dichotomy, we are the creature to consider "right v. wrong." It would be practical if to make us be minded, time by time, across the daily lives. It would be comprehensive to relate with our behavior as a whole. Is it morally permissible to take a hundreds dollar bank note abandoned on the street? Is it right to leave for entertainment although the assignment is due for tomorrow? Is it ethical as a student of Walden? Most of our time, we frequently face some kind of ethical decision, in the least behind within our mind, if not acted out. As I proposed in the Discussion Post, ethics and moral aspect of leadership are delicate in nature. That is because it difficult to quantify and because it may differ according to the limits and confines of specific organization. To be worse, however, ethics alone is usually unable to account for the whole of leadership. 


\section{References}

Dzur, A.W. (2008). Democratic Professionalism: Citizen Participation and the Reconstruction of Professional Ethics, Identity, and Practice. Pennsylvania State University Press.

Jung-Ang Dairly. Jan. 20, 2013. Seoul, Korea.

MacKinnon, B. (2011). Ethics: Theory and Contemporary Issues. Wadsworth Publishing; $7^{\text {th }}$ ed.

Moehring, J. (1994). Improving governmental ethics: Washington State and Seattle. The League

Noonan J.T. \& Winston, K.I. (1993). The Responsible Judge: Readings in Judicial Ethics. Praeger, Westport: CT.

Shaw, W.H. \& Barry, W. (2012). Moral Issues in Business. Wadsworth Publishing; $12^{\text {th }}$ ed.

Svara, J.H. (2010). The Ethics Primer for Public Administrators in Government and Nonprofit Organizations. Jones \& Bartlett Learning; $1^{\text {st }}$ ed.

The Act of Transparency for the Employees of Korean Government (2008).

The Korean Code of Judicial Ethics (1998).

Thomson, K.J. et al (2010). Implementing Ethical Leadership: Current Challenges And Solutions. Insights to a Changing World Journal. No. 4, 107-130.

United States Office of Government Ethics (2010), Standards of Ethical Conduct for Employees of the Executive Branch: Final Regulation Issued by the U.S. Office of Government Ethics, codified in 5 amended at 67 FR 61761-61762 (Oct. 2, 2002) University of Michigan Library. 


\section{Chapter VIII. Diversity in the Workforce and Organization}

\section{Diversity in the Workforce}

\section{1-1. Some Traits}

For a brief on structure and classification, I wish to design the concepts interactively. As with our central topic on leadership and organization change, it comes at forefront that the organization continues, grows to sustain, recycles and on feedback, shares and participates to intern an deadlock equilibrium, finally subscribing toward the biological satisfaction of members, adaptation and contribution to the society in general.

Provided if the diverse workforce matters, we need to consider, in terms of organization viewpoint, three traits generally. First, it is important if it harbors the concept of followers. A workforce is elementary in organization as with the leadership aspect. The followers are generally the workforce of a specific organization, and thus our scholarship has massively been shed on this point. It comes second in order that it is phenomenological as requires looking at the status of organization. Third, it is typical rather than general. There would be a number of organizations, in which no diversity comes into an actual matter. While globalization actually occurred around the Mediterranean Sea in medieval times, the discourse rose saliently in the last three decades as one of dominant scholarship.

Globalization now becomes a prime cause to the diversity in workforce, and may properly be matched in understanding the topic.

\section{1-2. Diversity and Organization Change}

So we need to be critical how much globalization impacts on the leadership and organization change. In due course, the response to a globalization grated for a hybrid concept of glocalization, a word coined by mixing the "global and local." Place-based accommodation is naturally consequential, and it rose to be one way of scholarship gradually instilling the paradigm change in various sectors (Hambleton, R., 2011).. For a more foreign investment, the local government needs to turn flexible in its mode of rule, in which civic leadership would be considered more effective. The traditional notion of "local government" may have to find a way in the mindset or preparation in comport with the concept of "local governance." They are effective and could be more strategic in terms of local competition. In other instance, Korean people had been amazed at the monster high school, "Minjok Academy," which I believe was a creature of globalization myth. Minjok means "Korean people," but the nature of organization is absolutely global or US oriented to raise a caliber of international workforce (Fowler, F.C., 2012). It produced a number of graduates who had been admitted to many of prestigious US universities. They usually scored high in SAT, but they are alleged to be patriotic and functioned in allegiance of the Korean orthodoxy. An illustration of MA is fairly interesting and exemplary since it shows an extremes in contrast between the most advanced and most traditional given the nature of Korean orthodoxy (Finch, J. \& Kim, S.K., 2009). In any case, this plainly evidences how much globalization pressures to change.

Earlier years, however, Koreans had already been pushed into the kind of business jungles, as like Sam Sung or Hyundai, major multinational corporations of Korea. Therefore, it is phenomenological, but mostly dominant, particularly if we think about the organizations 
other than individual, cultural or educational . The scale of organization would also factor generally in positive correlations, I suppose. I like to say it "phenomenological" since there is no uniform rule or principle about its "positives or negatives." It highly depends on each context and points of focus. That means the leadership role is essential requiring a correct and meaningful understanding of organization's status.

School administrators of the US college usually see a situation, which differs from that of Korean's. For example, a race or LSB is usually irrelevant for the latter group. A gender or disabled would come similar, however, in considering and shaping a school policy. Their leadership role would perhaps differ corresponding to the distinct traits or environment (Fowler, F.C., 2012).

It is typical also since it touches on the distinct aspect of workforce despite some kind of general force or motivation in the organization. There would be the goals and direction, or a kind of corporate theme announced in various ways. Some companies may shingle the words of maxim given by his boss, principles or codes for uniformity. Therefore, it is one way of looking into the joint venture between the developed and developing countries if we are guided by the dualism on "cooperation and competition." For the dominant nature of race issue, the basics between the "colorblind and multiculturalism" is necessary for any inculcated leadership. This topology, in most of scope, likely is rooted in the human intrinsics or sees it through the cultural lens generally. Assuming if the prevailing motivation comes from economics, diversity is typical against the general discourse in dominance, but not exactly being alienated therefrom. They interplay in the usual context, if we are not on the position of orthodox communists.

It basically does not see the workforce in a commodity concept. An issue of diversity also is not alienated from the mainstream of leadership, but is the subject to interact and to be included in general end of this discourse. The diversity in workforce, on its definition itself, is oriented to the autonomy of workers, which opposes the kind of alienation from their labor in assumpsit of the Marxism.

\section{1-3. Diversity and Its Challenge}

Diversity in workforce is pragmatically urgent the phenomenon being no negligible, and should be importantly incorporated into our concern (Hambleton, R., 2011). That is critical to the points of focus, in terms of organization studies. Since it deals with the cultural element of organization, it is keenly related with the biological concept thereof, work motivation or job satisfaction, and contribution to any higher and sublime end of society. This topic covers virtually all niche of our focus, and is also delicate prompting on the AIM proposition as a general introduction (Hickman, G.R., 2010).

Let us, however, turn to some of them. Can we acknowledge that the female workers are fully included given still powerful "glass cliff or ceiling?" We often see that cadre ranks are filled from male workers, and the promotion is a kind of hurdle which many female workers experience (Hickman, G.R., 2010). Family-friendly benefits can effect at some extent, but do not address the whole of gender issues in the work place. It would be revolutionary indeed if a European model of compulsory quota for the female board members in corporate organizations. But it is predictable if interested workers or shareholders could react in other ways in evaluating it. Diversity in work force needs "learning and improving," 
but within the purview of organizational dynamics and goals. We would take the role, in some point, as a reformer, but in the steady and gradual course to learn, interact, debate and participate (Guttmann, A., 2012). Korea now holds the 2013 Special Olympics World Winter Games, in which intellectually defected athletes could only be enrolled to share. I am not sure how they define a legitimate scope for participation, but it plainly signifies the diverse context of globalization. In the beginning, we had not eventuate this kind of Olympics (Guttmann, A., 2012). The paradigm shifted to include the physically disabled, and later for intellectually disabled. It seems to symbolize the democratization and universal welfarism, which were perhaps enabled by globalization on one hand, and likely from a learning culture of contemporary times, on the other.

This vision, I believe, needs to be forged into reality, from organizations through organizations. It would conducive to the shared models of leadership and AIM ideals. We have to shame if the disabled workforce generally lacks the learning to be informed (Hickman, G.R., 2010). This aggravates their participation within the organization.0

\section{1-4. Some Thought On Strategic Points}

Diversity in workforce brings two ways of highlight. They are an opportunity on one hand, but a challenge on the other. Any leadership involved in this aspect, I suppose, requires more engagement and interaction. In some cases, the servant leadership may properly operate. It should be honed to define the organization unless the minority workforce are excluded in some ways. It is a critical factor to effectively mobilize the workforce, who would serve the organization. The group of workers, in my cases above, are really challenging, but a factor to bring the change. In the place-based strategy for foreign investment, the traditional type of officers are ineffective through the core of mission, and workforce drawn from the civilian base generally functions to be productive. The diversity between the public and private nature of workforce in share can cooperate and serves to realize the goal. In MA, the high school students are Korean natives, and would perhaps have a learning disability about English or other abnormally upgraded dimension of philosophy. A high caliber of international professors have been comingled to work in team, which enabled to produce such unprecedented success of the graduates (Finch, J. \& Kim, S.K., 2009). It is practically usual to work with females, and occasionally comes in reality with the disabled. I wish to utilize Pyunchng Olympic now held and other summer events to stress our commitment and sharing with the group of people. They should truly be challenging over the illustrations above, but can be improved. The context may even outpace the singular form of workforce if the leadership is creative as in the case of MA or local government.

\section{Globalization and Diversity in the Workforce : Some Korean Context}

\section{2-1. Globalization and Its Impact on Leadership}

The meandering path of globalization in Korea began with a revisionist view of the state-led capitalism, which had been sustained by strong power of military-like government. Interestingly, two ways of cause played multiple factors to push forward the nation to upstage the past track of developmental paradigm by neo-liberalization. That had been a key to uplift the middle country, which could usher in the doorway for the developed group. It coincided with a new leader Tae woo Noh 1988, who was from the military background, but was deemed as also experiencing years of civilian politics. He was a friend and alumnus of 
Korean military academy, and one of revolt groups in 1980 with his predecessor, Chun. This context, however, has less meant if he cultivated Korea as a democratic and modest mediator toward the completely civilian nature. In 1993, Korea elected Young Sam Kim as president, who was a career politician and long had mutinied against the totalitarian way of military government. During their tenure, neo-liberal initiative from Reagan and Thatcher could find its way to effect in terms of deregulation, privatization, competitiveness discourse, and so. For Korea, these concepts actually were inextricable given its powerful force of international dynamics. Asian countries had been pressured by developed countries, and fair trade as well as level playing field were highly toned to ensure. A state protectionism became a target to be attacked by them. They are virtually coerced to lay out their country as is, to the global competitiveness. The neo-liberalization and globalization had functioned to impact the organizational leadership in significant ways. The impact is multitude over various aspects, but it would perhaps be wise if we perceive it in two basic points of contrast.The leadership turned to cast on new adaptation effort, which was pivotal to survive economically. Their business could no longer endure to lose the sight to the thrilling atmosphere, which globalization impacted to bring in any way. They had to restructure, and must compete with other global rivals on the level playing field. Laws and ordinances to shield their business interest no longer could be iron clad under the mask of state sovereignty. A competitiveness came at the forefront to subsist in that harsh challenge. This, in turn, as a matter of course, drove the leaders to restructure their organization (Hickman, G.R., 2010), and the hard nature of labor law was softened to boost the transformational leadership.

Other aspect of impact generated new perspectives about the leadership role, which concerns to manage on the diverse workforce(Hickman, G.R., 2010). Globalization dominantly shifted a culture of society at wider scope of the social groups. It dissected customs, traditions, prevailing perceptions and attitudes of the society. Oriental factors had gradually disorganized to generally change our identity to face the western mode of competitiveness. Female workforce increased to staff many organizations not for the sphere of automatic labor, but at the ranks of management and qualified professional circles. As with the migration of workers from other east Asian countries, the nature of workforce in a number of businesses became of more hybrid nature, and Korean government now pursued a policy of social harmonization with the slogan "multi-cultural society."

\section{2-2. The Articles that Influenced the Leadership of Diverse Workforce}

A western mode of reform toward the open, liberal, and welfare society often led the public to rethink the socially deprived around us (Robinson, F., 2006). Solo sections of the parking lot was mandated to secure the disabled as not abridged in his or her mobility. Social care and regulatory protection for women was extended to most of public and private organizations. Women are now the prime topic over the businsse world, and how to effectively cultivated their workforce in productive way makes our central focus usually. They should be given a privilege and advantages in the hiring and promotion decision (Robinson, F., 2006).

These changes along with the globalization now require the leadership to rethink their tactics and ways of dealing to manage on the diverse workforce. It would be more starkly pressing if they are leaders of the multinational organization (Robinson, F., 2006). Other interesting point can be charted over the wake of globalization reform. To say, the education paradigm of English language was intensified at private and public level, and raged 
the Korean community (Finch, J. \& S. Kim, 2009). It is, of course, because it is considered a global language, but accused generally as a prime factor to daunt the middle class household economy. This issue profiled long years to tremor the society. In reinforcement, the public education has been globalized that some of foreign universities now invest in Song-do, Incheon. The area was designated as a government-led parish, which was designed strategically to support the global education. English speaking village also was especially zoned for-profit by the initiative of private capitals. ESL teachers from abroad were recruited to teach the college students, other lectures of international nature involving at a gross scale in many of private lessons or education business.

A notable case signified the impact of globalization in Korea. Around the times, Korean Minjok Academy was created to raise a competent cadre of global leader, which was at the level of high school (Finch, J. \& S. Kim, 2009). They educate the students in a completely a national passion, who are, however, fostered dominantly to respond to the demand of globalization. They have effectively superordinated the programs to combat the challenges for Korean youths. In order to meet this contrast of dimension between the nationalism and globalization, they exploited a variety of programs and employed a superb group of teachers (Finch, J. \& S. Kim, 2009). It could, in my view, one of most documented cases to realize the paradigm of glocalization or place-based leadership in the new era. Many of their graduates have, over the decade, been accepted by prestigious US universities.

Other typical elements would perhaps lie in foreign and contingent workers in Korea, in which the leaders address carefully and deal with their inclusion for the congruent and productive organization (Chambe, M.J. \& Fontinha, R., 2009). In the frame of AIM (Allinclusive Multiculturalism), we may infer, in analogy, the status or ethic-blind approach and multicultural one. The concepts of decategorization, recategorization, and subcategorization generally did not hit a full wedge, but could be applied in a weak form. This is problematic provided if diversity in the ethnicity and culture had been developed over the period of globalization (Finch, J. \& S. Kim, 2009).

Around the couple of articles surveyed through this assignment, they focus on the diversity of contemporary workforce in direct and analogous way. They are all converged to empower the minority workforce to be organizationally congruent, productive, and participatory. They are women traditionally discrete, and in some cases, linguistically deficient or foreign, and marginalized on the contingent basis. That could be overcome in various ways of inclusion by educating in a suited and tactical way or special dealings to incorporate, and so.

\section{2-3. My Leadership on the Foreign and Female Workforce}

Foreign workers in Korea gradually increased around late 1980's, and amounted to approximately 6,400 in 1987, 44,850 in 1991, and 425,107 in 2007 (Jung-Ahng Daily, 2008). Given the considerable number of workers in my multinational organization, I have known that the governmental policy was encouraging to make our work team more cooperative, goal-oriented or committed. For the foreign investment in southeast Asian nations, I like to launch the apprenticeship program to pull in the foreign labor. It plays positively to hire necessary workers with a comparatively cheap price. It is, however, important to comply with the calls of humanity and justice demanded from the national and international community (Zhang, S. \& Luo. G, 2013) If they are workers of poor country, the mind of instance would 
see the exploitative aspect. Business conscience and ethics, however, are implored to observe. In this context, the leadership needs to be austere on a strict adherence to the government permit system of employment as was introduced in 2007. It generally situates me to experience the larger scale change, which was voiced and urged by the social or religious leaders about the human and social right of foreign workers. Their point of focus was ignited by the increase of illegal foreign workers, who had no basis for any lawful immigrant status. Their assails have been usually directed to the Government, but their engagement downgraded significantly at the introduction of 2007's permit system. Things now undergo as weak, but the role of leadership needs to reinforce advising and counseling about the legal status of workers. It is one way of dealings to recruit an in-house counsel, who has a career in the field of immigration law.

Most importantly, the problem of foreign workers lies in the context of capacity building, particularly at the group level. It is, therefore, necessary to procure the atmosphere, in which they can organize their competence and power to share and cooperate (Zhang, S. \& Luo. G, 2013). Their aspirations, at most possible extent, have to be accommodated, in order that they share the goals of organization and themselves in the same direction (Hickman, G.R., 2010). As guided, the proposition between "cooperation and completion" would work to draw more active engagement, commitment and participation of the foreign workforce (Hickman, G.R., 2010). Given their high motivation for a better pay, the constant monitor of unreasonable lower pay should be exercised to balance on the fair stance between the domestic and foreign workers. A family concept is useful to include them, and the international marriage fair may serve to support. Unionization as well as the construction of network with the social and religious institutions could be a strategic option, which the leaders should positively incorporate. A Machiavellian type, "divide and rule" between the union members and mostly non-union foreign workers, would perhaps contribute to push the leadership to impasse in the globalized settings. Some of evil instances on this kind around the peer leaders are exactly the point which the global leaders should forebear from.

As stated, the globalization redirected the prevailing social paradigm of workforce, and the female workers have marked a greater significance than any other times ever. It also could now be squarely applicable to Korea, to say, the male hierarchy or patrimonial culture of society and organizations as developed by the Western thinkers (Marchak, P., 1976). One of most strategic way to break into its potential aberration would be that the leaders purposefully plan and implement the scheme of raising more high rank female workers. This point sees a radical revision of the unionism predominated by male workforce. The union is assumed basically that the laborers are, in nature and theory, one unit to represent the working class. Is it realistically true given the current status of unionism. In other words, male and female workers are deemed one and same, and eventually fair, collectively representing the interest of workers in the workplace. It would perhaps be not merited if we argue on this issue earlier this century. A male works, subsidizes his family while the housewives do house chores and rear a child. Female workers in Korea, however, now increased to be 50.1 percents of the total working age females. It is still less than the number, 70-80 percents in the western countries, but larger than 37.2 percent in 1967.

One point in the leadership role, to react with the structure of male dominance, should first focus on the fair recruitment between male and female job candidates. The gender factor must not affect in a discriminatory way in the employment decision (Marchak, P., 1976). We had lessons from the Hyundai Auto and Central Association of Small and 
Middle Size Firms. Those two instances manifested an easy attitude of leadership, which was to the disinterest of female workers in the emergency situation. The restructuring plan of two companies in 2000 was extremely unconcerned of their status. It included, on process, the layoffs of 144 restaurant female workers (277 at total over all sections in Hyundai), and 99 percents of females in the latter, respectively. This, of course, seriously tarnished the social reputation of companies, which later incurred the cost deserving.

My leadership, in terms of the female workforce, would prefer building their constructive participation in the union. A share of participation, at national terms, are lower indeed, and this undermines an effective interaction in network and less factor for the participatory followership. The female workforce can be more effectively organized by unionization strategy. They are a principal factor, which is capable of altering the character and nature of the union. A cadre of female workers in the union could, in turn, exploit any plan or program to effectively mobilize the lower ranks or base of female workers. Womanconscious strategies would, in the course of effect, promote the woman activism (Marchak, P., 1976), which is critical to invigorate the dynamism of organization in this globalized culture. Raising a thick layer of female cadre or high and middle ranks, it can be escalated into "subcategorization" as stable and enduring, in which the culture could not moderate (Hickman, G.R., 2010).

\section{2-4. Conclusion}

Globalization in Korea has been a chronicled issue during the 1990's through the new millennium, and to these days. Why was it to be so central to penetrate most other dimensions of discourse? That is perhaps because it brought a paradigm change fundamentally, and actually made palpable of the working class in Korea, and dominantly influenced the social, cultural, and the routine pattern of existence. This, in due course, reshape the paradigm of leadership which should deal with the diverse workforce, which the globalization and liberalization brought into consequence. This shift thrust both of challenges and opportunities for the leadership of new millennium. 


\section{References}

Chambe, M.J. \& Fontinha, R. (2009). Contingencies of Contingent Employment: Psychological Contract, Job Insecurity and Employability of Contracted Workers. Contingencias del Empleo Contingente: Contrato Psicológico, Inseguridad en el Puesto y Empleabilidad de los Trabajadores Contratados. Revista de Psicologia del Trabajo y de Las Organizaciones. 25/ 3, pp. 207-217.

Jung-Ahng Daily, Jan. 28, 2008.

Finch, J. \& S. Kim (2009). Thinking Locally, Acting Globally: Redefining Traditions at the Korean Minjok Leadership Academy. Korean Studies. Vol. 33. pp. 124-149.

Fowler, F.C. (2012). Policy Studies for Educational Leaders: An Introduction (4th Edition) (Allyn \& Bacon Educational Leadership). Pearson; 4 ed.

Hambleton, R. (2011). Place-based Leadership in a Global Era. Commonwealth Journal of Local Governance. Vol. 8/9, p8-32.

Guttmann, A. (2012). The Olympics: A History of the Modern Games (Illinois History of Sports): University of Illinois Press; 2nd ed.

Marchak, P. (1976). WOMEN, WORK, AND UNIONS IN CANADA. International Journal of Sociology. 5/4, p. 39.

Robinson, F. (2006). Gender, Globalization and the Crisis of Care: Women and Care Work in a North-South Context. Conference Papers--International Studies Association. 2006 Annual Meeting, pp.1-24.

Simons G.F. \& Vazquez, C. (1993). Transcultural Leadership: Empowering the Diverse Workforce (Managing Cultural Differences). Gulf Professional Publishing. New York: NY.

Zhang, S. \& Luo. G (2013). China's Migrant_Workers: How Far from Being Citizens? Asian Social Science. 9/1, pp. 171-178. DOI: 10.5539/ass.v9n1p171. 


\section{Chapter IX. Organization Change, Resistance and Social Change}

\section{Resistance}

As a change leader, most basic and ideal way to address the follower's side would perhaps be making them to be identical with the leader in all round aspects of human. As Louis XIV pronounced, the King is, in other expression, a d'états. In analogy, this view may more easily resurrect within the context of various modern organizations. For example, a CEO would be the whole organization itself, while the chief of units or cells would be the unit or cell itself, which he is responsible for. Two ways of fundamental reflection needs to be made of application on this analogy, however. They are likely (i) the change v. ancient regime (ii) democratic v. authoritative. The pursuit of change would perturb, if partial, the identity of organization. In this case, the leader and follower should explore or strive for some new paradigm of organization. They could not be so arrogant like King Louis XIV, but should find a way to evolve toward the desired goal or perhaps some of oasis deserted in the large sands (Conrad, C.R., 2011). Paradoxically, the change, however, requires, more purposefully, same identification and common struggle for the growth, improvement or sustenance. As over the politics, economics and society in general, the democratic value or its adherence is extensive and prevailing (Martino, J.P., 2010). For this, the facial impression of this analogy would turn complicated. I suppose, however, if it functionally and idealistically can apply to the paradigm of organization studies. A most perfect form of shared or participatory leadership, in any case, would let directed to the same identification through the leader, follower, and organization itself.

Various elements, however, intervene to complicate this simple and straightforward way of perspective over modern times of organization (Conrad, C.R., 2011). The type of organizations would play to give variances, and the interactive nature of organizations with the society at large as well as other confines of environment would allow prodigious the features of them. To be specific, the many differences over pay, reward, extent of members to the status, affiliation, passion with the organization, skills and knowledge, specified job responsibilities and others, delineate a discrete and more intrinsic analysis for the organizational change and dynamics. For example, high shareholder or CEOs surely are defined a distinct position against the followers. If the company is an enhanced form or secured between the owners and CEOs in the management context, such distinction might be moderated. However, still a distinguishing factor is it if CEOs are highly salaried with any tremendous amount of success-based bonus. Within this complicated preserve, the most distinct factor would lie in the leadership and followers dichotomy. This generalization, therefore, should be carefully used to address the problems of specific organization. That is particularly true because even the circumstances could mostly differ. While the Louis dynasty ironically was collapsed with the resistance of followers, it is plainly best way to lead the followers into the leader's world to share the same identity. Given many circumstances, the organization may pursue the change from a "small inner mindset of followers" through any "big upgraded spirit to new deals." The change may range from "routine daily" through the "long-term period." It is also varying with any objective scale from the "small project" to some "whole scope of restructuring." Change also would occur if the "give and take" within the transactional leadership would, over time, develop as if we are on the Walden Blackboard. A motivation and sharing espoused in the transformational leadership often would pioneer to bring the organization change (Burke, 2011). 


\section{Strategies and Circumstances}

In this ideal, I would propose several strategies and circumstances to deal with the resistance of followers and radical challenge.

\section{Be aware that the leader is situated like in the johari window, which the followers would perceive and assess critically.}

A resistance of followers has scientifically a correlative with the value, trait and behaviors of leader (Oreg, S. \& Berson, Y., 2009). His value system, presumably long observed and evaluated, affects the mind and attitude of followers. This point starkly rises if we refer to the situation of French revolution (Martino, J.P., 2010). A self-awareness of value, therefore, is important and seriously defined to successfully bring the intended change. It is a prerequisite to comport his value adherence with the organizational circumstances. Hence, his extent of value adherence and the comport of change with circumstances would pertain to its success. Weak believers would probably fail to get persistent through the movement phase, and subsequent reinforcement, through the post-change phase. His trait and behaviors also play to form an impression of leaders, and thus, the change leader needs to keep this interaction for the mobilization of high readiness followers. For example, the change may be directed to bring a conservation of energy consumption within the organization. Privately extravagant leaders would perhaps make a contrary response, and implant a kind of satire or disloyalty within the mind of followers. Most importantly, the change leader would, in many chances, be better if he or she is oriented to uphold the novelty and innovation other than conservation (Oreg, S. \& Berson, Y., 2009). It merely emphasized the status quo.

Utilize the Fast Change Tactics As it Would Say Much to Realize the Intended Goals of Change.

According to the empirical study of organization change, most successful organizations in their change effort are classed as a strategic and fast dealings of goal (Murray, E. \& Richardson, P., 2003). There are three dimensions to grip, and ten important points of commandment which the study result vindicated (Murray, E. \& Richardson, P., 2003). This version is strategically and practically useful to undertake in effecting the change. Most importantly, the change leader should be aware that his activities critically matter to symbolize the core of change. He or she needs to be a competent member of marine corps, who even feels palpable his hair end and nail of feet. The change leader should be ruthless against the resistance of followers. The strategic team also has a shared understanding about the change, but it is not necessary to include all members. The small scope of strategic team would be effective and responsive. Strategically, the process needs to hasten over the first and second 100 days (Murray, E. \& Richardson, P., 2003). A critical concept in this way of dealings is to make a momentum to signify the change. That would be similar, in analogy, as the successful campaign of marine corps make their national flag at the ceilings of the conquered government. A sense of urgency is required to prevent costly procrastination, which is usual in the event of human dealings (Murray, E. \& Richardson, P., 2003).

One illustration can be made of the fast track procedure utilized by US congress about the enactment of international trade laws. The procedure is compact and brief to meet the challenge of normally sensitive trade issues. The circumstances involved in the trade matter are usually differing, and complicated like the change issue of organization. It is also sensitive to change since it requires some tradeoffs between the past and future. 


\section{Be an active engager who gets a high score on the scale of leader and manager exchange(LMX).}

We may employ a kind of tactics to push through the desired change. A sanction, legitimization, consultation and ingratiation are typical. Some studies found that the success of all these instrumentalities in reducing a followers' resistance would depend on the degree of LMX (Furst, S. \& Cable, D., 2008), in which the change leader performs his leadership role. For example, the delegation of managers to new task generally produce a different concept and sharing in the circumstances of different LMX. In high LMX, the sharing and concept increase to yield a high performance as if the leader himself pursued the delegated work. A consultation would be one way to democratize the change process, which serves a participatory followership in brining the change. That could also differ if LMXs within the organization are not same. Other tools to motivate the followers also stood in the same correlative between the high and low LMXs (Furst, S. \& Cable, D., 2008). This result bears a similar logic as I mentioned earlier. Leaders could create a most same identity sensibilities within the followers, and empowerment would be extended on the same playing field. For other circumstances on this dynamics, I have several instances to tell. Empowered attorneys may work more effectively by establishing close ties with their clients. One lawyer would go insipid and discouraged for the tedious court schedule. His client invited him to tour the factory he owned, and he naturally was exposed to the heartfelt experience about the seriousness of his case, and also about the result which the litigation outcome affects the factory. His vigor was revived to get through the litigation. One professor allowed his foreign student to use his office during the vacation since he leaves for a short term sabbatical. The student felt as if he became a professor and stimulated himself to study harder. The professor is an effective leader to increase the change effect, in which case he intended to raise the learning ability and boost the study of students. LMX is a deemed variable when we consider the organization change to counteract the resistance of followers. That also possesses, in some context, a symbolic nature that address the need of radical challenge.

\section{In the Beginning : Human, Organization, and Society}

As we get some point to address out topic, I like to draw an attention to the dualism between the property right and social structure. How do you think if we are unarmored with any material interest. That might be true if we are on any seminal imaginary of primitive production. We are unleashed naturally to work and survive for our subsistence. They would perhaps be a prototype of bio object, who work to subsidize himself and his naïve family. They cooperate, and struggle would explain nothing if given a peace. They live as they are, occasionally own but to serve their prototype needs of human subsistence. The power and might rose to organize something artificially to extort and exploit. They think about heading to exploit the labor of others to serve their materialistic interest. The system was supported by the kind of military might, which would be to forge it as some of idealistic structure of society. The propaganda is very splendid and obviously convincing from the tangible feels on their surroundings. This is instantaneous on surroundings. Their clothes would differ from their antecedents, and the food or aspects of livings improve. The prevailing social power gradually turns on the amass of capital for various reasons. They tend to lose their concept of the true nature of property, but have them on some object itself. This first stage between the labor and capital would be interrupted revolutionarily on the shift of production mode. The 
land is no longer the major basis for material production, but it goes in some other way to alienate the labor from their true beings to more higher extent. They may, in some cases, can hardly appreciate the nature of their labor in terms of the whole picture of society in general. They can be a component of some large plot to be forced in any way. In the course of development, the capitalistic interaction would prove themselves by sky scrapers in New York and materialistic welfare of the large base of society. Some radicals, who focus on "inter-human context," raise their voice of violence of the working class to sever fundamentally between the eradicable ground of human greediness and the exploited working class. They use the word "exploited" rather than "losing," which means a complex nature of this problem posited. We perhaps never lose to look back to our reality in some imaginary ancient context. We eat meat and drink wine if we are not a farmer. We use an automobile if we do not know of any iron making process. It might be true, however, if we are exploited.

Their theory would, at some point of time, be viewed to correctly point at the nature of problem if the struggle shows an inhumane consequence. They fought to expand their cheap provider of production components, labor or natural resources, and to market to sell their final production. They exploit a boy labor in abusive way, which could well sensitize. The "theory" was experimented to turn into "practice," as we are friendly with the title of course readings coming from Burke. Ironically, however, the success of working class violence occurred in the largest but less capitalized countries. An ideological discourse turns to phase other dimension over the existentialism or phenomenological narrative about our reality. The post modern dialectic flourishes, but with the criticism of less persuasion and clarity. The critical theory, or post structuralist approach gradually attains a power to explain "we-ness" and social constituencies (Horkheimer, M., 1975). In other dimension, the capitalist theorists deplore the market failure that they could not properly address the dynamics between the production and consumption. Their discourse seeks to find some of humanistic paradigm, such as noblesee obligee, benevolent capitalism, or social entrepreneurship, and so.

\section{3-1. Some Assumption: Leadership, Organization Change, and Social Change}

In the context of contemporary intelligence, we need to have some assumption among the leadership, organization change, and social change.

First, the leaders and followers are commonly science adhering way of thinkings, in which we are enabled and even forced into some kind of "human sicentia." That tendency is particularly prompted given the informative era intensified recently. For example, how could we imagine to read the e-journals or e-version of New York Times in the past decades. Second, the "soft and hard" nature of dichotomy can properly address the cultivation of intelligent circle to share more easily. The soft power seems pivotal to raise the competitiveness of modern organizations, and generally plays for boosting some open and socially interacting leadership or organization. The hard power symbolizes the "property concept" of our understanding while the soft power can allow the enterprise to be "socially more adaptive." I like to use the word "allow" since a major of soft power may still bears on intellectual property or business secret and so. The hard and soft nature dichotomy can also be found in the province of law. A social norm, if in the context of our basic living dimension, often is hard in nature as the government goal is viewed as limited as preventing a theft and defense against foreign aggression. That is a hard law to be respected seriously, and should be punished if breached. A soft law now shores up immensely to guide us intelligently and 
inter-humanly. This, therefore, tends to increase the nexus between the organization and social change.

Third, the organizational concept tends to be democriticized to effect on social change (Karp, T., \& Helg $\varnothing$, T., 2008). Aspects of consideration reinforce this hypothesis. The biological concept of organization, as we learnt, serves to make it to be open, evolving and socially interactive (Burke, 2011). Many of softness concept expands a horizon from the control and efficient management toward being interactive and mutually influential. The concept of leader is defined flexibly to adjust, and the followership and leadership are inseparable to address the organizational issues. This brings the start of social dialectic, which later turns to be more intriguing and multi-dimensional dynamics.

From Amsterdam, we had an enlightening grasp about the nature of current organization (Hicks, G.R., 2010). I would see the dialectic plausible to address our status of organizational life. It allows more of lesson if the Holland is a pioneering state to any shape of modern corporate paradigm. Nowadays, how do we manage of our time within the organization. Would we be pressured to be dismissed over most of our times? Rather, many of us would perhaps have a great time of internet pleasure. We are shielded from the labor law on working hours, maternity leave and annual holidays. We have a time of leisure for the weekend. We have time to meditate, and the society evolves on more intelligence basis. We see the lectures of open university on-line, and e-learning is now a popular concept hard to resist. We are followers, but also leaders, at least in the context of social change. The democratic power base is no longer the bourgeois' only, now the larger basis of working class are enlightened and empowered to see their organization more objectively. The typical leadership may be principally concerned the bourgeois' narrative with the rubric of leadership. That would not exactly the case the contemporary organizations face. Many organizations now well go on if with the sleeping boss. In some sense, the organization may be theirs, who know the most of it, and thinks to concern about its future (Reymers, K., 2004). Nowadays, CEOs may be more likely the owner of corporation rather than a major shareholder. This perception could turn more universal through the base of organizational members. In this context, I like to propose the word, "social leadership" of contemporary organizations. If we are asked to think the leadership and social change, we normally have ways of response covering the kind of social role of enterprises. Beyond them, the social leadership looks seriously at the dynamics of institutional and social change(Hickman, G.R, 2010). They are inseparable if we see the truths of our subsistence. We are consumers, local residents, and parents through the many of our generations as well as organizational members. Who can guarantee if mass loss of lives, like the Bhopal leakage of fatal chemicals, would not occur in our neighboring factories? Why do we have to tolerate the grey sky of early morning which the climate change has brought. Who should pay for that unpleasant living conditions?

\section{3-2. How We are Routine? : Leadership, Organization and Social Change}

For the teacher of Amstelldam, the social leadership can be classed as radicals and reformers (Hickman, G.R., 2011). They may be intramurals within the organization, but also can be largely tellable and cooperable with the outside networks. The outside network can be voluntary association of consumer or environmental groups. They may be governmentsupported women association. They may be NGOs, most eventualilzed creature to act on this direction. Let us turn to the beginning about the property interest. The boys might like to see 
some of monumental built-ups, but he might see, over some course of time, it make him be alienated from more socially justiceable and cultivated minds.

Ironically, the size of organization seems a workable factor to influence the dynamics. The article delivering the leadership of US government is interesting that the government leaders are very benevolently situated to mediate the long-term consequence of policy (Smith, P., 2004). This implies that the government leaders can be more idealistic and enduring to get through the sublime ends. That is less case of for-profit organizations. Sam Sung, a Korean conglomerate, however, is socially working to take a part. They raise the poor students to learn, and their research institute hire many economists, who are minded for all scope of Korean economic problems. They are one producer of economic knowledge basis to support the nation. Bigger size organization usually find their ways to expand into a social dimension, if party though.

Small or mid-sized firms may not turn their sigh to the social change. They may actually be squeezed to meet the terms of bank finance, or think about the imminent survival strategy. What is microcredit in the Indian context of corporate leadership? That serves two implications in terms of the transformational leadership and social change. The leadership concerned a social dimension by deriving the key concept, SHGs (Hickman G.R., 2010). They are social, but also be pivotal to make a restructuring success on economic terms. Hence, we can see that the social change, at some extent, can and needs to be bewildered to address the specific change needs of organization.

\section{Social Change, and Its Environment}

If we talk about the social change of organization, the most plain way to approach is to look at the mission statement the organization pronounces to the organization members specifically and the public at large. They may contain many beautiful words to define them, but it is soft to be substantiated by the continual process of constructive interaction (Lassey. W.R., 983). We have perhaps less chance to see the mission statement of small size firms. As it often is highlighted, the small firm is the basis of national economy and offers a useful paradigm of organization studies. If not strategically addressed, the waiver of mission statement is less desirable in terms of social network with them.

As mentioned, the society and organization culture would gradually increase the span of sharing (Hickman, G.R., 2011). The most critical factor to drive this interactive complicacies would be advancement of person's intelligence and science adhering way of approach. We may be inspired by any charismatic leadership as a whole, but the way of action would normally breaks down into intelligence and scientific argument. For example, President Obama may lead charismatically to stress the social change (Seyranian, V., \& Bligh, M., 2008)., but the action plan to accomplish it is on intelligence and science. The leaders and administrators, high and middle ranks, also may outlast the leadership of former administration, and they could be more of ideological pursuit (Smith, P., 2004).. Informatization, educational role of government, democratization of society generally provide a prime force for the social responsibility of organization along with a new millennium enlightenment of human intelligence and science.

\section{4-1. Two Trends of Social Change}

The trend of social change within the organizational purview needs to be viewed in several elements. I like to pick up two of them. 
First, the for-profit and nonprofit concept seems clearly operative to look into the nature. A non-profit organization would more prominently give their focus on the social role of organization. A for-profit organization gradually turns to be on more social concept, and their view between the organization and social change has some of intermixed nature between the profit and general goodness of society. Ben \& and Jerry's ice cream adventure, and restructuring plan of the uncompetitive microcredit bank business in India shows that kind of mixed dynamics (Reymers, K., 2004).

Second, the social leadership, as I introduced previously, has grown to rise that the organization and leadership is no longer viewed as monopolized by one top manager. We may properly calculate that there are radicals and reformers to concern their and organizational social identity. We-nees and enhanced form of sharing can be possible where the organization change is the kind of collective product (Hickman, G.R., 2011). It may not be planned or implemented, in its whole, by the top-down approach or trickledown effect. Their tactics and phase of social change, as taught by the Amsterdam scholars, could also be simulated in a paradigmatic way (Hickman, G.R., 2011), but which could be applied on a case and case basis. This kind of social leadership would be understood in line with the larger network of influence and cooperation. We can see many voluntary associations to claim a social justice and responsibility. The group of anti-nuclear power plant can be one example. It may operate in network with NGOs. This kind of out-of-organization association would be a major player of social movement (Hickman, G.R., 2011). The social leadership, in terms of organizational purview, further can be viewed more enhanced to influence the structure more practically. The inside members of organization can be conscious to bring a kind of social change to get it improved. The government also plays a positive role to push forward the social mission by providing an encouragement or other ways of support. For example, Korean government exempts the tax duty for a certain category of donations and givings. The minimum wage is warranted in ways of hard law, which is one of crucial achievements in the modern corporation paradigm. Now over a scope of various organizations, dealings seem to depend on the member leaders, who could be to realize the social good. That goodness is confirmed and supported by the government and also largely by the mission statement of that specific organization. The problem would seem to lie in the dormant practices of our routine days, who would usually not wake up to be socially responsive or improve.

\subsection{The Context of My Profession with the Incidents as Graced}

As I am in a teaching profession, it would be interesting to illustrate the recent criticism of Elsevier. Elsevier is the largest publishing company of science journals and other educational materials. Their practice of business was recently challenged by a scope of conscious scientists for their alleged failure on business morals. They practiced to sell their journals by tying-in terms across the world. The education institutions have to buy unnecessary journals if they need to purchase some of essential ones. In other cases, they offer a high rate of subscription fee, which is virtually forceful given their market status of monopoly or oligarchy. The consumers have no way to confirm that they reimburse an adequate ratio of income to the authors of journal article. If the nature of business is of heavily public and social service, this practice deserves a public criticism. The consequence from social reaction is not negligible in this case, and Elsevier had to adapt with a portion of restructuring. Paradoxically, Elsevier is an Amsterdam based corporation, which is the original country of modern corporate paradigm. The librarians and conscientious scholars concerned in this affair 
could perhaps be a member of social leadership, who are conscious and awakening. They are most minded and know better than others to bring the social change between the publishing company and its subscribers. They are weak to compete the larger company, and being actually an extreme minority given many dormant researchers and scholars. They stood to restore the Elsevier to comply with their mission statement if any.

Other example may be drawn on some of my colleague professors. Hong-yeop Choi and Young-rok Lee, both are a graduate of Seoul National University, and have taught the labor law and legal philosophy in our college for over ten years. They are close friends, and I have gotten to know their some kind of coherence on their attitude of social leadership. Choi is an active member of environmental movement to oppose the nuclear site program. Since Chosun University is a public institution, we see some of socially responsible program and activities. Choi would be, however, exceptional as a most enthusiastic participant to address the environmental challenge in interaction with the nationwide network of college professors. He is a participant for the network, but also a leader to mobilize the professors and concerned staffs in the focused context of CU. So the paradigm between the "member and out-oforganization activists" can properly apply to the behavior of Choi. It would be correct to see him as a reformer than radicals. His tactics and ways of approach, therefore, have largely been in comport with the topology of classification. Young-rok Lee also a catalyst reformer to bring a social change within the college. His pilot role to subsidize the fund for the poor students shows how a small initiative can invigorate the morale of organizational members and upgrade the nobility of organization. We regularly give five dollars monthly from our salary, which now is a fair amount in savings. The government is usually a supporter to promote a social change (Kriel, P.G., 2010). The laws of enhanced nature recently provide an incentive and penalty system to enforce the enterprise to comply with the environmental regulations. Of course, that is not always the case if the nuclear site is an indispensable agenda for the government. 


\section{References}

Conrad, C.R. (2011). Organizational Rhetoric, Polity; 1 ed. Malden: MA

Kriel, P.G. (2010). Leadership and Social Change. Xlibris.

Horkheimer, M. (1975). Critical Theory: Selected Essays, Continuum: 1st ed. New York: NY.

Lassey. W.R. (1983). Leadership and Social Change ( $3^{\text {rd }}$ ed). Pfeiffer \& Co.

Martino, J.P. (2010). Resistance to Tyranny: A Primer. CreateSpace Independent Publishing Platform. USA 


\section{Chapter X. The Case Studies : Chosun University and Chancellor Chun's Leadership}

\section{Introduction}

\section{1-1. Description of the Institute}

Chosun University (hereinafter CU) and its leader Ho-jong Cheon are dealt within this final project. I will describe the nature of leadership, organization change and evaluation of his leadership (Keohane, N.O., 2006). I chose them because I worked there as a professor since 2005. I began my teaching job as an associate professor of law, and the university launched a plan to prepare for the law school project Afterwards, I have served a full-time professorship, and have taught the international, constitutional, and common laws. In 2010, I promoted as a professor and was guaranteed of statutory retirement age. In this backdrop, the university is well known to me. Additionally, Kwangju, the local city in which CU is located, is my hometown where I lived until I was ten years old. Eight years for my service is not short that I could properly look into the nature of organization as well as the context of leadership and followers. This enabled me more intimate research, and I believe that it offers an experimental subject for the organization studies. It generally has common traits as with other non-profit organizations, but there are some distinct points for lessons. The following summary needs to be premised in understanding and appreciating my work.

Historically, CU has been nationalistic in strong sense. This characterizes a basic spiritual ground on which CU now stands (Keohane, N.O., 2006). Being nationalistic would not be the same as before. We, in this liberal times, may connote a negative sense in some aspect. That may be misunderstood in conflict with globalization or liberalization. The context, however, should not confused with $\mathrm{CU}$ history if nationalism had been created to oppose the Japanese emperor during 1910-1945, and since it has a keen nexus with democratization of Korea around 1980's.

In characteristic of organization studies, we consider that $\mathrm{CU}$ is a higher education facilities. It is non-profit organization and has the goal of teach and research. Their function is to educate the college students and produce a scholarly work to serve the public (Keohane, N.O., 2006). CU is a private university, and keenly affiliated with local community. The academic strength is modest, and large to have more than 900 instructors including a full time professorship. CU, located in southern part of Korea, is a private institution, and regionally competes with Chon Nam University, which is a state university.

In cultural factors, CU is distinctive in that a school policy is liberal. This is proven that it has an independent faculty board interplaying with the university administration (Hendrickson, R.M., Harris, J.T., Dorman R.H., 2012). CU members, i.e., students and faculty, would favor the social virtue and justice, and in some cases they place those higher than the academics (Sagnak, M., 2010). One note needs to be given that CU was one of national heart for the student activism during 1980's. The times underwent a political turmoil. CU is housed in Kwangju South Korea, the city of democratic sanctity. An initiative of students is influential along with this history, which see them important, nationalism, democracy and sovereign independence.

The management of CU is relatively stable, and the board of regent partly support a financial need (Hendrickson, R.M., Harris, J.T., Dorman R.H., 2012). As the situation goes tougher, the financial prospect is little pressuring. The size of student body and faculty, as well as educational performance has gradually increased in the national and regional context. 
A highest priority for Cheon's tenure would range a globalization, capacity building, increase of local cooperation and academic performance, and restoring the board regime to normal governance.

The circumstances, culture, and social cognition of CU members share the major characteristic that the higher education generally possesses. It is meaningful to know, however, that CU members are distinct in several points. They are highly democratic on one hand, but have some sensibilities from the long tradition of political minority. Kyunsang-do is larger than Chon Nam and had dominated the Korean politics. It was the region which produced many presidents. The only president from Chon Nam is Dae-jung Kim during about 60 years democracy in Korea. He is a Nobel peace prize winner in early new millennium, and highly respected from local people. This complex history affected the culture and passion of CU and its members. This aspect involves the issues on identity, inclusion and social activism, and generally fosters a collective action to mobilize and relates with the participatory paradigm of organization and leadership. The Association of Alumni and local politics are a critical player to lead CU, which the formal leadership could hardly keep in distance from its power and influence

\section{1-2. Who is Ho-jong Cheon?}

Mr. Cheon has been a revered campus leader, who served as a chancellor since 2007. After his first four years, he was appointed by the board as a second highest candidate in 2011 election. Two highest candidates were recommended for the approval of the Board of Regent. Upon the recommendation, the board conducted a stern review and examined their qualification, competence, ethics and other factors. It is within the sole responsibility of board to appoint for tow nominees (Hendrickson, R.M., Harris, J.T., Dorman R.H., 2012). One day interview was rigorous and considerate. As it turned out to prejudice a new highest candidate, the students and professors later rose to attack the illegitimate and undemocratic unilateralism. He eventually stepped down in the spring of 2012, facing the active antagonism of students and professors. His leadership for six months of second term, in my view, had been faithful and loyal, and fall well within a fiduciary duty and trusteeship. But the view of other CU members has been split as later briefed.Upon his resignation, new chancellor, Jae-hong Seo, took the oath for his four year terms. Generally, Cheon is deemed a successful leader and left a generous impression. He accomplished several major achievements.

Cheon is a scholar chancellor as a pathological researcher. His scope of engagement as well as rich career is impressive (Bowen, W.G., 1998). He is a graduate from CU, and also performed his graduate work here, leading him to earn a MD and Ph.D degree. This keen relationship with $\mathrm{CU}$ has pros and cons in evaluating his leadership. The history of chancellorship shows that CU has any more alumni chancellor than other universities in Korea. The current chancellor, Jae-hong Seo, is also an alumnus of CU. This helps to shape a typical of campus leadership, which positively affect in some dimension, but negatively comes in other context. In its leadership culture, this affiliation would bring a keen interest of hopefuls, generally working to breed their ambition as a campus leader (Bastedo, M.N., 2012). Because of this, they are more communicative to fellow professors, more mindlful to spend much time on campus issues. He was a competent researcher to study overseas as a visiting professor. His career path in $\mathrm{CU}$ is also brilliant. He took the responsibilities for the director of Radiation Center and served as an Associate Dean of medical college and later as a Dean. His leadership goals are five in major, which are represented by the plan of "Pride of Chosun (PC)." We can say them in short initials MBPWH; "Management Innovation, BuiltUp of the Financial Base, Production of the Global Elites, and World Renowned CU, and 
Happiness of the Campus Members (CU Brochure, 2010)" Many awards and research grants conferred on him evidenced his superb scholarship, which are usual over other cases of campus leadership.

\section{1-3. Literature Review}

\section{1-3-1. The Context of CU and Literature Review}

In understanding Cheon's leadership, we require to review the traits, characteristics quality of leadership. This aspect involves two ways of approach in general scholarship of leadership and the particularized context where the institution is a higher educational facilities (Bowen, W.G., 1998). CU, the institution of this final project, is a local university located in Kwangju, South Korea. Hence our analysis needs to be complemented with more specified dealings exclusively devoted to the academic institution. The literature review on this focus would, thus, be comingled with those of general nature. Cheon's leadership, as I described, is basically transformational and the quality of leadership is at a considerable extent, highly charismatic. That could be present from various reasons, but the nature of organization and his status as a top leader would be viewed most a factor (Bowen, W.G., 1998). That being said, his leadership is less transactional where the "give and take" concept or managerial role of leaders are mostly less probable or delegated to the lower ranks of bureaucracy. It needs to be transformational if the society is highly globalized, diversitydriven, and technologically revolutionary. The demand is pressuring. Since, the academic institution usually meets the challenge to correspond to this change demand. The leadership also concerns moving forward the innovation, reform, globalization, inclusion, and so (Bowen, W.G., 1998).

As would be revealed, CU critically depends on the community in terms of social and institutional reproduction, and on the network to develop the common venture of prosperity (Bowen, W.G., 1998). The region is democratically sacred, and the culture is highly shared in common disposition by both local and campus people. They are cooperative and networked to interact. In this context, his leadership can be properly evaluated by reviewing the articles dealing on this context. The ethics issue in his leadership is partially relevant by assessing the second term of his tenure, which is just about six months. The context of this short period, however, allows us to assess his leadership correctly. Campus people generally possess the high intelligence, and favor the democratic virtue and process. His leadership, therefore, could not exceed the ceilings which prevalent members participate to keep up with. Therefore, it is helpful to review the literature shed on this light. There are currently a stack of research to address the shared or participatory leadership, or democratic value in the organizations and leadership practice. During his tenure, most of his urgency is to increase the organizational competence to academically advanced status (Bowen, W.G., 1998). This is inextricable for CU to survive the hard challenge in the new millennium. Goals and vantage points for the developmental strategy were clearly defined, and communicated to the followers. The feedback mechanism, for the purpose of evaluation and redirection, was made prepared. The goals and tactics are grand to control the aspects of academic focus. Most central along with this adventure seems it to lie in the improvement of research performance.

\section{1-3-2. A Paradox of Participatory Leadership in the Modern Campus}

About the pros and cons of participatory leadership, Kezar A.J. offers a succinct understating within the community college (Kezar, A.J., 1997). Generally, the leadership 
discourse was bifurcated between the traditional hierarchical and participatory or shared mode. The typical dealings would employ both to see the complicated nature of leadership. The traditional hierarchical views are inevitable and reveal the truth of leadership practice. They generally concern the hereditary traits of leader, position power, patrimonial ethics of organization, and coercive understating between the leader and followers, and motivation or empowerment, and so on. The participatory or shared leadership is salient over the contemporary understanding of leadership and organization change, which has been endorsed by scientific evidence about its merits. In exploring a new avenue for the leading community colleges, Kezar argued on a specific application of participatory leadership in the context of community college (Kezar, A.J., 1997). For him, the leaders and public have a general perception about the small impact of traditional hierarchical models. That is true since the community college is usually open, liberal, and exposed to diverse elements on race, sex, ethnicity, social class, and so. The diversity brings multiple ways to behave and some topdown approach or power or influence-driven way of leading would not fit in general. Interestingly, however, participatory leadership is not a clue to resolve this dilemma, which differs from our gut reaction to favor (Kezar, A.J., 1997). This model lacks the critical role of positionality at the core of traditional concept, neither responds to the need of multiple definitions of leadership. They just see it undemocratic or improper. They also neglect the flexible nature of power conditions on and off campus, which is honestly essential and can address the particularized condition of community college (Kezar, A.J., 1997). This hypothesis actually yields another type of dominant culture within the campus in the mask of "participatory or progressive," which is one of fault lines in the traditional hierarchical leadership (Kezar, A.J., 1997).

\section{1-3-3. Identity, Inclusion and Democratic Values within the Academic Institution}

Portela's view is seemingly pertinent to understand the leadership role in the academic institution (Portela, A., 2011). We note that the identity, in the contemporary discourse, plays a central concept over various disciplines. It is lacking, however, how the leadership may function to shape the identity of organizational members. The concept of identity also is keenly related with the school inclusion (Portela, A., 2011). The built-up of identity and inclusion of members are typically prevailing if the leadership focuses on the psychological and spiritual domain of organizational members. As mentioned, CU and local community experienced hard times of democratization, and incurred a loss of many lives. It was designated a sanctity parish for the people of Korea. This is strengths in much aspect, but needs to be revisited for the weaknesses and improvement. For Portela, identity means a difference, and is often understood as a core aspect (Portela, A., 2011). It is usually invoked to something allegedly deep, basic, abiding, or foundational. It includes two senses covering personal and social. The important point, however, is that it could be shared. Inclusion presupposes an identity construction, and the school leadership can influence much in the process through the identity construction and inclusion (Portela, A., 2011). Portela argued three tiers of level in which the authentic school leadership plays to interact (Portela, A., 2011). Those are "individual, group, and organizational." For the school leaders, he argued that the democratic citizenship is basic and fundamental to perform successfully the leadership goals of identity construction and inclusion. For Portela, the nation state is site that the democratic citizenship can be found (where) (Portela, A., 2011). More importantly, we need to respond to the question of what is democratic citizenship (what). On this point, he suggested that it has a subjective meaning and takes some form of social membership (Portela, A., 2011). It does not exclude the formality citizenship, but the true context of democratic 
citizenship promotes the experience of members and activeness to participate. This context has more nexus with the social membership concept (Portela, A., 2011). More idealistically, the transformative citizenship could bring the members to encourage the value, moral principles and ideals. It upstages the active citizenship in which the members adhere to respect the existing laws, customs, and social practices (Portela, A., 2011).

\section{1-3-4. School Leadership, Shared Understanding and Emotion of the School Members}

To look into the deep nature of academic institution, we need to have some ideas between the school improvement and school effectiveness. B. Beatty argued that holistic school renewal requires a qualitatively different discourse around the crucial concepts, power and authority, and readiness of followers (Beatty, B., 2007). In this context, emotional attunements play a critical role to progress on shared understanding and emotion, which the leadership has to serve. This concept and approach essentially involve all leaders as well as the top leader, the principal for Beatty's case (Beatty, B., 2007). A most adverse factor would normally go to easy views of performance-driven organizational studies. The traditional notion about the power and authority should also be revised to infer the true context of organization change. The peril of performativity would less be connected with our conventional sense, such as objective or tangible elements. The increased pressure of performativity is now usually an environment that the school members now face. It is a technology, culture, and mode of regulation, and the performances, which usually work as measures of productivity or output, or displays of 'quality', or 'moments' of promotion or inspection (Beatty, B., 2007). They often offer a critical light of viewpoint to understand the organization and leadership. For Beatty, the Weberian concept of depersonalization would promote disconnectedness among the members and bring the peril on its basics (Beatty, B., 2007). It requires recasting the traditional understanding of key concepts such as power and authority. The alternatives may be found, but very powerfully, in the emotional aspect of school members, which essentialize the focus on moment-to moment emotional attunements.

\section{1-3-5. Leader and Manager Exchange (LMX) and Resistance of the Followers}

In understanding the follower's resistance and strategies to grip its nature and address the challenge, two articles gave a helpful insight to look through the organizations in general and CU either. One article draws a critical correlation between the resistance of change and leader-manager exchange (LMX) (Furst S.A. \& Cable, D.M., 2008). The leaders generally utilize many tools of managerial influence in order to combat any employee resistance against his change plan that he intends to implement. Most extant research show how each tactics could affect the extent of resistance, but the author saw that there is no scholarship to connect the factor of LMX with the extent of effect that the tools can make. D. Cable, in his article, employed four types of managerial influence, which include a sanction, legitimatization, ingratiation and consultation (Furst S.A. \& Cable, D.M., 2008). They tend to show correlatives with the level of resistance to the organization change. Another variable, LMX, also shows a strong correlative with the level where the high LMX increases the effect of tools, in all scope (Furst S.A. \& Cable, D.M., 2008). The low LMX would, in general, saw a contrary consequence to reduce the effect of each tool (Furst S.A. \& Cable, D.M. (2008). This finding conveys a sensitive message that the change leader should maintain the high LMX to increase their strategic ways to countervail the follower's resistance. 


\section{1-3-5. Leader's Characteristics and Resistance of the Followers}

S. Oreg also presented helpful views between the leader's characteristics and follower resistance to change (Oreg, S. \& Berson Y., 2009). While the leader's primary concern would be on the resistance or turf situation in the process of change, the article guides much lesson which the change leader should have deep awareness of. In this article, the author saw that most macro studies of organization change focused on the follower's reaction, and that little attention was given to the leader's side (Oreg, S. \& Berson Y., 2009). He argued, however, that the value and behaviors of leader are a critical element to affect the attitudes of follower whether to follow or resist (Oreg, S. \& Berson Y., 2009). Based on his empirical studies concerning 120 Israel public schools, he demonstrated a crucial relationship between two points of interaction. The leader's value, behavior, and transformational quality interplay with the extent of resistance. In his findings, the leader's conservation value operates negatively while his openness to change plays to reduce the follower resistance (Oreg, S. \& Berson Y., 2009). A leader's dispositional resistance to change is positively correlated with the follower resistance (Oreg, S. \& Berson Y., 2009). The transformational leadership generally moderates between the dispositional resistance of employees and their resistance to a specific change (Oreg, S. \& Berson Y., 2009). This result would help to understand many cases of organization change in our surroundings.

\section{1-3-6. Charismatic Leadership and Herb Kellerher's Case}

As Cheon's leadership is charismatic on its basis, the analysis and application of the leadership to Herb kellerher and the Southwest Airlines would offer the paradigm for the Cheon's case. That is particularly meaningful if the current university and CU are facing a hard condition to reform and improve. Thorough the sections, Gibson and Blackwell provide the classic conceptualization of charismatic leader, their traits and behaviors with the summary of key points (Gibson J.W. \& Blackwell C.W., 1999). They finally apply their framework to Herb kellerher's case over the vision of how to make or do things better and self confidence of his ability (Gibson J.W. \& Blackwell C.W., 1999). The author utilizes the lens of their framework, that derives his leadership elements; high communication and articulation skills, high level of energy, enthusiasm and willingness to work hard. He also found that Herb Kellerher always was minded to behave as a role model for his followers (Gibson J.W. \& Blackwell C.W., 1999). He dramatized the vision and encouraged the follower's commitment. The leadership also demonstrated an empathy and sensitivity to the follower's needs. His strength to lead the Southwest Airlines are not limited, but included the followings: projects self awareness and treats the followers in respect and attention, projects competence and success thereby increasing his own image, empowers the followers and assures them of their competency, provides the followers the opportunity and make them experience the success (Gibson J.W. \& Blackwell C.W., 1999). All these leadership behaviors demonstrate the traits and behaviors of charismatic leader, which the authors argue powerfully to evaluate the Herb Kellerher's case and also with a fine match for their framework.

\section{1-3-7. The Transformational and Transactional Leadership in Higher Education}

As the transformational leadership dominates on the campus leadership, it is required to distinguish between the transactional and transformational ones (Basham L.M., 2012). This does not mean that the transactional leadership needs not be employed. In some context, 
the leaders of higher education find it properly address their need of organizational management. Basham argued that the leadership of higher education meets the challenge and the change leader needs the qualities to make a climate of change (Basham L.M. (2012). The element of quality leadership is found at every level of functionaries, and may frame across the group and individual context. They are relevant if the unit influences change and positive outcome can be seen as quality leadership. Within the group level, the author pointed out five factors, which include a shared purpose, collaboration division of labor, disagreement with respect and learning environment (Basham L.M. (2012). The individual level also incorporated five elements; commitment, empathy, competence, authenticity, and self knowledge. According to the author, transactional leadership plays on exchange, and garner, as a prime tool, contingent rewards and management by exception. For our thesis purpose, three points seem pertinent. First, the comparison guides them distinctive. The transactional leadership is usually entered for the status quo, and works on the give and take basis. But transactional leader also has to respond to the change needs of followers to be effective. Transformational leadership, on the other hand, looks deeply into the personal value system (Basham L.M., 2012). The leader and followers share a collective ambition, and promote performance beyond the expectations. The core concept of this leadership, therefore, values charisma, consideration, motivation and stimulation (Basham L.M., 2012). Second, ten elements illustrated for each of transactional and transformational management are helpful to analyze the Cheon's leadership style. For example, the transformational leader provides a clear sense of direction and purpose with long- term vision. The transactional leader devotes time to communicate the organization's vision, purpose and values (Basham L.M., 2012).

\section{1-3-8. Fostering Shared Leadership}

Cheon emphasized the role of shared leadership and participation of members. This requires to see some of practical lessons from the article "fostering shared leadership." In this article, T. Wilhelm began with Edward VIII in 1933, and can give an insight about the principal and teacher's role in high schools. He presented three theses to foster the shared leadership. They are (i) creating significant achievement goals (ii) importance of being the learning leader (iii) principals of being the learning leader (Willheim, T., 2010). His case, drawn from the studies of the California School Leadership Academy, goes with a testament to the power of shared leadership. Though many responsibilities are confidential with the principal-ship, the mid-continent research for the education and learning also corroborates the definite effect of shared leadership in certain areas (Willheim, T. , 2010). A sharing and learning, therefore, center at the core of his proposition. For the teacher leadership team, skill development and discussion opportunities among the participant teachers play a key role, yet the role of principal is also essential to develop leaders (Willheim, T., 2010). Wilhelm also saw that effective principals are responsible to be aware of the situation posited (Willheim, T., 2010). The situational awareness is pivotal for success in major changes, which leads the followers into the second order implications. This concept leads, then, to his conclusion that the shared leadership becomes the norm for all schools and can bring a dramatic change for students outcome. One point is appealing from his sayings, "a principal lacking courage will find ways to avoid addressing unprofessional behavior, bringing swift death to his teacher leaders' belief... “ (p. 24). Also is helpful it to list some of reflexive questions that the leaders balance his leadership to effectively and appropriately build the shared leadership. For example, the question, "What criteria do you use to decide when to be more or less directive?" may apply to see a Cheon's behavior over the law school project (p. 38). 


\section{Methodology : Interview with the Former Chancellor Cheon and Participants}

This research will be conducted through an interview with the former chancellor, Cheon, and concerned people of each episode, and relevant sources of the university record will be reviewed for useful information. Upon the feedback of interviewee's response and literature information, I will be able to evaluate his leadership and effect on the organization in responding to the challenges, and will hopefully find a bit of lessons for the contemporary context of CU.

I made five contacts on Mondays in the weekly interval from Dec. 21-Jan 25, each for three hours in his office at CU campus and the second one half hours in the nearby restaurant in Kwangju city. Interviewees other than Cheon was conducted two occasions on the first and second day of Febuary in the Café of the Global House located at the northern Campus of CU. The interview ran roughly three hours on each occasion. Before conducting an interview, I gave a standard of interview. I also advised to respect the interview ethics and asked for the interviewee's cooperation in order to obtain true evidence to prove the thesis. The process was completed based on the guidance of qualitative research at the first meetings, which were held four o'clock, Dec. 21 in the Cheon's office and three o'clock in the Café respectively. Cheon's office was located in the college of medicine of CU since he is now a former chancellor and returned to the college.

Relying on the general guidance of interview, I involved a face-to-face meeting and asked a series of questions which were prepared to address each research question given about this final project. I tape-recorded the interview process, and that later formed a basis for the summary to deal with the description and discussion required of this final project. I fully shared the series of questions with the interviewees. The advice was kept seriously that the interviewer should not be afraid to ask questions if they arise during the interview, but are not prepared. The exact transcription is important after the interview which works to prevent any perverted miscarriage of original message. By replaying the interview and sharing with the participants, I double checked the accuracy of note summary.

The interview method, in the context of scientific research, is required of several elements which the researcher should respect to keep up with. They are a completeness, accuracy, confidentiality and avoidance of bias. Through the interview process and its summary, I did my best to abide by the general instruction. For example, I employed one assistant to confirm if he can get a clear and correct picture of what was discussed by reading my note summary. In order to prevent a bias, I have taken a care not to add any presumption or assumption, and got beware if I correctly collect what I have observed.

\section{Description and Discussion of Cheon's Leadership}

\section{3-1. Leadership Style: How Do We Perceive the Charisma of Chancellor Cheon?}

For understanding his leadership style, his personhood needs to be briefly described. $\mathrm{He}$ is tall at height, looks calm and handsome, but evokes a bit the feel of tranquility and meditation as if requesting a deep concern about the matters which the leader and followers would share (Eeden, R C. F. \& Deventer, V., 2008). His eyesight is profound, and likely attracts his counterpart to some of esoteric dimension. His tone of speech is low, but steady likely being grounded and being comprehensively settled about a scope of serious CU issues. It seems to prove his concern, research and meditation, firm developmental strategies and 
tactics, as well as long years of faith and commitment as a campus leader.

His leadership style is vision-oriented, which is also inclusive, transformative, and value sharing. The vision was clearly articulated, which could create the dominant minds and attitudes. His communication, deep engagement and dialectic skills as well as persuasive way to lead likely elevate the followers to feel the same identity fused each other (Brito C.E, Vanzin T. Ferraso M. Saldanha J.A.V., 2010). The force of interpersonal unification would seem to bring a set of important organization changes during the time of his administration. His four year vision to guide the campus was presented, as above, in five vantage points.

Practices confirm the type of his leadership as the kind of mixed nature with the charismatic and transformational ones (Basham L.M., 2012). Virtually his every effort was made to acquire a consensus of followers in forming a common platform or value sharing (Sagnak, M., 2010). That is inextricable in a greater sense since his debut as a candidate. The follower's vote was decisive to realize his ambition, and the followers are highly intellectual and critical in evaluating his candidate proposal and enforcement possibility. Therefore, his mind and approach are charismatic from his candidate's speech, and for one month period of election campaign (Gibson J.W. \& Blackwell C.W., 1999). His leadership seems to fit within three characteristics of charisma, sharing of vision, constellation of leader's behaviors, and actual enforcement (Hickman, G.R., 2010). His work history, accomplishments as the dean of medical school, as well as other major social involvements tend to increase his charismatic imagery. The medical school of $\mathrm{CU}$, due to his contribution, has become redeemed and aspired as one of prestigious peer schools within the national context. Its annual revenue serves a substantial part of university budget, which expands over the span of years recently. His manner and content of speech are highly echoing, which enables to convey impressively the clear message to implant the vision and pathways on followers. The image of tall height and smart feature seem reinforcing his leadership role during the election and his tenure years. He created a plan to reform the administrative units in which we are able to find his perspective of organization as the kind of biological concept (Eeden, R C. F. \& Deventer, V., 2008). The leadership is transformational to replenish an organizational efficiency, network, and interconnectivity and management. He sought other effective channels of investment or worked to save disbursement. Therefore, his vision served increasing a negative entropy in two aspects, biological upgrading of organization and saving of unnecessary dispensing. He correctly perceived an equilibrium as the end of organization.

His reform plan is normally innovative to match up with his charisma. For example, he envisaged to introduce sectors of vice chancellorship, who would be four or five other than the unitary or comprehensive vice chancellor. Although his plan was endorsed on his election, but could not realize due to the resistance of interested groups and also for other reasons. He intended to increase the strategic role of planning office, which actually enforced a scope of innovation about mid and long-term development plan.

His leadership also can be found in the aspect of recruitment of high quality professors. He and the followers deeply share this point as much important since the campus organization emphatically depends on the performance of faculty members. As we know, the recruitment bears a share of significance to change the organization, but should not be led to any unethical or immoral context of stalemate or personal misappropriation. For the leadership being sustained, the recruitment of faculty members needs to be fair and most serving to elect a most useful, qualified, and reputed professors. If this kind of important issue were to be questioned, it usually brings a serious consequence to oppose the leadership or to buy the campaign to remove the office of chancellor (Moerschell, L. \& Lao, T.M, 2012). It is because $\mathrm{CU}$ is an academic institution, and the recruitment of professors is generally deemed most important in the Korean practices of academy. His leadership is generally sound 
and ethical provided if there is no case reported for this kind of misconduct. This is despite the high chances if the chancellor is charismatic, powerful or influential. His perspective seemed determined to respect the tradition of past, but invented a special process of summary review while increasing the standard of public recruitment process (Eeden, R C. F. \& Deventer, V., 2008). Over his years, the summary review devoted many contributions to recruit qualified professors.

\section{3-2. Qualities, Characteristics and Skills of Leadership: How Would We Evaluate the Qualities of his Leadership: Trust and Authenticity?}

\section{3-2-1. New Paradigm of Entrepreneurship, and Social Responsibility of Public Authority}

In a deep structure of contemporary capitalism, a new paradigm of entrepreneurship and social responsibility comes within the highlight. The paradigm inculcates the limit of capitalism and new vision to enhance the dilemma as well as to resolve social issues in various contexts. For example, one can find a message in the conflict between the developmentalism and environmentalism. It sometimes surfaces to address the poverty or polarization issues in the society. The paradigm also involves the perspectives of open theory of organization. It is, therefore, ethical or ontological on one hand, but the concept of learning organization was intrinsically entailed inside the nature of dynamics. Social responsibility leads the managers and leaders to have a deeper awareness, which constitutes the deep structure and corporate culture or environment. For illustration, Sam Sung now administers a large scale of student assistance program who are competent and will study abroad pursuing the doctoral studies. It could be ethically true that Sam Sung should support the promising, but economically short students. Sam Sung was raised as a national enterprise, and made a brilliant success. It is desired and deemed right to do that. The students would, in turn, serve the competitiveness of Sam Sung if they return to Korea. This is, on some aspect, a kind of network and interaction with the social base, which are ingredients for the success of Sam Sung. Sam Sung makes it open to interact, which also facilitates on any sound cycle; input, throughput and output for organizational dynamism. This example would increase an image of social goodness and participation not only within the mind of general people but also within the followers inside the organization (Kezar, A.J., 1997). They are more ethically reinforcing, and normal pattern of moral mazes on the patrimonial or bureaucratic concept could be improved. In the future, we may, on trend, envisage the kind of social competitiveness. The concept of social capital or social responsibility might work as touchstone to weigh the competence of society and nation. A north European modality seems to have much say if we think about the classified and enhanced context of developed capitalism. For Korea, it is gloomy that IMD competitive index of nations rated it for $39^{\text {th }}$ place among the whole of 49 countries.

\section{3-2-2. Performance of Socially Responsible Leadership as Trust and Authenticity}

Social responsibility and Chun's leadership are situated in a distinct context provided if the leadership incurs the concern of university administration (Sagnak, M., 2010). In terms of social responsibility of educational organization, I would perhaps be allowed to derive several distinctive points: (i) it is more desirable since the university is supreme intellectual community in general (ii) the financial aspect seems generally moderate between the high 
profit and ill profit organizations (iii) the university stands at the center of social reproduction, which represents the general base of public as if the national military on compulsory mobilization. They are supreme to intellectually lead the country. Their virtue is generally heritaged and maintain its groove on the democratic framework, social congruence, social justice along with other educational ideals (Kezar, A.J., 1997). They are not highly profitable organization generally, but they operate on the stream of public concept even in the financial terms. It is partially a type of charitable organization aided from the government support and other sources of givings and donations. For-profit attributes are just found in tuition, or research income, and some kind of brand sales context such as the licensing agreement with the enterprises. The tradition or culture of academic institution also takes a part to define the extent of social interaction. One note needs to be given if the university operates as heavily locale oriented. This usually positively functions to make the university more socially engaged. As stated earlier, CU has major dispositions in this aspect over their strong commitment to the local community (Morill. R.L., 2010). Both are vitally intertwined to define the direction and ethics of CU.

Other point concerns a social reproduction in the higher education. The college admits annually are drawn in most share from the local youths. Therefore, the community itself are parents and students of $\mathrm{CU}$, and vitally inseparable. One point is remarked that many superb high school graduates apply for Seoul-based universities. It raised a pivotal concern for the policy makers of $\mathrm{CU}$ how to mobilize them to stay in $\mathrm{CU}$ and Kwangju. The situation turns worse if the age group of high school graduates sharply decline in coming years. CU experienced and will do the multigenerational time sequence. It began with traditionalists, and later baby boomers born 1946-1964. Generation X who were born 1965 through 1980 would fall within the group of recent CU graduates, Millenials are relatively small in number, which now poses a serious challenge for the school administrators.

In any case, CU has most elements, in opportunity and challenge, to perform a social role or responsibility, which is actually complicated. His leadership, however, shrewdly snaked through it (Moerschell, L. \& Lao, T.M, 2012). That is mainly successful by means of his charisma and its status within Kwangju (Gibson J.W. \& Blackwell C.W., 1999). They are cooperative financially in some cases, and most benevolent to lead the social moralities in the province (Brwon, D.G., 2005). Most notably, we can highlight the construction of the local center for enhanced livings. It had an important goal to breed the local elites at bottom line. His shared leadership marched to conclude the construction agreement with the financial assistance program for the students. The partnership was enabled by the donations of Kochang county, a nearby county to Kwangju (Simplicio, J.S.C., 2004). Kochang is one of most producers of $\mathrm{CU}$ applicants for the college admission. The Foundation of County stipulated to invest 0.1 million dollars, and $\mathrm{CU}$ arranged to represent its commission by shingling out its contribution and priority assignment of dormitory rooms for the students from Kochang. Many local popularities commended and praised the significance of center construction at the ceremony of donation. The ceremony was headlined in the local newspapers under the title "the university in cooperation with the local community." Kangsoo Lee, the president of foundation gave the words in his interview, "I believe that this moment would signify the cooperative challenge for the improvement of local condition. The local university is an essential ingredient for reproduction and to effectively respond to harsh economic conditions, for example, a high rate of youth unemployment. I desire that Kochang and CU play a pilot role to lead other universities and counties."

\section{3-2-3. Identity and Inclusion of the School Members}


This moment has a scope of implications about the vitality of locale. Particularly, the partnership could prevent a chronic problem of migration outflow (Morill. R.L., 2010). A number of students, who are superb and obtain a high score in the college entrance exam, certainly move to Seoul, a capital city of Korea for more famed universities. This delicate factor was triggered to change by partnership. Lee furthered, "the Foundation was created to meet the poor parents and students to study at the college level. It was founded in 1997, and devoted to support the local university to advance. We already built on 3 million dollars in available funds, and dispensed the total of 0.34 million dollars to 600 poor students." The key is to upgrade the local universities, and the partnership is effective to mobilize the resources and work positively for the capacity building of CU. The partnership, in this context, was designed to boost many special programs, which include the mentoring of poor or home coming college students. It also instituted the reading and writing club shared by parents as well as the extension program for prestigious local high schools (Willheim, T., 2010).

The latter context is exemplified if CU annually visits lonely and superannuated households to make givings and support. The gifts vary and the photo scenes are regularly publicized to spiritually and educationally share with the members of organization and community people.

Do-chull Kim, aged 73, is living alone in the vicinity of the CU campus. He is a focused beneficiary administered in the program for the solo habitant of aged group. The program was enforced by the CU Welfare Center of Aged People (Yong seop Kim, a chief charge under the leadership of Cheon ). A systemic care was undertaken since June 2007, but he was afraid to have a diagnosis due to the economic reason. Upon the advice of social work expert, he was found to suffer a cancer. Do-chull Kim remarked on his recovery, "I was poor that could not pay for the fee of medical operation. The center assisted me to receive two times surgery, and also was provided the free nursing service. Now I recovered and live a healthy life." His social leadership also extended to provide the living necessities regularly during the winter season (Moerschell, L. \& Lao, T.M, 2012). Cheon stated his experience of visit for the aged people, "Around December, 2007, I paid a visit to shabby habitations near the campus. Do-chull Kim, an old man and Duk-rye Myung, an old woman, received my small present, a quilt specially made to warm the user in his bed. Old woman, Myung, was a middle deaf, and subsisted barely in the worn-out solo habitation." Interesting is that the quilt was not bought, but was prepared directly by CU from the small cotton zoning within the campus. Twenty four pieces of additional quilt were provided to old men and women, who livie near the campus. The cotton zone was raised by Cheon's initiative and financed also by his private funds. It occupies the site between the nursing building and subsidiary high school of $\mathrm{CU}$, and its exotic beauty attracted the campus and local people. It is one of two products, one of which is the Rose Garden zoned in the similar context. Those are to distinguish him from other usual university chancellor.

\section{What Implications Can we Infer from the Rose Garden In Terms of Characteristics and Skills of Leadership?: Motivation and Empowerment, Emotion of Campus Members and the LMX Factor}

\section{4-1. Shared Leadership and His Participation in the Law School Project : High Level of Exchange}

One of most notable touchstone in understanding the empowerment and motivation strategies would be about the law school project. It was traced to 2005 through 2008, mainly and now forward. As an agenda of upgrading Korea for the globalization, the government 
pursued the reform of judiciary. They thought that the reform of legal education was demanded to model after the US type of graduate school. Until 2007, the law education was based on the European modality, in which the students were educated on the undergraduate basis. If they passed the highly competitive national exam, they promoted to the Judicial Institute of Apprenticeship. It is two years course without an academic degree, and the apprenticeship was principally on the case law as well as the basic forms of court or legal document. Besides, they were dispatched to other major public institutions to experience and for internship. Of course, the ethics and culture of lawyers, and institutional adaptation program was offered. For CU, the law school bidding is pivotal to maintain its status as a major regional institution (Morill. R.L., 2010). For the power dynamics of interested group, the quota of law school was rather limited, and thus it was actually not an easy task to obtain the approval. One of factors in this process was the balance of region, however, that CU should compete with the Chon Nam and Won Kang Universities. A success of bidding, thus, was critical about the reputation of CU. The bidding project was pursued from 2004 by constructing a new law building, and recruiting a practitioner professor. The practitioner professor is one of mandatory requirements. In the process of preparation, his leadership effectively penetrate the core of empowerment rubric (Moerschell, L. \& Lao, T.M, 2012). Particularly, twenty four law professors were perniciously influenced by active engagement of himself, but he kept in stance to defer to merits of professional perspective (Polizzi J.A. \& Frick W.C , 2012).

He effectively led the point of strategy, but delegated the role or commission required in the context of law school. Therefore, he perceived an empowerment and motivation as important, and lynchpin of dealings was to build the trust-ship and authenticity. As I described earlier, his personality and deep understanding of organization did not permit him to rest within the deep arm chair. He was active, transformational, and lived as well as loved paradigm of CU tradition (Basham L.M., 2012). He was culturally maturated to mobilize the members to share the organizational goals. His appearance, manner, and speech or written message was charismatic, but integrative to be visionary (Gibson J.W. \& Blackwell C.W., 1999). For the law school project, his long years of engagement in medical school much contributed to create a shared leadership (Moerschell, L. \& Lao, T.M (2012). The leader and followers operated in a similar intelligence and expectations. The medical school in Korea was also reformed in the same manner about the years ago. The conditions and qualities of his leadership seem favorable given this congruency. I noticed that the chance of "Bogus empowerment" would be, at extent, diminished under these conditions. He likely acted to have a great awareness of our situation, and motivated effectively to increase our followership.

A readiness of followers was ensured in his guidance surrounding the success of medical and dental schools. He also employed the tools in the context of path-goal theory (Hickman, G.R., 2010). The university administration instituted a separate system of incentive to hire the revered and esteemed practitioner professors. They were crucial to move forward the project not only because they are statutorily mandatory, but also because they could help with lobbying and creating an impression of any superb law school hopeful. Three thousand dollars additional compensation, and special benefit for the sabbatical or other context, were introduced to address the situation. The followers should be viewed, in this case, to well know the nature and quality of their engagement. They were mostly senior professors teaching and researching, and had career years on the department or university administration. New hired professionals were an expert of project on many court litigations and law firm management (Polizzi J.A. \& Frick W.C, 2012). Therefore, the capabilities element in the transactional leadership paradigm should be unequivocally high (Basham L.M., 
2012). A readiness in that paradigm seemed dubious if they just transferred withdrawing from their more paid jobs (Moerschell, L. \& Lao, T.M, 2012). An additional compensation above readily stimulated the morale and participation to turn on their best. They were a carnivore to pursue dollars for more clients and bigger contingent attorney fees. A "give and take" interaction was guaranteed to create the trust and empowerment (Furst S.A. \& Cable, D.M., 2008).

His engagement was serious and sincere over the crucial aspect of project. He demonstrated his authentic leadership role to motivate the spirit of followers (Dunn M.W., Dastoor B., Sims R.L., 2012). The financial campaign to mobilize the funds rose over all the candidate departments nationwide. It was important in the evaluation process that the candidate departments should be financially competent to assist the deprived students. The evaluation panel of government looked at this essence more seriously provided if the national sentiments militate against the ill consequence between the rich and poor. A new form of legal education required three more years to become a jurist in Korea. For the nature of law school, the tuition fee would be costly, and their allegation invoked a constitutional right of equal opportunity for the public office. They opposed, unlike the previous mode, that new system works to bar the poor from becoming a lawyer. The leader and followers shared this point strategically, and advanced all efforts for the financial campaign. In the course, Chun's leadership role was brilliant. His awareness and value was well defined and self-evaluation in the prelaunch phase enhanced his commitment and flourished through the movement or change phase (Norris E.A, 2010).

\section{4-2. A Firm Adherence to His Value and the Transformational Characteristics of his Leadership : Resistance Could not be Present!}

In 2007, the CU law department failed to obtain the approval of government, which aroused many reactions to criticize aspects of the organization change process. The reactionary voice was toned high and echoed in the wider scope of local community. Most interested groups were disappointed seriously, and new attempt for the law school bidding has actually swayed depending on the situation. Over the years since 2007, however, his initiative enabled the department to survive, even nowadays, for the chance of obtaining the governmental approval. There were actually created some turf or resistance being pessimistic for new challenge. If some members talked about new mindset, they usually responded, "now feeble and on fatigue with the law school bidding preparation... We are more suited to the undergraduate mode for breeding the police officers or local posts...The activists or administrators in that direction would just signal a puppet role to evaporate over time." His leadership, however, was impacting for the activists to still voice our realigning for the governmental approval even if more than five years have passed (Dunn M.W., Dastoor B., Sims R.L., 2012).

His reflection over the value of campaign was philosophical and sublime that he himself or others could not refute if not depraved to be gotten down. Therefore, it should be enduring and insistent. An analysis of self in terms of his capabilities and environment was concrete and appropriate with a rich career as the dean of medical school. He perceived the purpose of financial campaign in three demands. CU should be a local leader to raise competent lawyers, who can serve the community and provide a quality legal service. It was deeply committed in his self assessment that lawyers are key players to pioneer the locale and nation. As a school administrator, he saw it to be focused on the lower rate of tuition fee. He also recognized deeply in the level of personal conviction that it should be less than that of other national universities (Norris E.A., 2010). For the bidding competition, it is strategically 
the ligne maginot that our tuition fee should not exceed other national universities. This pretense and self-orientation escalated over the process organization change, and to the postchange phase even through these days. Given the law school bidding was failed, we may think if there can be any kind of post-change phase. Many CU law personnel think otherwise, and they undertake the role to make a success through the time even of least possibility. In this context, I acknowledged that pre-change phase is much important, and left an impressive wake over the whole matters of change. His devotion was also firmly based on his perception that the financial campaign is a top priority to correct the social injustice between the rich and poor. This message was effectively communicated and shared to increase the opportunity of deprived students (Willheim, T., 2010). It is certainly a prerequisite that the tuition fee of prospective law school would range as less as 9000 dollars per semester.

The campaign was designed conceptually that each donator was responsible for each student. It was also framed practically that he would give ten accounts, 2,000 dollars yearly and 3,000 dollars through three years. He allowed himself as the first donator by giving 3,600 dollars. This proved, in some sense, that his leadership is truly a shared form (Willheim, T., 2010). The members and social donators felt boosted with his pioneering example. His devotion to lead later affected the law professors to give one hundred dollars monthly since 2007, the year of our failure. We also can find the attribute of ethics in his leadership (Dunn M.W., Dastoor B., Sims R.L., 2012). A general tendency of the staffs and professors may lead the public or followers, but moral mazes long formed in the university personnel go other way forbearing from any unnecessary payment. It is also because their pay is usually less to give or donate. Cheon saw it serving and doing right, however (Brwon, D.G., 2005). This aspect was not only related with the context of campaign goals, but also proved his overarching role and culturally deepened personality from the history and tradition of CU.

The campaign was successful with his superb leadership. A strategic team was arranged to manage the ads, the contact of prospective givers, the incentive system from givings, the ceremonial assistance, and so. Short months thereafter, huge success was made to chart 0.75 million dollars in givings. The givers are local businessmen, professors and staffs of CU (Beatty, B., 2007). To name a few, 72,000 from the medical clinic of Ha, 36,000 from the Namdo Informatics, and other sums from Vice Chancellor, Dae-won Kim, now Law School Dean, Byung-rok Kim, acquisition team staff, Jung-ki Choi.

\section{Organization Change and Cheon's Leadership: How does the Cooperation Network Serve the Campus and Local People?}

\section{5-1. A Change Demand From the Environment}

In playing his role as a chancellor, his focus of leadership is probably most highlighted for capacity building of CU. The higher education in Korea has turned competitive partly because of the globalization and privatization drive. The colleges and universities are no longer the past paradigm of romance or a pass course for the youths. The demand grows to push the stakeholders to be competitive. The modality gets akin to the Anglo-Saxonian concept of private dealings other than the public concept of higher education, which would be rather like the continental Europe. The consequence is serious that SNU (Seoul National University) was reformed as a legal person from the kind of governmental branch. The colleges and universities across the nation voiced to innovate and focused on the world class competitiveness. They hired working horse professors and famed ones to staff with the administration. The demand has the nature to make them advanced and put in pace with the globalization. Educational goals pursued breed an international context of competent 
workers, who speak English fluently and have a competitive edge of professional knowledge (Polizzi J.A. \& Frick W.C, 2012). This, of course, requires the learning culture more emphatically than any other type of organizations. Professors and students learn to survive, and they produce the knowledge and paradigm. They create the data base for the national interest, which build up the content and represent the cultural as well as intellectual capacity of nation. Human capitals actually are essential for the future of Korea, and the approach of heuristic kind is made up through a fine match. The beliefs prevail widely at national scale that the competitiveness of higher education is directly tied up with that of nation. Under these circumstances, the demand became enormous to transform the university for any desired concept of advanced university. Most of his energy and involvement through his tenure, therefore, triggered the point of capacity building to respond (Beatty, B., 2007).

\section{5-2. Vision, Change Process and Resistance}

His vision and process of change included the bright-line goals, which are explicit and could be clearly communicated. In Nov. 2007, the Commission of Developmental Strategy was created, and six months of the marathon-like work schedule finally enabled to shape the goals, direction and vantage points (Morill. R.L. (2010). The leadership role was pressuring given some of resistance from the followers. In some cases, they grumbled of heavy research load, and complained about the stricter code of promotion. The followers, however, mostly shared the content and process of change since the constellation of accomplishments implanted the kind of trusteeship inside them. The vision was titled "Pride Chosun," but its birth into being was never easy. Faithful indeed is it that he did not abandon the democratic tradition of CU. He even cultivated the democratic process for the wider of volitional support (Kezar, A.J., 1997). It is his firm belief that the coercive nature would never be effective in the educational facilities. The nature and culture of professor's work was important as initially pointed out. That concept also complies with the rule of capacity building. At this point, the faculty board is distinct within CU, and a key factor to interplay with the Chancellor's leadership (Hendrickson, R.M., Harris, J.T., Dorman R.H., 2012). Some group of the board raised an ill effect as the tough plan put much stresses on the group of professors. Others picked up an insufficient arrangement for the welfare of professors. His shared leadership finally persuaded them to collaborate for the systemic change (Simplicio, J.S.C., 2004)

He remarked on one episode, "One night, I patrolled through the lighted site of convention, who argued about the draft 'Pride of Chosun.' One young professor approached to raise the unrealistic aspect of goals. I illustrated Columbus' wisdom about the broken egg...and, of course, with the detailed ground for each stage of development. He finally nodded.." This episode reflects his sharing and constructive companionship, which is essential to motivate (Sosik J.J., 2000). The individual goals should be matched to the desired goal. They should not conflict, and it would more easily falter if entering into the competitive context. The "cooperation and competition" dualism between the individual and organization would be more agile given the diversity in workforce. The academic faculty in Korea is distinct if many young professors are foreign educated. They are not strictly the foreign workforce, but recently recruited professors less share a common national identity. Their personal assumption or belief system may differ given the intellectual diversity. As stated, the culture, heritage and tradition are distinctive in terms of democratic adherence (Kezar, A.J., 1997). His leadership, as a chancellor, properly accommodated the AIM (all inclusive multiculturalism) paradigm to pursue the goals. It would also be comporting if a number of professors are female and foreign professors are also grouped for some share. 


\section{5-3. The Change and Movement Phase}

The final draft of PC 2015 revealed seven points of focus in strategic management. They cover transparency, the match up among the generations (Simplicio, J.S.C., 2004), efficient finance, balanced upgrading between the research and teaching, the pioneering role for the nation and local community, beauty and convenience concept of the campus, and welfare of the campus members. These seven goals symbiotically correspond with seven focal strategies. They are, "recruitment and holding of competent professors, customeroriented tailored system of education, outcome-basis research support system, efficient and transparent administration, financial build-up and welfare, specialization for the pioneering role, and innovative campus environment." The focal strategies are pursued in the kind of concrete action plan (Norris E.A., 2010).

His leadership on capacity building also adopted a strategic goal of specialization. This point was constructively linked with his globalization leadership. As later viewed, the goal of CU during his or her tenure engineered a local partnership with the community. This concept and definition of goal is generally inextricable if he or she is a school administrator of local university. For example, Wisconsin idea long pursued by University of Wisconsin System has impacted, in a great extent, on the local development. They are culturally and economically affiliated in a constructive viewpoint, and interaction would bring a consequence. That is more stimulating if the college or university is placed in the strife of particular locale. As I began with the characteristics of CU, CU and local community have a tight and inseparable bound to share. They interacted historically, culturally, economically and even politically to struggle in some uniform context. Kwangju is CU or Chun Nam University. If CNU comes more of national context, $\mathrm{CU}$ is truly the citizen's of Kwang-ju.

\section{5-4. The Postlaunch Phase and Reinforcement of Change}

The feedback system was instituted, which was essential in this kind of organization change. It was designed to operate on the basis of twenty central management indexes (Morill. R.L., 2010). They were four within the education track, which cover the quota ratio between the students and faculty, expense of the students per capita, class satisfaction, the number of applicants for a dual or joint degree. Six of them lay in the research track, which included the research income of professor per capita, the university support of research per capita, the number of oversea journal articles for professor per capita, the number of oversea journal articles for the science and technology field professor per capita, the research impact on citation studies, the number of registered intellectual property rights. Student elements include five indexes, which are the number of registered students, attrition rate, employment rate, passers of national exam, the number of internships and on job training. The internationalization index was shaped in three, including the ratios of foreign professors, foreign students, students on study abroad program. Finally, the financial index had two points, givings and tuition share of total income.

His leadership of capacity building took the step for collaboration for the systemic change, but also strictly respected the principle of democratization process. The specialization goal and each phase of implementation are designed thorough the participation of interested groups (Kezar, A.J., 1997). Experts and key local figures were invited to express their views, comments, and opinions. His leadership, in this aspect, would be properly understood in the open system theory where the organizational environment is critically incorporated. He seems to acknowledge it vital that $\mathrm{CU}$ could not survive without an interactive network with the 
local elements. That is likely working with the modern biological concept of organization (Beatty, B., 2007). Within the Van de Ven's four paradigm of organization change, the teleological concept could more properly explain the context of his leadership. It was fairly wise and foresighted if he would less believe in the efficiency of coercive leadership. In corresponding with two thesis of the local government, CU chose three strategic fields; upgraded component materials, life science, as well as culture content and information. They were designed to collaborate with the center of culture, Kwangju and province of tourism, Chun Nam) (Morill. R.L., 2010). CU planned on two other fields in subsequent years. The strategic team and collaboration support were made a network, in which Vice Chancellor assumed the chief role. The network was responsible to select two more strategies, and would be offered the financial support for three years depending on its merits.

\section{The Research Ethics Institute: Can it Make a Difference to Increase the Capacity of CU?}

If we see his leadership in a shared form, one of his accomplishments should be the instituting of Research Ethics Insitute (REI) (Simplicio, J.S.C., 2004). This vision represents his traits of globalization leadership, in which the research ethics of professionals tend to share a common concept (Norris, E.A., 2010). It also bore on reflection that nowadays researcher could no longer carry their job duty without the ethics compliance and the capacity of campus critically incorporated this concept. The moral hazard of Korean researchers had been questioned over all levels from the top of chancellor through recently recruited professors. An ethics issue in the higher education surfaces in this distinct aspect, but has been long lousy in Korea to make them bugs on vague orientation just. The kind of Foundation of the Doctoral Studies course normally is not offered in the training program of Korean universities. They may be imperfect to comprehend the exact nature and requirements of research ethic, and that is all, if not exposed personally through his career path. The creation of REI can be understood in that (i) it was environmentally demanding in terms of organization, (ii) teleological to push on certain organization change, (iii) raising a conflict capital in terms of capacity building (iv) the concept of learning culture and organization worked out.

As defined earlier, the research ethics was brought to attention from the context of environment (Beatty, B., 2007). The demand was implicitly pressured in general context of the global researcher circle. Particularly, the example of Woo-seok Whang's misconduct and alleged failure in the stem cell research and duplication of lives stirred the Korean public. It was aired to global public, and the admirations and reverend of him held by Koreans were seriously depraved. This shock particularly influenced the Korean Academy, which created a moment of upgrading as leveled to the international standard. The researchers generally cherish the impact of their research and buy the efficiency concept more readily. That would perhaps dominantly feature in terms of capacity building of higher education. The ethics, in its way of operation, would go generally contrary if it regulates on the kind of moral basis. Then, what does capacity building connote in a shared paradigm of CU (Willheim, T., 2010)? That is an essential component to allow the sustainable growth. A violation of ethics, at some time, could seriously taint the reputation long efforted to build up. The monitor of ethics is required to surveil constantly as like the conflict capital to be raised and compete to increase the organizational capacity in the heuristic way. They interact smoothly and constructively for the organizational progress (Morill. R.L., 2010).

It is also required in the concept of contemporary paradigm of learning organization and culture. The Institute offers an updated knowledge which the researchers should know 
and apply in due course of his research performance. As the student researchers should know it, it is imperative. For the faculty, it is pertinent with the concept of lifetime learning (Furst S.A. \& Cable, D.M., 2008). It is open to local public through the extension of CU, which enabled to make a lifetime learner. REI was nationally designated by the Department of Education, Science and Technology. Their mission was clearly set forth: (i) it provides a scope of information and issues relevant with the research ethic (ii) it acts to network with the community, and promotes a voluntary engagement of researchers, and encourages an instant plot on the ethical guidelines suited to each research project, (iii) it stimulates an action for voluntary upgrading of each researcher. The action program of REI also requires: (i) it collects an information of research ethics at the national scale and selects the agenda of urgent priority (ii) it collects and develops the data or reference materials for research ethic (iii) it manages on the line research center (iv) it supports networking among the researchers and also does the community maintenance (v) it promotes on-line and off-line education of the research ethics.

REI was opened March. 19, 2008. It supports the special lecture, as titled "life ethics" in the spring term, 2008, which was arranged in the graduate school of life science, Yon-sei and Suk-myong universities. It also hosted a tour series of seminar across many universities nationwide. Eun-hee Cho, the director of REI, gladly introduced, "we expect that the REI plays a central role as the venue for enhanced research ethics. It is a forum in which we define our mindset and practice enhanced performance in terms of the research ethics."

\section{The Detracting Aspect of his Leadership Through the Change Process : A Paradox of Particpatory Leadership? Ethics, Resistance and the Democratic Dynamics of CU}

\section{7-1. In the Beginning}

In terms of organization change, we may see partly if his leadership would be viewed in a kind of detracting aspect. The point of detracts, again should be defined in some correlation with the history, culture, and the atmosphere of $\mathrm{CU}$, which is an academic institution in general, specifically in the context of Korea, and fundamentally in its massive profile of interaction with the local community. This implies that the virtue of democracy and culture of ethics are a prime theme in which no engineering of organization is virtually possible if in breach of this essential element (Portela, A., 2011). For the detracts, the above version for the positive aspect of his leadership style can be properly perverted to explain. His self-awareness, value and high motivation may well be ego-centric if placed in a different light. His charisma may be received to forge his personal ambition to establish his reign of campus in long and formidable context.

\section{7-2. Ethics and Moral Aspect of Leadership}

His transformational leadership was pursued effectively for the first term of his office, but the situation turned to go other way given the intense conflict about his status during a short of second term (Basham L.M., 2012). He had no way but to resign provided if the members resisted persistently and in some of systemic way. This principally was caused by his weak concept about the organizational heritage of democracy and dominant culture upheld by the campus members. They may well be said of democratic expertise, who are stern of any bit of undemocratic attempt (Kezar, A.J., 1997). To be honest, Cheon might not 
be wrong to persist on the struggle to stay in his second term of office. That is because he was legitimately elected by the Board of Regent in accordance with the bylaws of CU and pertinent national statute. However, it is often said that the leader should know the time to retire, and the ways of dealings would be rather more on the "socially constructed" rather than any "precise demand on justice." Organizations recruit, and utilize the leaders for sustenance or restructuring as well as for the change of improvement. Their chosen leader will fade away if his mission is connected and replenished with other leadership. That may, in some context, be one of the leader's ethics and function to refurbish the organizational paradigm and also against its entropy (Brwon, D.G., 2005). He achieved a second high vote for nomination to the board approval. The Board of Regent bought his four years intimacy and more odds for some friendly interaction with the Board (Furst S.A. \& Cable, D.M., 2008). New nominee, ironically one of his peers in the medical school, was rather challenging and required new effort to interact or even manipulate given the decisive power of the Board (Simplicio, J.S.C., 2004). Apparently, the appointment of Cheon, in 2011, was formally no erroneous in any way since the appointment power is exclusively conferred within the discretion of Board. As mentioned earlier, however, the circumstances are fairly different given the high profile of democratic tradition within the CU community (Kezar, A.J., 1997). The faculty board launched a struggling movement, which was to endure for one year. The case was even brought to the courtroom which contributed to tarnish the reputation of CU. An organizational change for that harsh period should be properly stomped to maintain the minimum level of essential function. For the important moment of turmoil, one of professor's public notice, which was e-mailed to the members for sharing, partly helped us to understand the situation. He is Korean, but was educated in US for his doctoral education on journalism. Interestingly, the public notice heralding some important days of event was delivered in "his English" as he is a leading professor for the English education partnership with the Murray State University. That would be available in the Appendix of this final thesis. I did not change even a word if there might be an error in his English expression. That is because it could be vivid as is.

\section{7-3. A Boomerang from his Charismatic Leadership, Resistance, and the Prevailing Culture}

In the development of turmoil, we were driven to think about the ethics issue and moral mazes in the CU community (Portela, A., 2011). As guided, the moral mazes and patrimonial culture are dominant over the western mode of bureaucracy. CU also has this aspect, but the group of endogenous members are particularly disposed with some kind of strong moral adherence. Given the distinct nature of $\mathrm{CU}$ as mentioned earlier, the moral mazes should be more likely on his personhood if he or she has more affiliation with the institution. Their ethics and perception of organizational culture would be autonomous in nature, which are shared by their intimate group and strenuously power-oriented (Simplicio, J.S.C., 2004). The informal support group would be formed in each case of chancellor election. They shape a strategic action plan and include informally the promise of administrative position for their group members. A success in the election means some of valued office, which is similar to the spoil system practiced in the US politics. Cheon's personal traits and background, as an alumnus, are more friendly to mislead him to be biased about his status (Oreg, S. \& Berson Y., 2009). This would incur him to be grappled with the pitfall of Cinderella syndrome, and failed him to see the problem more objectively. It took it long to step down with six months stalemate, and the failure of leader could be captured in the kind of johari window. His brilliance of leadership to elevate $\mathrm{CU}$ in his first four years 
suddenly brought him down to taste a failed leadership. A kind of defense for the forced nature of progress may be attributed, in some persuasive power, to his case. His image and personal honor could be secured if he raised an intimate group confidentially. It could work to make it more intact about his personhood. A recent development fortunately calmed down that he recently returned to the normal performance as a senior professor in the Medical School. It is regrettable that he was severely hurt from the resistance of followers in the first phase of turmoil. Behind stories were revealed in a depraved manner, many of which were actually not evidenced in nature. Again, the CU history, tradition and culture are distinctive that we usually see the alumni candidate, who are well knowledged of CU, culturally disposed, and highly interactive and motivated. Cheon's lessons are just theirs in the ways forward (Brwon, D.G., 2005). This kind of pestilence underlying the current system of Korea is not unique in CU, but at some extent must be perceived nationwide. Hence, it is one of reform issue that the Korean government intends to introduce the US system for open candidacy, screening process and appointment.

\section{Strategies to Address the Resistance: Fostering the Followership, Emotion and Harmony as Most Effective Strategies Against the Resistance of Followers}

\section{8-1. Democracy, Participation and Campus Leaders of Korean Academy and CU}

Two distinct efforts on zoning would perhaps prove his distinct point of leadership. It really governs if they occupy a central and large tract of campus. It can only be properly explained that he has the natural traits as a leader. The zonings reinforced his charisma evoking the sensibilities within the followers that he can do something great (Gibson J.W. \& Blackwell C.W. (1999). A zoning project is not so easy if it requires much financial investment as well as strenuous care and vigor. Followers share the vision of social harmony within the campus emanating implicitly from the products. An entrenched culture and struggle for democratization, as mentioned, generally disposed the campus image to be hard and stiff (Wallace D., 2012). This aspect is used to aggravate given the intense competition for the election of chancellor. The election of campus leader is one of typicality in the universities of Korea. It has pros and cons, and most weakness is found in the aftermath of election, in which the campus members tend to be split zealously and faction is created frequently. The ways to create a vision in terms of charismatic leadership was made implicitly in the course of zoning. It also represents one of the constellation of accomplishments to strengthen his charisma, provided if it was actually never an easy project. The nature of zoning also enhanced his image as a leader that he is soft, generous, cultural, humanistic, open and sharing, and socializing. Hundreds of verbal communication would not rival this tangible and symbolic expression, i.e. zoning of the Rose Garden and the Cotton Field. The campus members readily share to participate (Brito C.E, Vanzin T. Ferraso M. Saldanha J.A.V., 2010).

\section{8-2. Resistance of the Followers, Leader's Characteristics and LMX}

In terms of the organization change, two zonings vindicate a high extent of self awareness, value reflection, and communication for change, which are typically required in the pre-change and change phase (Oreg, S. \& Berson Y., 2009). The investment from private fund represents his firm conviction and devotion to the development of CU. He knew that his 
personal and cultural disposition are in concordance with the direction of CU (Sosik J.J., 2000). These visible creatures placed in the core of campus enabled him to persist on change, and tactically exploited to communicate or persuade against the resistance of followers. The symbols generally worked out his first 100 or 200 days rapid change process, in which ruthless dealings could be finally harmonized at post-change phase. In terms of leader's characteristics, The Rose Garden and Cotton field could highly fit to minimize the negative attitude, hence, a resistance of followers (Oreg, S. \& Berson Y., 2009). The followers generally can have a concept as shaped from the zonings that his leadership is transformational, who were, hence, motivated to participate (Basham L.M., 2012). The leader-manager exchange (LMX) is most outstanding in this context (Furst S.A. \& Cable, D.M., 2008). The rose and cotton within the campus allowed the followers to attach his identity in a close and passionate way. In the approximate nature of campus environment, they all know the nature of zoning: who paid to construct, in what passion was it zoned, and so. The symbols are another expression of the chancellor's office, but very humanistically interact with the enjoying followers in a short lunch break and other leisure time. It, therefore, can be perceived as most efficient way to increase the LMX. In turn, his leadership could see less resistance on many moments of organization change during his incumbency while many managerial tools, such as sanction, legitimatization, consultation, and ingratiation could be enhanced in its function. The high extent of LMX implicitly accumulated through two symbols influenced to moderate the resistance of followers (Furst S.A. \& Cable, D.M., 2008).

\section{Shared and Transactional Leadership, Biological Concept of Leadership and Organization}

The two symbolic expressions also pertain to the biological concept of leadership and organization change. A former chancellor, Cheon, went on to retrospect his unique "give and take" or needs of campus and local people, "Jangmi-won is the Rose Garden open to public access in May 24, 2003, and it became a most popular place in Kwangju that the citizens spent their leisure hours. It is located at the center of campus right beside the library to greatly enrich its beauty. A sort of roses in Jangmi-won bloom and flourish from May through November, and evoke exotic feels and comforts of the nature to relax the citizens retarded from stressful routine days. The construction design was made by Sam Sung, and the site was full of fifteen thousand roses of 160 sorts spanning over large acre. A construction required a budget of 0.9 billion in Korean currency, which was drawn from his fund in major and partly from the givings of alumni, professors and staffs, students, and parents. Among the roses implanted in the site, the visitor can find a famous "Prince de Monaco" dedicated to Princess Grace Kelly as well as top rated roses in the international contest. A zoning of this rose garden originally has been enforced as a public hub project of campus that now fully operates to satisfy an original intention. Its beauty and feelings of virtual nature amongst the large-scale campus environment certainly refreshes the elementary, middle and high school, college students, teachers and professors, staffs, and local workers and citizens (Beatty, B. (2007)."

As you can note above, the Rose Garden facilities the biological need of campus members in its input, throughput and output process. A number of hard working professors share it to reproduce their energy and increase a motivation for more productive research and teaching (Sosik J.J., 2000). It is the kind of "promise of sex" enabling the leader and members to penetrate through the process of organization change. We can recuperate ourselves enjoying the garden and came back to work in fresh condition. 
In other ways, the garden plays positively to interact with the local community (Portela, A., 2011). CU, as an organization, is given and defined in terms of its environment. As stated, most of $\mathrm{CU}$ features are intertwined with the locale, and the isolation or monograph on the way of action alienated from the community directly means a kind of organizational entropy. As introduced, the Rose Garden is a popular place for local people for the recuperation and pleasant leisure time. This dynamics support CU to be a living creature, which is biologically healthy. The job satisfaction of campus members is needless to specify, and foreign professors also had been amazed at the facilities, who participated in the international conference. It enhances a reputation of $\mathrm{CU}$, and partly contributes to his globalization leadership. A symbolic expression through the Rose Garden is precious indeed, exceeding any effect from hundreds of verbal word (Oreg, S. \& Berson Y., 2009).

\section{Conclusion}

In the course of discussion, it seems essential to shed his leadership style in two fold aspects, say, "environmental and leader's attitude." These are not let alone to function, but rather interact each other to shape his leadership style and to effect an organization change.

First, he had no other viable choice but to mostly follow the transformational and shared leadership (Simplicio, J.S.C., 2004). In the essence of his personal direction, Cheon should be elected and implement his reform plans of university. Of course, most leaders, in the contemporary times, favor those leadership styles, which are more pressing in the context of university election and administration. That is principally because the public university is particular: (i) in terms of its members, a cluster of liberal and intelligent ones both with the faculty and group of students (ii) in terms of the Korean context where the university president is elected by campus members, which differs from the US case (iii) the culture and dominant atmosphere are disposed to see "us" as peers more than any bureaucratic elements (iv) the financial aspect of public university is orthodox between the profit and non-profit nature (v) the input, throughput, and output process are not simple in the universities, but rather complex involving the diverse features and globalization (vi) the commission of present university is normally pioneering with the expectations of community more than other types of organization.

Second, the university president is expected, in a fair of its paradigm, of the kind of charismatic leadership. That is affiliated with the nature and role of organizations which is philosophical, professional, and as the vanguard of social as well as human conscience.

Third, the process of change is a paramount concern of involved parties where the faculty and intelligent students usually obey the rule of due process and place a critical emphasis on reason and persuasion. This is typical of most Korean universities, which is more implored given the distinct context of CU history, tradition, and culture. This, on one aspect, reinforces the effect of Cheon's leadership while it militates, in some context, decreasing the power and influence of his leadership performance. Eventually, this factor plays a decisive role to frustrate one more term of chancellorship.

Fourth, it is not unusual in the university context that the prospective or current administrators generally employ both task and relationship-oriented leadership style. This is the case of Ho-jong Cheon, but the relationship-oriented leadership was more strongly profiled in the election process. And the task or goals initially promised during the election would be less focused or debated later in the feedback process, although there were no serious problems during his times of incumbency. That is distinct from the profit organizations partly because there are less "quantitative" frames than "qualitative" in the campus. There is general tendency to perceive the finance of university seriously, such as 
voucher system or the transfer of funds from the Board of Regent. The financial aspect of university, however, is not a critical focus unlike corporations, which are more sensitive on this point to their hired manager or leader. While we talk about the switch of top managers in corporations because of less income or less profit of organization, there are seldom a case for the university president on that respect. The concept of "entrepreneur university administration" has, nevertheless, been intensified in Korean society, which would slant on the Anglo-Saxonian approach other than European modality. On that progress, we can identify points of change promise in which the candidates launch a set of policy packages to improve toward the entrepreneurial campus, and later became not clear without any work of feedback to confirm its performance or implementation. The term of chancellor (generally four years across the colleges and universities in Korea) and final responsibility of finance on the Board of Regent would blur that point between the election promise and responsibility to implement it. Therefore, we are used to welcome the campus leader with a splendid vision of financial or wealth plan at the outset. We gradually, however, turn to see the kind of manager at the top position, who is just but a mediator or subordinate for the Board of Regent. In any case, the university president, once elected, is considered as more relationship-oriented for the nature and culture of organizations.

Six, in understanding the campus leadership, therefore, the prelaunch phase appears critically important in which the candidates are contested through the election or screening process for the appointment. A self-examination is required, which leads to some correct and serious nature of self-awareness, motives and value of his self in the context of ambition, environment, and desired organization change. 


\section{References}

Basham L.M. (2012).Transformational and Transactional Leaders in Higher Education. Advanced Management Journal. Spring Issue. pp. 15-23.

Beatty, B. (2007). Going through the Emotions: Leadership that Gets to the Heart of School Renewal, Austrailian Journal of Education. 51/3. pp. 328-340.

Bowen, W.G. (1998). Universities and Their Leadership. Princeton University Press. Princeton: NJ.

Brito C.E, Vanzin T. Ferraso M. Saldanha J.A.V. (2010), Leadership Focusing on Communication in A Post-modern Context. 10/3 of Academy of Business and Economics . pp. 112-122.

Brwon, D.G. (2005). University Presidents as Moral Leaders. Rowman \& Littlefield Publishers. Lanham:MD.

Chosun University (2010). CU Brochure, Chosun University Press. Kwangju.

Dunn M.W., Dastoor B., Sims R.L. (2012). Transformational Leadership and Organizational Commitment : A Cross Cultural Perspective. Journal of Multidisciplinary Research. 4/1. pp.45-59.

Eeden, R C. F. \& Deventer, V. (2008). Leadership Styles and Associated Personality: Support for the Conceptualization of Transactional and Transformational Leadership, South African Journal of Psychology, 38(2), pp.253-267.

Furst S.A. \& Cable, D.M. (2008). Employee Resistance to Organizational Change: Managerial Influence Tactics and Leader-Member Exchange. Journal of Applied Psychology. 93/2. pp. 453-462.

Hendrickson, R.M., Harris, J.T., Dorman R.H. (2012). Academic Leadership and Governance of Higher Education: A Guide for Trustees, Leaders, and Aspiring Leaders of Two- and FourYear Institutions. Stylus Publishing. Sterling: VA.

Gibson J.W. \& Blackwell C.W. (1999). Flying with Herb Kellerher,: A Profile of Charismatic Leadership, The journal of Leadership studies Vol 6, No. 3/4. pp. 120-137.

Gillham, B. (2000). Research Interview (Continuum Research Methods). Continuum; 1 ed. New York: NY.

Keohane, N.O. (2006). Higher Ground: Ethics and Leadership in the Modern University Duke University Press Books. Durham:NC.

Kezar, A.J. (1997). Exploring New Avenues for Leading Community Colleges: The Paradox of Participatory Models. Community College Review. 25/4. pp. 75-

Kim, Kiyoung, Fiscal Administration and Public Sector (March 22, 2015). Available at SSRN: http://ssrn.com/abstract=2586039 or http://dx.doi.org/10.2139/ssrn.2586039 
Kim, Kiyoung, The Relationship between the Law and Public Policy: Is it a Chi-Square or Normative Shape for the Policy Makers? (September 10, 2014). Social Sciences. Vol. 3, No. 4, 2014, pp. 137-143. doi: 10.11648/j.ss.20140304.15. . Available at SSRN:

http://ssrn.com/abstract $=2577832$

Kim, Kiyoung, The Leadership of Korean Universities: A Case Study Concerning the Chosun University (March 30, 2014). Science Journal of Business and Management. Vol. 2, No. 2, 2014, pp. 50-66. doi: 10.11648/j.sjbm.20140202.12 . Available at SSRN: http://ssrn.com/abstract=2577828

Kim, Kiyoung, A Promenade on the Ethics and Ethical Decision Making: Should Chae be Botched from the Korean Public? (October 1, 2014). International Journal of Advanced Research (2014), Volume 2 Issue 10, 15-23.. Available at SSRN: http://ssrn.com/abstract=2577806

Kim, Kiyoung, A Reform Agenda of WTO Revisited: The Elements of Public Administration and International Organization (December 1, 2013). International Journal of Advanced Research (2013), Volume 1, Issue 10, 634-648.. Available at SSRN: http://ssrn.com/abstract=2577787

Kim, Kiyoung, Amidst the Temper Across the Equality, Equity, Ethics and Responsibility: A Stymied or Pondering Administrator? - A Little Highlight on the Concept of Equality (September 1, 2014). Management and Administrative Sciences Review. 3(6). 909-921.. Available at SSRN: http://ssrn.com/abstract=2574739

Kim, Kiyoung, The Strategic Planning: Some Dangling for the Socio-Historical and Organic Lives (September 1, 2014). Management and Administrative Sciences Review, 3(6) 845-857.. Available at SSRN: http://ssrn.com/abstract=2574732

Kim, Kiyoung, The Constitution and Tripartite System of Government: From the Mutiny for the Limited Government Through the Interbranch Subtlety. (September 1, 2014). International Journal of Advanced Research (2014), Volume 2, Issue 9, 392-401. Available at SSRN: http://ssrn.com/abstract $=2574711$

Kim, Kiyoung, The Separation of Powers Principle: Is it a Lynchpin or Pushpin for the Voyage of American Public? (August 1, 2014). International Journal of Advanced Research (2014), Volume 2, Issue 8, 887-895. Available at SSRN: http://ssrn.com/abstract=2573560

Kim, Kiyoung, Theories and Tenets: An Impalpable Troll for the Policy Makers, Research Officers and Administrators? (March 4, 2015). International Journal of Interdisciplinary and Multidisciplinary Studies (IJIMS), 2014, Vol 1, No. 8, 30-50.. Available at SSRN: http://ssrn.com/abstract $=2573526$

Kim, Kiyoung, Human Rights: Are They Just a Tweak for the Policy Makers or Administrators? (March 3, 2015). European Academic Research, Vol. II, Issue 6, September 2014. Available at SSRN: http://ssrn.com/abstract=2572951 
Kim, Kiyoung, A Case Study Concerning the Strategic Plan: V2020 of Chosun University (.October 20, 2013). Science Journal of Business and Management. Vol. 1, No. 4, 2013, pp. 43-57. doi: 10.11648/j.sjbm.20130104.11. Available at SSRN:

http://ssrn.com/abstract=2572943

Kim, Kiyoung, Two Illustrations from South Korea and Some Reflections About the Public Administration Studies: Are We Granted to Pillory the Ethics or Social Justice? (September 2, 2014). International Journal of Philosophy 2014; 2(4): 48-59 doi: 10.11648/j.ijp.20140204.11. Available at SSRN: http://ssrn.com/abstract=2571903

Moerschell, L. \& Lao, T.M (2012). Igniting the Leadership Spark. E:CO. 14/2 pp.54-68

Morill. R.L. (2010). Strategic Leadership: Integrating Strategy and Leadership in Colleges and Universities. Rowman \& Littlefield Publishers. Lanham: MD.

Norris E.A (2010). The Third Dimesnion of Leadership: Change Oriented Behaviors, Journal of Academy of Business and Economics 10/4. pp.126-136.

Oreg, S. \& Berson Y. (2009). Leader's Characteristics and Behaviors and Employees' Resistance to Organizational Change. Academy of Management Annual Meeting Proceedings. pp. 1-6.

Polizzi J.A. \& Frick W.C (2012). Transformative Preparation and Professional Development : Authentic Reflexive Practice for School Leadership. Teaching and Learning: The Journal of Natural Inquiry \& Reflexive Practice 26/1 pp. 20-34

Portela, A. (2011). Identity, School Inclusion and Leadership, Contemporary Management Quaterly. Vol. 2.

Simplicio, J.S.C. (2004). Shared Goverance: An analysis of Power On the Modern University ampus From the Perspective of An Administrator. Education 126/4. pp. 763-768.

Simplicio, J.S.C. (2004). The Personal Touch: A Guide to Acquiring Power Within A College. Education 130/3. pp. 457-460.

Sagnak, M. (2010). The Relationship Between

Transformational School Leadership and Ethical Climate, Educational Sciences : Theory and Practice. pp. 1136-1152.

Sosik J.J. (2000). The role of Personal Meaning in Charismatic Leadership, The Journal of Leadership Studies, Vol. 7 No. 2

Wallace D.(2012). How a Campus Culture Created? Techniques. 10-11.

Willheim, T. (2010). Fostering Shared Leadership. Leadership. Nov./Dec. pp. 22-38. 


\section{An Epilogue of Case studies}

For the course of leadership and organization change, we like to conduct the case studies, which requires choosing one institution and the organizational leader familiar with me. Then we are assigned to conduct an interview with the leader chosen and asked to describe several aspects of his leadership style, and, of course, its nature, strengths, weaknesses and lessons for the future. My instructor also required to choose eight articles to form a basis of literature review for the project and in the purpose of discussion reference. Articles chosen would provide the requisite theories of leadership style, application to the actual settings, analysis and discussion, way of dealings in the leadership and organization research, implications of research and its limitations, and other available information and professional discourse. We are also required to submit until week 3, the plan of project describing the institution and leader chosen for the purpose of evaluation and comment by the instructor. I have chosen the Chosun university and its past president, Mr. Chun, which I now serve and who is well known to me for the nature of relation as a peer in the university. In this way, the project work was oriented and shaped, which would deal with the leadership in the higher educational sector and the leader as a university president. I have also arranged an interview date, time and place at five different occasions on a weekly basis.

With the guide of e-library, I chose several scholarly resources, two of which would be described in the context of final project research (Study Notes, 2012). Resources were retrieved from the research data base as shown by the website guide. I applied a basic keyword searching, and noticed that the tips are helpful to correct some cases of bone-head. For example, it was true that search is delicate with the results if we are on even small variances. Indeed, I confirmed that library databases aren't like Google, and that they are very literal (Study Notes, 2012). I applied a basic Boolean searching by utilizing three operators "AND, OR, NOT", which would narrow or expand the scope of search. Once we get to a citation page of articles, I found it easy and rather straightforward to locate the full text. Most of work in the library search took me to the journey of key words and the section of research resource was my popular base of search. I later realized that the tactics to directly locate a specific journal and article would enable me to the fast way of retrieving searched materials.

Two scholarly sources, I introduce, would support my research in the leadership style in a general and special context. For the project, I need to frame the elements of leadership unearthed from the interview result of a former university president, Mr. Chun. Then I advance to the theories and points of discussion learnt through the courses and expanded or reinforced with those eight articles. One article I intend to utilize is titled "leadership focusing on communication in a post modern context" and authored by four professors including C.E. Brito. It is a scholarly and peer-reviewed article, which is nine pages long, and featured in the Journal of Academy and Business and Economics, 2010 November issue. The article deals with the communication aspect in the contemporary leadership, which is particularly weightier with the introduction of new technologies and global systems of communication management (C.E. Brito et al, 2010). For the leadership style of Mr. Chun, I found his great skills of communication and observed him to highly rely on the shared or participatory leadership to change Chosun university. He regularly held a strategic meeting across the departments of campus, and effectively communicated his vision, philosophy, the environment of campus, basic direction and goals of the university. As we feel shoulder-onshoulder with the university's chief administrator, we were actually motivated to find our duties and the path to cooperate toward a desired goal. If the campus community is highly 
professional, individualized and less affected by any established value or social practice, it may be viewed as in the context of post-modernity in some aspect. That is also pertinent to the case of Chun's leadership if he made an individual contact to each faculty member for his election. An opinion of each professor later turned into his resource to lead the university, colleges and departments and even for an individual professor at some extreme occasion. Therefore, the article is considered to help to increase the merits and persuasive power of the final project.

The other article, I introduce, is "Shared Governance: An Analysis of Power on the Modern University Campus from the Perspective of Administrator" It is authored by J.S.C. Simplicio, a professor of Palm Beach Community college, Florida. It featured in vol. 126, no. 4, the journal of Education, which is brief on six pages, but took a manner of the scholarly writing with citations and section of the abstract. The article raised three questions at forefront in response to the hot debates of shared governance within the campuses of United States. They are about the definition of shared governance, and how the decision making authority should be shared by the faculty board and university administration. And the last question inquires if any special sector could be identified to give a sole responsibility of decision making to the faculty members (J.S.C. Simplicio, 2006). Given this dealings of article, I could obtain a useful information, and highlight a special context of university organization about the shared leadership. That is particularly meaningful in the circumstances where the Chosun university is a unique institution having all faculty convening body in parallel with the formal university administration. The body is advisory in its nature, but is actually powerful to influence the formal leadership. The article helps to look into that special context of university organization, which also offers a standard of evaluation between US and South Korea.

- Study Notes: "Searching and Retrieving Materials in the Research Databases"

- C.E. Brito et. al (2010). Leadership Focusing on Communication in a Post Modern Context, Journal of Academy and Business and Economics vol. 10, no. 3.

- J.S.C. Simplicio (2006). Shared Governance: An Analysis of Power on the Modern University Campus from the Perspective of Administrator, Education, vol 126. no. 4. 


\section{Appendix I (From Prof. Dong-keun Lee, Department of Journalism CU)}

E-mails Retrieved from Dong-keun Lee's Public Notice, who is currently a journalism professor in CU.

October 13, 2011

Dear Mr. so-and-so,

Chosun Univ. is currently in turmoil. Presidential Election ended on Sept. 22, but something wrong happened. The incumbent President got 318 ballots, so he remained in the second place. The other candidate (Dr. Suh) got 398 ballots, so he won the first place. But the Board of Regents appointed the incumbent President as next President without proper explanations on Sept. 26. Five out of nine Regents were for the incumbent. Council of Faculty and Union of Staff are strongly opposing the Board of Regents' unreasonable decision and began fighting for the revoke of the decision. In the meantime, lots of faculty and staff are complaining on the Intranet Board about unfairness and wrongfulness of the decision by the Board of Regents. The inauguration is scheduled on Nov. 10. Dr. Suh has recently filed for provisional injunction of President's function in the Court. We are waiting for the Court's decision. There are total 12 banners hanging around the campus, which contain such strong phrases as, "Out, Incumbent President!" "Second-Place President Resign!" "Out, Board of Regents!"

The incumbent President and Dr. Suh are in the faculty of the same department in Medical College. Most of the faculty and staff are crossing their fingers for the good news from the Court.

October 27, 2011

Dear Mr. so-and-so,

We are still fighting for democracy on campus. The second-place candidate (the incumbent President) refuses to give up the appointment made by the Board of Regents. So we are waiting for the decision from the Court, which is to come before Nov. 10, the inauguration day. In the meantime, Council of Faculty and Union of Staff jointly set up Emergency Committee for Dragging Down the 2nd-place President, and I am in charge of public relations in that Committee. The first-place candidate (Dr. Suh) went on a hunger strike, and a professor and a staff member shaved their heads as a sign of protest. We also performed funeral service to offer consolation to the deceased democracy at Chosun University.

November 13, 2011

Dear Mr. so-and-so, 
Unfortunately, the Court rejected Dr. Suh's application for provisional injunction of President's function. So, President Jeon began his second term as President on Nov. 10. But Dr. Suh symbolically began his Presidency on the same day. Now, we have two Presidents at Chosun. Dr. Suh has filed a lawsuit for nullifying the Board of Regents' appointment of President Jeon. It is expected to take a couple of years to see the final decision by the Supreme Court.

Recently, the Board of Regents disclosed the recorded conversation together with the proceedings of the Board Meeting dated September 26, the day Dr. Jeon was appointed as next President. The purpose of disclosure was to persuade faculty and staff to believe that Dr. Jeon was better than Dr. Suh in the interview with the Regents. But President Jeon's shocking utterances during the conversation with some Regents were exposed, so lots of the faculty and staff members have become outraged. In response to one Regent's question about plan for restructuring the university, Dr. Jeon said, "I am willing to get blood on my hands in the process of bold downsizing." He mentioned it three times throughout the conversation. Dr. Jeon also mentioned that it is meaningless to try to discuss with faculty about the restructuring since it is more difficult to deal with university faculty than to deal with flees. Nobody knows what will happen at Chosun University tomorrow.

November 17, 2011

Dear Mr. so-and-so,

Please be informed that President Jeon yesterday has promised he would make a big announcement by the end of this month. I will keep you posted.

November 28, 2011

Dear Mr. so-and-so,

I am so glad to inform you that President Jeon has made a landmark decision to step down from President's Office today. We are going to elect new President by the end of January next year at the latest. 


\section{A Socratic Conversation}

From Kiyoung: Hi, Kimberly. I agree that the leader and follower are not separable to find the true nature of leadership over the vast sorts of organization. Particularly as the automation of production became less important, it would be short that we see the followers as one of labor components on generalization. We now generally perceive the workers of organization as of human nature other than commodity-like utility subject. It seems to be more so in this post-modern society distinguishable from the concept on mass-production and mass consumption. Blunt R. guides in this context, “..building value into the lives of others coming behind you, be they your colleagues at work or your young ones at home-or both. ... to see someone thrive and love what they are doing when you have had a hand in it as a mentor, a boss, a coach, a teacher, an example--or even as a grandpa or grandma.. (Blunt R.)"

While the Tailor's study and general practice of accountancy fairly favor the view of common and general aspect of labor status and value, that is probably just basic without a more enhanced understanding. In this context, the follower and its scholarly description seem to be crucial in understanding the leadership and organization. This relational aspect fosters, as we share, the participatory leadership. I personally surmise (i) the informal leadership in

the industrial period would possess more negative implications, (ii) it would have more potential of being active in the post-modern and informative period of these times, (iii) the informal leadership and formal leadership, in some cases, overlap to affect the orientation of followers in the internet era.

The informal leadership of a first point seems to lie in the hard nature of systematization and scientific supervision of followers. At the initial stage of industrialization, maximum efficiency is a supreme goal of industrial organization generally. There is no consensus of entrepreneur moral or the kind of ethics code on multi-national corporation, which is unlike

the contemporary discourse of business organization. The line of authority and formal leadership would operate under the efficiency-driven context, and would do well if no deviations were found. In this structure, the informal leadership generally means more extortion of labor and punitive context of followers.

For the second point of informal leadership, I like to raise a point on many of schemes including the incentive system, outsourcing the management staff, honorary consul or mayor, parents' participation to improve the students, free mode of working hours arrangement, and

so on. That scope of new organizational tools would be strategic to meet the challenge

between the leaders and followers, and to a considerable extent involves the aspect of informal leadership.

Finally, the internet device would bring a blurring effect on the extent of influence for the followers, which is in the context of formal and informal leaderships. For my case, I one time noticed that the informal leadership would work out effectively other than the formal line of authority. The university faculty elected two candidates last year, and recommended those two, who were two highest point of elects, to the board authorization. The board of regency has a formal and final authority to choose one from two recommended elects as a university president. The board actually chose a second highest elect among the two. The university faculty went outraged to protest for its allegedly undemocratic nature. Although it is legally permissible to choose the second elect, the faculty saw differently. My university has long been esteemed as one of sanctities for the democratic tradition of Korea, and the professors 
are so oriented. In their eyes, the board decision seems to be undemocratic given the first elect was denied without any far persuasive reason. The intra-communication of university website was raged by the high tone of leading professors. They actually exercised an informal leadership, and would lead over 800 professors university-wide. Its impact was serious indeed, and the board of regency, in the event, withdraw their appointment. We convened to re-elect the president, and finally, this September, welcomed a new president, who was the second elect last year. In this case, I realized that the information technology was really powerful to change the mode of politics and the pattern of leadership.

From Kiyoung: Hi, Christy. I have been interesting to be told about the dynamics of US embassies. I saw an informal leadership more likely occurs in the foreign context. It seems because the formal leadership would presuppose an official basis of lines, having a character of being routine, settled, common, structured and systematic, expressed, disciplinary and awarding. The informal leadership may share many of those, but on the less extent, otherwise it may not in some cases. It poses various elements of consideration in order to work effectively in the diplomatic mission, which are not found in other governmental branches. I can also make up the point similar to your context.

In the late $19^{\text {th }}$ Korea, Korean people had an empress crowned in the name Myeongseong. She was situated over the decades to improve the waning feudal dynasty Joseon. Her period of time was critical to confront the western imperialism for Chosen and China. One other oriental nation, Japan, actually was a pioneer to receive the western mode of development, which turned to exploit rather than defend. On this challenge, the empress had been a pleasant client to utilize some of local diplomats, who were a German and a Russian. One of German diplomat was named Mullendolf, whose Korean name is Mogindeog. He exercised a great influence to shape the basic orientation of empress. He wears a traditional costume of Korea to attend the counseling meeting, and formed a close diplomatic dynamics with Korea under the multilateral imperial force. His power and leadership were immeasurable indeed to overwhelm the official line of authority of German commission. Although the mode of diplomacy was $19^{\text {th }}$ traditional, we can see it very fitting and demanding to that specific case of Chosen the informal leadership of Mogindeog, as one form of dated LES for the German diplomacy.

As for the level of organization itself, the followership discourse seems fairly useful enabling to look into the true human interaction within the organization. For many of stable organizations, my experience tells the followership would be more focused point rather than the leadership. How to create more star followers would be a desired destination for the case of leaders. For the above illustration, the informal leadership of Mogindeogk also could be perceived to evolve on to a different direction. His leadership was played in the secretariat of Joseon, whose western perspective was virtually absolute to guide the feudal Korean mandarins. Germany was a less aggressive power among Japan, France and Great Britain in China, which could properly assimilate the Joseon fate. It established symbiotic relations with the Joseon followers although his leadership was actually dismantled from both other formal line of conservatives and deep structure of Japanese mightier power.

After all, the informal leadership would be present despite a probable pattern of dominance within the formal one. It would also be proper to see it:(i) more fitting and demanding to each specific environment, (ii) more affiliated with a creative aspect of leadership, (iii) more sensitive and symbiotic with the followership. The followership would be far more important given the unstable nature of Chosen secretariat during her times. 
From Kiyoung: It was interesting that I have read your introduction about three leaders. And your final comment on the limited context of leadership role is echoing as you plainly experience your nation. Leadership seems, in some aspect, to be a kind of myth that is easily overstated about its true interplay and effect across many cases. That divergence would deepen given the size and network of organization. Most typically would be found in the case of national or state leadership. I suppose that there is generally no disagreement of each greater leadership you illustrated. On my basic understanding of the western history, I also have long respected three figures. In the three cases, we can find the symbolic implications on their footage over the wake of national evolution. Dalai Lama would perhaps feature intertwiningly with a religious and pious imagery as one of world leaders. The practical consequence of a specific leadership, however, could be disputed by opposing views. Therefore, I thought it useful to consider more scientifically in the context of true nature of each specific organization.

For the case of Dalai Lama, I like to raise his leadership activity long charted over the decade. The environment is a very probable factor in evolution of his leadership. Tibet is a small country usually overridden by a bigger political power, but he and his followers possess a very strong attitude on religious beliefs. The niche could be utilized powerfully to defend his nation and attracted the world attention. It has also been useful to combine the religious belief with a scope of philanthropic commission. The connection of both would effect as they share a fair of similar context of human subscription. He is a superb leader over the content and process of organization change if we can in any way assume a kind of organizational concept about his group or territory. He now became a spiritual leader of most of global public, whose commissioned vision is greatly sublime, interconnected, and has pragmatic virtue. It is not difficult to confirm via many sources, particularly including the wikipedia page of his personal profile. His process is not revolutionary rather evolutionary and based on a concrete plan to give a lecture in the western universities and meeting with other influential leaders, and so on. We can see an importance of given environment to understand the true nature of leadership. That is also pertinent with the Greater Peter whose leadership, on your introduction, can be seen to resemble the late 19th Korean leader, the Great King's father Lee. Lee actually was not a King, but exercised a power as the guardian of King. He rejected the westernization of Korea, but he has not be revered by Korean people. Korean people generally think that his extremely defensive policy gave a cause to delay the nation's prominence. That is probably because both cases differ in many points of element, which affect a shape of more effective leadership

The concept of leadership can be viewed in several aspects. Plainly, it means the nature and quality of leaders who is responsible to manage and develop, and in some cases effects a change on the organization. It is one of aspect that he needs to ensure a proper circulation from input to throughput, and to output, which could reinvigorate to prevent an entropy. Given that we all expect an entropy as the kind of inextricable natural justice, it is 
fairly a great wisdom of humans to invent the concept of organization and leadership. For the past, we were animated to hear our neighbor's utterance "Samsung (as you might know, internationally renowned Korean corporations, interchangeably what we call chaebol) would be permanent notwithstanding its people). That could likely be a symbolic sequence in this modern capitalistic society. Nevertheless, the pattern of corporations across the culture is not exactly same while Korean people now turn their concern to chaebol reform.

A most notable point in thinking about the historical aspect of organization would perhaps be the econo-politcal transformation of the society. We experience other various kinds besides the for-profit organization and the national or state government which may fit within the non-profit category. From a wider extent of consideration, however, the organization of various kinds would normally receives the structural basics as a "given" or "environment", which implies to enable a similar standard in the purpose of analysis. In this context, I have thought about, based on my personal assessment, four stages where the concept of leadership was structurally impacted. The first thesis would be an "ancient communal" that would not be scientifically verified in cases or theory. The Marxian assumption about the primitive form of communist society is one illustration where no exploitation and worker's whole can reside. The other potential, as a matter of assumption , could be found in Roseau's "the origin of human inequality." In this case, human is unequal among his neighbors who need to be educated and improved. Both thesis may get their way of legitimacy, and would perhaps offer a different basis of leadership. In the first case, we can be easier to subscribe to more participatory or followership approach. In the second case, we can see a plenty of options about the organizational evolution, leadership education, modern scientific management of industry and so forth.

I believe that the feudal structure, as a second stage, would greatly propel the concept of "command and control." In the wake of transformation toward the industrialization and intensification of the capitalistic concept, the orthodoxy of "command and control" gradually turned to receive the science -based efficiency concept, which we generally agree to form the basis of organization study. The fourth stage, which we now subsist, would be seen the kind of human-centered, and quality-focused on object or phenomenon. The life science can lead the enchanting ideas to foster an organizational or leadership study. It is thankful to see the capital-oriented inhumanly analysis of industrial study turns to adapt with the life concept.

I return to Samsung story briefly in the exemplary purpose. The name of Samsung originated from Japanese, and it has a history of generations. Samsung now has a multiple facet. It is one of greater foundation to support the poor, but promising students, which represents the faith of society. It would be reformative, as is assumed by Rousseau, toward the idealistic society as Marxian's. The command and control concept is notorious in one aspect that the authority of CEO is empowered with a plenary power. It is heard now to gradually devolve upon a scope of special and line divisions. The think tank and research institute of Samsung can be properly seen as something like huge bureaucracy. It is one of biggest employers to hire doctorate level researchers and strategists. Beyond the scientific management concept, it is a prime contributor to lead the national concept of life and environment in various contexts. One most crucial point is a continuous reprimand of Korean public about their familial ties and possibly impermissible succession. The capital is symbolic in this context, and the invention of current form of corporations, based on the share idea and the division of labor between the ownership and management, seems to be most notable when we talk about the leadership of the for-profit organization.

From Kiyoung: Your plan is great indeed, and would certainly come into fruits. In many experiences, I realized it most difficult to bring factions or separate interests into productivity. 
Even in some cases, the faction or different minds could disable the working place to find a humanly coexistence. One of cases is found in the context of university professor recruitment process in Korea. Once one leading professor in an influential position got determined with a candidate, it could go into success. The story is humanly, however, which would create a dissident group. The group normally represents a younger group of professors who are legitimate to share a voice for the selection. Then such implicit confrontation later develops into a separate position or faction since the selection of professor is most crucial in that small community of 20-30 constituents. It took, in some of serious cases, a retrenched form to perpetuate its undesired condition. Other organizations, like the health administration, would less fit within the case given its typically large structure. It is really one of most delicate and difficult issues within the organization. You are very aspiring to bring them up to the front of working together.

While commuting, I actually have several hours to view the TV. That is because I took a weekly travel for the locale where my working place is sited. One of public programs have made me to be gone with a sad story. One poor young girl lives with her grandmother while working part-time. He worked at the restaurant and other available posts on the contingency basis including the public health institute. I was disposed if we can simply class between the working class and the haves. We normally refer to the working class concept when we identify a public problem. I realized that there are many more other elements in the case we consider the dynamics of society, organization and nation or state. The empowerment of KBS (a major broadcasting media in Korea) about her sad story was impressive. The faction was diverse indeed, which she faces over the progress of the program. The work to interact with the peers and lower classes, and to promote the organizational efficiency by leading the working force up to the front seems to involve a very difficult context.

From Kiyoung: When we see the type of leadership, the answer would seem different. In its definition, an informal leadership is found when his or her leadership lacks the formal title and outside of the formal line authority. I agree, therefore, with Christy on his comment, "Informal leaders often lack a formal title and emerge to fill a professional gap or "free space." They are often work quietly behind the scenes and are a respected resource for guidance"

In the formal leadership, on the other hand, the linear hierarchy and system generally work to define a leader at the top of organizational charts. Therefore, we may basically say 'no' to the context of informal, but 'yes' to the formal. I suppose if they are not always true nevertheless.

For the state organizations, we can see a collective leadership who are of equal rank to lead the organization. Of course, the presiding judge or spokesmen may lead the proceedings, but they are nevertheless equal, and only a majority vote would be an expression of the body. In specific, the member judges of chamber are not a follower, but are constitutionally required to make an independent decision on laws and conscience in Korea. The congressmen are not followers to the speaker of House although they may be led by their party direction. Both generally have an independent ground from an democratic election or presidential appointment. The concept of star followers, alienated followers, or the sorts, generally would not apply. In this case, it would be that all the members form an entire body as leaders and followers. The kind of cooperatives found in underdeveloped or socialized nations would require an equal share of community members in an economic terms. The leaders of cooperative, if any, has a limited role for the basic administration of organization, and are hardly perceived as a leader to create the vision or gain a support of followers. Of course, the 
organization may be on vertical or horizontal sections that the leaders may, according to the formal lines, be responsible to a smaller unit, not to the organization as a whole.

The critical question between the leadership and formal lines or more extent of management perception, I suppose, would likely reside within the creative roles of leaders and way or extent of interaction or process to motivate the followers to the desired direction. In that context, the leadership discourse would be less involved with the formal hierarchy. As introduced, the Burns point is guiding to understand the true nature of leadership: "....Leaders are creators of social change but also satisfy wants and needs. Leadership is relational, collective and purposeful. All leaders have power but not all who have power are leaders... (Burns, 2010)." In this perspective, the leaders are not necessarily at the top of organization. Vice versa, the leader of lower rank may finally effect a meaningful change of organization. The government of Korea in early 1980 would be the case on this point. Then president Kyu-ha Choi is on the highest rank of government, but had to submit to General Chun, who soon seized an official power. Chun's vision was imprinted in Korea on the next seven years titled social justice. In this case, Chun's leadership may be more properly termed a kind of power wielding, charismatic sort, informal nature operating behind the official scenes. His status would later be formalized with the official title, president of Korea.

- Burns, J. M. (2010). Leadership. In G. R. Hickman, Leading Organization Perspectives For A New Era Second Edition (pp. 66-75). Thousand Oaks: Sage Publications, Inc.

From Kiyoung: Hi. Wayne! Interesting point to find ourselves to play similar mistakes year by year in the labor union context here in Korea and Japan. I know that the annual fare of labor and management are typical in two counturies. It is called Shunto, which means "spring wages offensive" by the union. It has been powerful to influence Korea because of many of common traits among them. So it can be said if the tradition evolved in Japan is regularly practiced in Korea. Among others, that suggests two points of implication in our leadership studies. One is a cultural element which the leader needs to consider for the context of organization change. The other is that that is fairly structured and the unprepared or less minded leaders may play same mistakes every year.

Given the differences on a year term, the cultural element may not be a factor for the yearly strike. If we see it from other angles, it can be more plausibly viewed in terms of practical reasons, such as pay increase or job security. That seems greater actually, but in my experience and from my neighboring sources, the cultural elements of Asian capitalism make some of causes to bring forth the strike annually. The union workers, in some aspect, consider it the kind of periods to expose and identify themselves over the insipid year-long work schedule. While I am not sure if that tradition would continue given the sagging economy of two countries, that may persist since it may be a part of way to invigorate and replenish the workers. There are, in some cases, managers of foreign origin, who are educated in the premiere business schools and would think about a servant leadership model. Then, the situation may turn better, but generally vast ignorance of cultural factors has likely aggravated the past series of labor negotiations in Korea. In the case, the transformational leadership, particularly, servant leadership may better get the leaders to know the situation. An usual course of development in the "spring wage offensive," however, would not go that way in many aspects. The leadership is autocratic at its start, and later slightly slants on the transformational, but finally erupts toward a fierce confrontation. In some years of last misfortune, the public authority intervenes to suppress the union. I am curious if the leaders 
are prepared in advance to understand its nature, and restrain from the unilateral or autocratic way of leadership. Thank you for your posting to incur reflections about the Korean story.

From Kiyoung: Response to Jennifer.

Thank you, Jenniffer. I like to share your point about the servant and transactional leadership styles. Your view seems practically more dominant to look around our society. And that is also powerful to see it within a periodically short context. More task-oriented, and goal or performance based management are usual to our situation available around us. But that seems partial to fall short of whole and true dynamics of organization. In my personal experience, I have known that a regular event to motivate the followers serve the status of organization as continuing. It seems true if the organization would not remain good as a kind of biological creature unless there has to be a transformational or organization change. In this context, the sayings "equilibrium is the end normally" would perhaps be true. I think it may sound that the time would make us and organization not the same, but changed, even if every objective phenomenology on the members and organization themselves remain same as before. So I would think that the transformational may fill the gap to develop or maintain the status of followers and organization. That seems with the difficult nature of leaders, and I now realized why the boss of small firms in Korea uttered in grumbling manner "I am tired to hold a monthly dinner feast to boost the morale of workers." For his case, he knows that the work performance would not be the same without that kind of motivating event. The social and spiritual aspect to arm and motivate the followers seems indispensable.

For a wider context, I once suspect why the national leaders were worrying about the growth of national economy. I later realized that at least 2-3\% growth of GDP would guarantee the current status of national economy. That might be from various reasons, birth rate, feel of nationals, and changing expectations of followers, or so forth. In any case, the organization requires of such growth as marginal though. For them, $0 \%$ growth does not guarantee the former status of nation, which could be explained, in some aspect, from the biological concept of nation. The time element seems delicate and requires us to change. Of course, we may be disciples of asceticism or may see the changing effort an impasse from outer force (Hurricane, 9.11 attack, etc).

- Manz, C.C. (1998). The Leadership Wisdom of Jesus: Practical Lessons for Today. San Francisco: Berrett-Koehler Publishers.

\section{From Kiyoung:}

Hi, Ramiel,

It would probably be a great work to come for the final project. I also once have been interested in the privatization of public enterprises, although not approached as a kind of scholarly work. Privatization seems working fairly to benefit the consumers of nation generally. That is economically true, and once made me a high proponent to support the privatization.

Along with the recess, I came to be complicated about its many aspects of interest. One point is that the quality of job can be weakened by the private management. For the cost reduction, they very prefer to use a contingent workforce, who can be dismissed at the 
employer's will. As of the nature of organization, the private enterprises, as we know, tend also to be highly profit-driven or on other corruption with the government if not successful with profits. They may bargain for other unethical compensation if they undertake an unprofitable privatized business. For the privatization drive since 1990's in Korea, I realized that most humanistic were laid in the government organization, and the logic of competition dominated a private sector of industries. A neo-liberal initiative to privatization and deregulation, actually reshaped the minds of Korean people, and the society seemed to turn individualistic and strategic, which is a paragon of the western capitalism. I suppose, however, that we are both a supplier and consumer. We work and consume, but the privatization drive seems to shed a unilateral focus on the consumer's side, allegedly an optimal equilibrium and maximum production. For that logic, I fall dubious if many of worker's side, who is usually a pillar of family and society, are bypassed without a consideration. It is really interesting to see that your work also touches on the union aspect of that issue. We are a consumer, but also worker in other aspect. If we are troubled with an unhumaistic job insecurity, what if that means to have some part of economic growth, or one more bite of chocolate cookies. There seems to be some kind of angles that the plain economic rule is unable to clarify.

- The Korea Economic Daily, Jan. 13, 2013, Seoul, South Korea.

I agree that the servant leadership is most direct and exhaustive to achieve the leader's vision. It is plainly true that "the serving" would make "the served" "a server," which means a final unity or shared identity of leaders and followers. I wonder, however, how it became so desired and demanding. The servant leadership may symbolize the peak of capitalistic demand which seemingly requires the leader to be put into the shoes of followers. When I was younger, I thought that the managers or national leaders were elected merely to personal esteem or welfare. They were seen to live pleasantly or on social accolade. I realized that they are the persons to be stressed and entangled. In any case, the servant leadership say much about effectiveness. That would not be exactly the case about the organization study, but I like to illustrate. I was once supported by the administrative team of computer. The team was staffed with high-skilled graduate students. One student gave me an aid with an oral instruction like a normal leader, but other student quickly made an appearance to serve the computer actually fixed. The later type of assistance really worked to educate and train me practically. I thereafter feel a more gratitude and readily follow his instruction.

The servant leadership seems likely working through an expansion into the culturally diverse context, and may be properly utilized into an international expansion of the businesses. A more serving to bring the followers close and the concept of education or training would be required. There would be a good prospect to delegate the local leaders bred in that way. It may go in analogy to teach the foreign students. Once I received a student from China, and that way of approach is better way to penetrate through my duty. He had later gotten far improved to be a Korean scholar. I also recognized that the servant leadership turns to be amusing at some point of progress.

From Kiyoung:

Dr. Bruno. Interesting to have a chance to reflect. Besides the leadership style, the characteristics, skills and knowledge, and the leaders' sincerity or the way of involvement appears to work bringing a success, or necessary even to interact progressively. The government and public authority now usually post to recruit out-of-organization expert to 
staff their leading position. In that case, how to select a most productive as well as welcomed candidate would pose a serious issue, normally never easy on a compact process. Other than the purity of principled approach found in politics or economics, the organizational study seems to raise a multi-faceted dimension in which the unique recourse has to be traced on the kind of biological concept. It would be naïve, though, to connect the word "organ" to "organization." The leadership style tends to focus more strongly on the leaders'. It is true, in the way of political approach, to emphasize that aspect, if the organization is determined to converge or assimilate to the leader. He is a paragon, and super idealistic figure whom the followers interact with and even emulate. He would like to allege on inferno to assimilate toward the organizational unity, and offers the ceiling of organization. In a bit democratic or socialistic concept, the leader becomes an analytical object and sometimes their qualities are highlighted if we enter the realm of empowerment. . .

Beyond the commonplace understanding about the skills and knowledge or characteristics of person, I suppose if a most influential element would come from his passion, interest or involvement, as well as a sincerity or authenticity. In this context, a for-profit organization seems to see more chances of intense leader other than non-profit organization. An intermediary nature of intensity may be found in the non-profit organization. Once and still now, Chosun people are struggling for more autonomy and progress from the board of regents. The board of regents is staffed with out-of-campus figures on social esteem, who are stripped as conservative, less involved, and formalistic. Progressive activists and a scope of normal professors or students are generally democratic and change-oriented for a better campus. Trust and empowerment have gone in other way between them, and the campus group even criticized if the meeting place was regularly set in Seoul. Seoul city is a place of bylaws, in which the regular meetings should be convened. I am not sure if they do not know this, but incidentally was raised as one of trust issue. They sometimes argued if they even paid more than six visits to Kwangju a year notwithstanding the meeting place. Truth and honesty were seriously questioned while the board leaders continue to just adhere with the laws and regulations. For the period of contest, we generally have sensed if the sincerity or authenticity is more pivotal than others. In the eyes of Chosun people, they may be seen as an absent-minded, who just continue on their formal status.

For the leader inspiring, he or she is required to understand the context in which an organization is situated. Second, it is necessary to consider any available resources or communicative means to effectively create a spiritual adherence. Typically, he or she efforts to devise the kind of symbolic expression to implant an inspiration.

The context of organization's status is critical to trade out an inspirational leadership with followers. What is a goal to inspire them to be enthusiastic or engaging? For example, the leadership of Napoleon in the course of war campaign might see how their men could cross the snow and height of Alps Mountain. Is the army healthy and well equipped with marching or climbing? Is the war campaign just and legitimate for the followers to be morally loyal and highly supportive? The context is a factor that the inspirational leadership comes into play. Second, the leader needs to think about the way to deliver his message to followers. There is no same ways to reach between the top national leaders and managers of a private enterprise. Due to a high exposure to publicity, national leaders usually have an ample chance to communicate, and the way of its operation can be dramatic. That would be a rare case for the leaders of normal organizations. Therefore, an inspiring initiative can be through more of symbolic expressions, such as V-sign fingers of Churchill or mustache of Stalin. In other case, however, a weekly meeting for open debate may work more effectively to see the nature of 
problem and inspire the followers to upgrade as well as to be productive and adaptive. For the case of Napoleon, the picture to expose him mounting on the rising horse would work to high probability of success. And his message "there is no 'impossible' in my dictionary" reinforced to drive the followers in vigor. A symbolic expression needs to be concise and readily communicable in a simple and expressed context. We can properly illustrate this aspect on the traffic signs and umpires of an athletic game.

In my surmise, a relative share of importance should be considered on the context and factors involved. First, the size, nature, and leadership of organization seem to come into play. Second, the attitudes and readiness of followers also factor to identify the top priority among three levels. Third, the deep structure and exterior conditions also come to define a concrete step for the process of change. Forth the change goal would generally affect the extent of focus on each level.

Generally the sizeable organization seems less on the individual other than group even where they posit an idealistic imagery of their workers. For example, one of global enterprise from Korea, Sam Sung, may envisage and encourage to share, "Sam Sung Man", but it is just symbolic. Organization change may rather enchant a group or larger scale usually, although "Sam Sung Man" may offer the standard for a better change. I suppose if the nonprofit or charitable organization would incur more focus on each individual since it is usually less organized or the nature of work tends humanly or morally required. I also like to address if the charismatic leadership would favor any larger context of organization change. If he finds it necessary, however, he may pour an extreme emphasis on the level of individual to make them conform to the idealistic type of members.

On the second point, the change agent would perhaps be required to apply his efforts on an individual level in the case the attitudes and readiness of followers are significantly lower. In other cases, the point of change would generally govern the relations of each level.

Provided if the exterior conditions are seriously worse, the change leader generally considers an extensive transformation. Then his most views and concerns would trigger the larger system change. On the last point, the change goal has to be seriously defined whether it is related with human resources or mechanic aspect of organization. The types between "revolutionary and evolutionary" would also concern a different emphasis on each level. In my personal experience, I saw no or less returns when the leader reshuffles on the larger system change. One department once was merged into the college of social science, which was to elevate the research performance of faculty and efficiency of administration. The chronic attitudes of departmental faculty would remain virtually same as before, but the change leader saw just an extreme group resistance. I found that each individual really matters, particularly in this context, playing a central role for the change goals.

\section{From Kiyoung:}

Hi. Smith! Thank for your helpful exposure to the Diocesan Campaign. Generally, we tend to perceive that a religious leader is less secular to fairly and effectively administer the kind of business nature. That seems not the case within your illustration. I wonder how you power in weighing the spiritual and economic as a factor. We learnt that the value sharing and readiness of followers would say much of organization change. Do you think if the governmental cutbacks and financial aspect are determinative of the program's success? The poverty rate is a hyperbole around the globe, and the charity or other public 
organizations play a role as a moderator. I suppose if there are any rate of differences between a usual charitable organization and religious one. Once I encountered a very cheaply priced restaurant, but the food is like the kind of buffet. Later, I was heard that the restaurant was owned and managed by one Buddhist temple. I felt that no nutrition problem could reside for the neighbors of that small community. I also became fancied as coupled with a forest and river environment which is about the Saint Simon's type of idealistic and primitive society

I know a little about the Catholic and Martin Luther's reform impact on the Christian society. It goes fairly desirable, however, if the Catholic Church would favor much engagement with the secular society. I also wonder if the Catholic may be more active to redress the poor class than many reformed branches. In the version of Durkheim, religion can well be a starting base for the intellectual experience or approach as well as social values, and practices. It is placed at the center of contest within the modern industrialized society. It might be compared, in principle, with the paradigm of new and fourth phase within the capitalistic framework. In that phase, we now urge a human-face capitalism where CEO's are leaders of quasi-religious nature. We thankfully charted in the news over the years, many of donations and givings from CEOs and wealthier class. I respect the leadership of Bishop Poprockie, and feel excited for his success on organization change. Thank you for sharing. 